\title{
COVID-19 Vaccine Rollouts and the Reproduction of Urban Spatial Inequality: Disparities Within Large U.S. Cities in March and April 2021 by Racial/Ethnic and Socioeconomic Composition ${ }^{*}$
}

\author{
Nicholas V. DiRago, ${ }^{\mathrm{a}, \mathrm{b}}$ Meiying Li, ${ }^{\mathrm{c}}$ Thalia Tom, ${ }^{\mathrm{c}}$ \\ Will Schupmann, ${ }^{\mathrm{a}}$ Yvonne Carrillo, ${ }^{\mathrm{a}}$ Colleen M. Carey, ${ }^{\mathrm{d}}$ \\ and S. Michael Gaddis ${ }^{\mathrm{a}, \mathrm{b}}$ \\ ${ }^{a}$ Department of Sociology, University of California, Los Angeles (UCLA) \\ ${ }^{\mathrm{b}}$ California Center for Population Research, UCLA \\ ${ }^{c}$ Department of Sociology, University of Southern California \\ ${ }^{\mathrm{d}}$ Department of Policy Analysis and Management, Cornell University
}

November 4, 2021

$\begin{aligned} \text { Words: } & 3,468 \\ \text { Tables: } & 3 \\ \text { Figures: } & 2 \\ \text { References: } & 158\end{aligned}$

\begin{abstract}
* Direct correspondence to S. Michael Gaddis at mgaddis@soc.ucla.edu or c/o UCLA Department of Sociology, Box 951551, 264 Haines Hall, Los Angeles CA 90095-1551. This project was supported by the California Center for Population Research at UCLA with training support (T32HD007545) and core support (P2CHD041022) from the Eunice Kennedy Shriver National Institute of Child Health and Human Development (NICHD). The content is solely the responsibility of the authors and does not necessarily represent the official views of the NICHD or the National Institutes of Health. This work used computational and storage services associated with the Hoffman2 Shared Cluster, provided by the UCLA Institute for Digital Research and Education. Thanks to Jonathan Daw, KaYuet Liu, and Elizabeth Wrigley-Field for comments and suggestions. Additional thanks to Marc Caswell and Alexis Lantz.
\end{abstract}




\title{
COVID-19 Vaccine Rollouts and the Reproduction of Urban Spatial Inequality: Disparities Within Large U.S. Cities in March and April 2021 by Racial/Ethnic and Socioeconomic Composition
}

\begin{abstract}
Rollouts of COVID-19 vaccines in the U.S. were opportunities to redress disparities that surfaced during the pandemic. Initial eligibility criteria, however, neglected geographic, racial/ethnic, and socioeconomic considerations. Marginalized populations may have faced barriers to then-scarce vaccines, reinforcing disparities. Inequalities may have subsided as eligibility expanded. Using spatial modeling, we investigate how strongly local vaccination levels were associated with socioeconomic and racial/ethnic composition as authorities first extended vaccine eligibility to all adults. We harmonize administrative, demographic, and geospatial data across postal codes in eight large U.S. cities over three weeks in Spring 2021. We find that, although vaccines were free regardless of health insurance coverage, local vaccination levels in March and April were negatively associated with poverty, enrollment in means-tested public health insurance (e.g., Medicaid), and the uninsured population. By April, vaccination levels in Black and Hispanic communities were only beginning to reach those of Asian and White communities in March. Increases in vaccination were smaller in socioeconomically disadvantaged Black and Hispanic communities than in more affluent, Asian, and White communities. Our findings suggest vaccine rollouts contributed to cumulative disadvantage. Populations that were left most vulnerable to COVID-19 benefited least from early expansions in vaccine availability in large U.S. cities.
\end{abstract}

\section{Keywords}

COVID-19, disparities, inequality, neighborhood, pandemic, race, socioeconomic, spatial, urban, vaccine 


\section{INTRODUCTION}

\section{Background: COVID-19 Vaccine Rollouts in the U.S.}

In early 2021, state and local authorities in the United States (U.S.) vaccinated millions of people weekly against Coronavirus Disease 2019 (COVID-19). ${ }^{1}$ Vaccination curbed viral infection and transmission and reduced illness, hospitalization, and death from COVID-19. ${ }^{2-8}$ Vaccines were free countrywide regardless of health insurance coverage. Eligibility progressed in stages per state and local policy. Health care employees received first priority, followed by seniors, workers in designated occupations, and individuals with particular medical conditions. ${ }^{9}$

The most significant expansion in eligibility occurred during late March and April 2021. Doses remained scarce, but most jurisdictions allowed everyone age 16 and older to be vaccinated. ${ }^{10-15}$ On January 1, 2021, 5.5 million people had received at least one dose of a COVID-19 vaccine. That number increased to 30.3 million by February 1, 57.0 million by March 1, 111.1 million by April 1, and 153.7 million by May $1 .{ }^{16}$ Growth plateaued in May. Over 206.6 million U.S. residents were at least partially vaccinated by September 1; nearly half of them received their first dose in March or April. Eligibility expansion enabled rapid increases during these months.

Vaccine eligibility rules did not account for two key predictors of the burden of the COVID-19 pandemic in the U.S.: race/ethnicity and socioeconomic status (SES). At the community level, infection and mortality were more common where low-SES individuals and people of color (POC) comprised more of the population. ${ }^{17-24}$ At the individual level, Black and Hispanic people were disproportionately likely to experience infection, hospitalization, and death. ${ }^{9,25-34}$ Socioeconomic variables partially mediated racial/ethnic disparities.

Decision-makers might have opted against conditioning vaccine eligibility on racial/ethnic or socioeconomic factors to avoid legal challenges. ${ }^{35,36}$ Still, there were viable ways 
to use vaccine eligibility policy to mitigate inequality. ${ }^{37}$ For example, the Advisory Committee on Immunization Practices (ACIP) initially recommended prioritizing essential workers, which would have increased eligibility for low-SES people and POC. ${ }^{38}$ Authorities ultimately hewed closer to ACIP's final recommendations, giving greater weight to advanced age. ${ }^{39}$

Geographic allocation may have been the most promising indirect means of addressing disparities through the rollout of COVID-19 vaccines. SES, race/ethnicity, and geography are tightly linked in the reproduction of inequality in the U.S.; socioeconomic and racial/ethnic inequalities manifest in space, usually at hyperlocal scales. ${ }^{40-51}$ Prioritizing local geographies in which residents had the highest risks of hardship from COVID-19 probably would have reduced mortality more than the age-based rollouts authorities chose. ${ }^{52}$ Regardless of whether demographic targeting was constitutional, spatial targeting could have advanced vaccine equity.

\section{Motivation: Early Vaccine Distribution and Cumulative Disadvantage}

Authorities relied on individual initiative to distribute vaccines outside the health care workforce. This approach favored individuals with internet access, reliable transportation, and flexible schedules. States and localities used first come, first served online scheduling for scarce appointments at small numbers of sites. People with reliable internet access and white-collar jobs were better positioned to sign up. Limited locations and timed appointments were disadvantageous for people with restricted transit options and strict or uncertain work schedules, including the poor and many people with disabilities. Barriers to vaccination in March and April 2021 may have reinforced socioeconomic and racial/ethnic disparities.

Concern over vaccine hesitancy in the U.S. has abounded, but framing vaccination solely as a matter of individual choice obscures structural and material impediments. Researchers mostly attribute stagnant U.S. vaccination rates to misinformation, mistrust in institutions, and political party affiliation. ${ }^{53-64}$ At the same time, survey evidence suggests vaccination was linked 
to SES in Spring 2021. ${ }^{65}$ Unvaccinated respondents reported three major economic concerns: taking time off work to get the vaccine, missing work due to side effects, and out-of-pocket costs. Plausible economic determinants of vaccine uptake as eligibility first expanded suggest racial/ethnic and socioeconomic disparities may have arisen.

If disparities persisted through April 2021, vaccine rollouts contributed to cumulative disadvantage. ${ }^{66,67}$ Advantages secure future advantages; inequality begets inequality_including at the neighborhood level. ${ }^{43,68-78}$ Vaccine rollouts may have propelled a circular process. POC and low-SES communities were most likely to experience serious illness or die from COVID-19. Equitable vaccine distribution would have mitigated racial/ethnic and socioeconomic gaps, but early vaccine distribution did not account for these inequalities. As a result, geographic clusters of unvaccinated people could have emerged, restarting the cycle by facilitating viral transmission. ${ }^{79-85}$ Understanding racial/ethnic and socioeconomic vaccination disparities at the local level identifies harms that marginalized people experienced during the pandemic and helps explain the reproduction of urban spatial inequality in the U.S. ${ }^{86-89}$

\section{Overview}

Our analysis provides a unique perspective on socioeconomic, racial/ethnic, and spatial disparities during the pandemic in the U.S. Numerous studies have focused on geographic dimensions of COVID-19-related inequality, ${ }^{90-97}$ but few have examined spatial differences in vaccination below the state level..$^{59,98-100}$ The temporal persistence of geographical vaccination disparities is particularly underexplored. We also contribute a novel dataset ${ }^{101}$ that harmonizes initially incompatible sources. And unlike many studies of COVID-19 disparities-even analyses with a geographical focus—we modeled spatial dynamics.

We tested two hypotheses. First, we hypothesized that local areas in which POC and lowSES individuals comprised more of the population had lower vaccination levels in March and 
medRxiv preprint doi: https://doi.org/10.1101/2021.11.19.21266593; this version posted November 21, 2021. The copyright holder for this preprint (which was not certified by peer review) is the author/funder, who has granted medRxiv a license to display the preprint in perpetuity.

It is made available under a CC-BY-NC-ND 4.0 International license .

April 2021. Second, we hypothesized that, despite lower starting points, the same areas had smaller increases in vaccination between March and April.

We used spatial quantitative methods to test these hypotheses. We estimated associations between vaccination levels and racial/ethnic and socioeconomic composition, adjusting for populations with early eligibility due to age or employment. We collected administrative data on vaccination by postal code, covering eight of the 10 most populous U.S. cities in March and April 2021. We combined these data with demographic estimates and geospatial data from the U.S. Census Bureau. We used spatial interpolation to reconcile reporting irregularities.

We found that, although vaccines were free regardless of health insurance coverage, local vaccination levels in March and April were negatively associated with poverty, enrollment in means-tested public health insurance (e.g., Medicaid), and the uninsured population. By April, vaccination levels in Black and Hispanic communities were only beginning to reach those of Asian and White communities in March. Increases in vaccination were smaller in socioeconomically disadvantaged Black and Hispanic communities than in more affluent, Asian, and White communities. Our findings suggest vaccine rollouts contributed to cumulative disadvantage.

\section{DATA AND METHODS}

\section{Data}

\section{[ TABLE 1 ABOUT HERE]}

From online public databases maintained by state and local public health authorities, we gathered official counts of individuals with at least one dose of a COVID-19 vaccine in March and April 2021. Only geographically aggregated data were publicly available. We secured them for eight of the 10 most populous U.S. cities: New York, Chicago, Houston, Phoenix, Philadelphia, San Antonio, San Diego, and Dallas (in descending order of population). The 
vaccination data capture a three-week window during which eligibility expanded significantly. The number of individuals with at least one dose of a COVID-19 vaccine in the eight cities increased 34.7 percent from 4.6 million to 7.1 million during this period. We present key details of the vaccination data in Table 1; we elaborate in Section e2.1 of the online supplement.

We used two datasets from the U.S. Census Bureau. We collected demographic data from the 2015-2019 American Community Survey (ACS) Five-Year Estimates ${ }^{102}$ and geospatial vector data from the 2019 TIGER/Line Shapefiles. ${ }^{103}$ We provide further detail on these sources in Sections e2.2 and e2.3 of the online supplement.

\section{Unit of Analysis}

For brevity and interpretability, we refer to our units of analysis as ZIP Codes, the name for postal codes in the U.S. The units of analysis were based on ZIP Codes, but reporting irregularities made ZIP Codes themselves inviable. Where necessary, we used overlay interpolation $^{104,105}$ to exclude populations residing outside city limits. We provide extensive detail on the units of analysis and interpolation in Section e3 of the online supplement.

\section{Independent Variables}

\section{Vaccination Priority Populations}

We accounted for vaccination priority regulations by adjusting for populations of health care workers and seniors. Specific estimates were unavailable for health care workers, but ACS provided estimated counts of individuals employed in "health care and social assistance.” We also adjusted for the share of the population age 65 or older. These variables were the best available measures of the first groups prioritized for vaccination. We include more information on these variables in Section e2.2 of the online supplement. 
To examine the dependent variable’s association with socioeconomic composition, we included four indicators of SES. Two independent variables estimated health insurance status. Health insurance coverage was not universal in the U.S. as of the COVID-19 pandemic, and medical care remained expensive and stratified compared to other rich countries. ${ }^{106,107}$ We included variables estimating the share of the population enrolled in Medicaid or other meanstested public health insurance and the share without health insurance altogether. Together, these variables captured populations that were among the least integrated into the U.S. health care system. We also included variables estimating the shares of the population under the federal poverty line and without internet access. We included the latter because making appointments online was usually the best way to secure a vaccine in early 2021. We include more information on our SES variables in Section e2.2 of the online supplement.

\section{Racial/Ethnic Composition}

We accounted for racial/ethnic composition because racism causes health inequity in the U.S. ${ }^{108-115}$ Although race/ethnicity itself cannot cause anything, distributive systems that allocate resources according to racial/ethnic hierarchies create disparities among racial/ethnic groups. ${ }^{116-}$ 120 These disparities often surface net of SES. Including measures of racial/ethnic composition in our models enabled us to examine its direct association with vaccination, adjusting for SES.

Racism, however, is more than a conditional association between an outcome and racial/ethnic composition. ${ }^{121-126}$ It undergirds the gamut of U.S. social, economic, and political processes. The distributions of socioeconomic covariates and unobserved mechanisms were racialized. We analyzed racism in the aggregate by considering direct and indirect pathwaysmainly through simulations, described below and in Section e4.3 of the online supplement. 
From ACS racial/ethnic categories, we created variables measuring the estimated populations of four mutually exclusive, non-exhaustive racial/ethnic groups: Asian, Black, Hispanic, and White. We defined Hispanic as Hispanic, Latino, or Spanish origin, of any race(s). We defined Black, Asian, and White as non-Hispanic and Black or African American alone, Asian alone, and White alone, respectively. This approach implies a fifth category comprised of non-Hispanic individuals of multiple races or any other race alone. The racial/ethnic variables did not sum to one (100 percent) unless the estimated population of the fifth category was zero.

We include more information on our framework for race/ethnicity and racial/ethnic variables in Section e2.2 of the online supplement.

\section{Dependent Variable}

The dependent variable approximated the share of each ZIP Code’s vaccine-eligible population that was partially or fully vaccinated against COVID-19. We calculated it by dividing the estimated number of residents with at least one dose of an approved vaccine by the estimated population age 15 and older. This denominator was the best available measure of the population to whom agencies were authorized to administer vaccines in March and April 2021. More information on the dependent variable is available in Section e2 of the online supplement.

\section{Spatial-Statistical Analysis}

We estimated population-weighted regressions ${ }^{127}$ with conventional adjustments for spatial clustering. We report spatial error models (SEMs) estimated by maximum likelihood. ${ }^{128-}$ 133 Standard linear models (SLMs) are ill-suited to estimate associations that vary across space. In this analysis, spatial heterogeneity could have arisen from unmeasurable factors such as COVID-19 exposure, hyperlocal idiosyncrasies in the effects or implementation of vaccination policies, and cultural influences. Standard tests ${ }^{134,135}$ strongly suggested SLMs exhibited spatial heterogeneity in our setting. We estimated SEMs with row-standardized $k$ nearest-neighbor 
weights $(k=8) .{ }^{136-138}$ As the Moran’s I test statistics in Table 3 demonstrate, the SEMs eliminated the residual spatial clustering that emerged in the SLMs. The models incorporated city fixed effects to adjust for unmeasured variables that were constant among ZIP Codes within each city, ${ }^{139}$ including elements of vaccination policies. Because multiple cities were in Texas, we calculated heteroskedasticity-robust standard errors clustered by state. ${ }^{140}$

To illustrate the estimated associations, we simulated outcomes at representative values in the racial/ethnic and socioeconomic distributions of the sample. This approach resembled a marginal effects analysis but accounted for spatial clustering and yielded an overall average rather than a unit-level estimate. ${ }^{141-144}$ We present eight simulated scenarios: ZIP Codes with high Black populations and (1) low SES or (2) high SES; high Hispanic populations and (3) low SES or (4) high SES; high Asian populations and (5) low SES or (6) high SES; and high White populations and (7) low SES or (8) high SES. We defined low and high levels as below the 10th and above the 90th within-city percentiles, respectively.

We provide additional details on all aspects of our analytical approach, including the models and simulations, in Section e4 of the online supplement.

\section{RESULTS}

\section{Descriptive Findings}

\section{[ TABLE 2 ABOUT HERE] \\ [FIGURE 1 ABOUT HERE]}

In Table 2, we present descriptive statistics at the ZIP Code level. On average across all 552 ZIP Codes, 28.0 percent of the population in March and 42.4 percent of the population in April had at least one dose of a COVID-19 vaccine, with a mean difference of 14.5 percentage points between March and April. Other than Philadelphia and San Diego, each city’s mean vaccination level fell within a two-point range (27-29 percent) in March and a five-point range 
medRxiv preprint doi: https://doi.org/10.1101/2021.11.19.21266593; this version posted November 21, 2021. The copyright holder for this preprint (which was not certified by peer review) is the author/funder, who has granted medRxiv a license to display the preprint in perpetuity.

It is made available under a CC-BY-NC-ND 4.0 International license .

(40-45 percent) in April. Although there was some variation between cities, vaccination levels varied considerably more across ZIP Codes within cities (see Figure 1). In March, the standard deviation in vaccination levels was 3.0 percent between cities and 8.8 percent within cities; in April, it was 4.2 percent between cities and 11.9 percent within cities. The mean difference between the 10th and 90th percentiles of vaccination levels across cities was 21.6 percent in March and 31.0 percent in April.

\section{Model Estimates}

In Table 3, we summarize the results of the SEMs with all independent variables for three outcomes: March vaccination levels, April vaccination levels, and the difference between March and April vaccination levels. In both March and April, four variables were significantly associated with the dependent variable. The first, the percent of the population age 65 and older, reflects the policy choice to place older individuals among the earliest priority groups. The other three variables were measures of socioeconomic composition: the shares of the population under the poverty line, with means-tested public health insurance, and without health insurance. Adjusting for vaccination priority populations and racial/ethnic composition, markers of low SES were negatively associated with vaccination levels. In April, vaccination levels were positively associated with the Asian share of the population.

\section{[ T A B LE 3 A B OUT HERE]}

Five variables were significantly associated with differences in vaccination between March and April. The shares of the population age 65 and older and employed in health care were associated with smaller increases. These associations probably reflect that these prioritized populations were widely vaccinated by the end of March. The Hispanic and Asian population shares were associated with larger increases in vaccination levels. The share of the population without health insurance was associated with smaller increases in vaccination levels. 
medRxiv preprint doi: https://doi.org/10.1101/2021.11.19.21266593; this version posted November 21, 2021. The copyright holder for this preprint (which was not certified by peer review) is the author/funder, who has granted medRxiv a license to display the preprint in perpetuity.

It is made available under a CC-BY-NC-ND 4.0 International license .

As we detail in Tables e4.1 and e4.2 in the online supplement, we examined associations step-wise for socioeconomic and racial/ethnic composition. Racial/ethnic composition measures were often statistically significant in the absence of covariates measuring socioeconomic composition. When we included socioeconomic variables, however, the coefficients of the racial/ethnic variables were indistinguishable from zero. We further discuss implications below and in Section e4.3 of the online supplement.

\section{Simulated Outcomes}

The simulations, illustrated in Figure 2 and in Figure e4.2 in the online supplement, contextualize relationships between racial/ethnic and socioeconomic composition. At both time points regardless of racial/ethnic composition, vaccination levels were higher where SES was higher. Socioeconomic disparities in vaccination were smaller where there was a high White population and larger where there were high Black, Hispanic, or Asian populations. In March, the highest vaccination levels (36.1 percent) were associated with high White populations and high SES; the lowest levels (17.7 percent) were associated with high Black populations and low SES. In April, the highest vaccination levels (53.8 percent) were associated with high Asian populations and high SES; the lowest levels (27.5 percent) were associated with high Black populations and low SES.

\section{[FIGURE 2 ABOUT HERE]}

Across racial compositions, the simulated change in vaccination levels between March and April was larger in high-SES than low-SES ZIP Codes, as indicated by the numbers above each line in Figure 2. Vaccination levels increased most (18.3 percentage points) where there were high Asian populations with high SES, followed by high White populations with high SES (16.9 percentage points). Vaccination levels increased least (9.8 percentage points) where there 
medRxiv preprint doi: https://doi.org/10.1101/2021.11.19.21266593; this version posted November 21, 2021. The copyright holder for this preprint (which was not certified by peer review) is the author/funder, who has granted medRxiv a license to display the preprint in perpetuity.

It is made available under a CC-BY-NC-ND 4.0 International license .

were high Black populations with low SES, followed by high Hispanic populations with low SES (11.4 percentage points).

\section{DISCUSSION}

\section{Key Findings}

We examined COVID-19 vaccination in eight of the 10 most populous cities in the U.S. In March and April 2021, vaccination levels varied more within cities_across ZIP Codes_than between cities. This finding suggests differences in state and local eligibility criteria contributed negligibly to disparities. Our models and simulations confirmed our hypotheses that ZIP Codes with higher shares of POC and low-SES individuals had lower vaccination levels and smaller increases over time. We now turn to three key findings.

Our finding that measures of racial/ethnic composition were statistically insignificant in the presence of socioeconomic covariates does not rule out racial/ethnic disparities. It suggests economic inequality and access to health insurance were fundamental mechanisms of local racial/ethnic gaps in vaccination. Furthermore, the relative magnitudes of the racial/ethnic variables’ coefficients were sometimes nearly as large as those of SES variables, albeit with slightly larger standard errors. Given the distribution of SES, ZIP Codes with high Black or Hispanic populations were associated with lower vaccination levels than those with high Asian or White populations.

Unlike internet access, measures of health insurance coverage were consistently associated with lower vaccination outcomes. This finding is surprising because internet access but not health insurance was directly tied to obtaining vaccine appointments. The insurancerelated variables may capture multiple unobserved mechanisms: unfamiliarity with the medical system, perhaps due to reduced or discriminatory encounters with providers and insurers;

incomplete or inaccurate information, including unawareness or skepticism that vaccines were 
free; and employment or other economic circumstances that impeded getting vaccinated or recovering from side effects. Survey or interview data may clarify individual-level mechanisms. Nonetheless, our results show that residents of large U.S. cities who had tenuous connections to the health care system were less likely to benefit from an intervention that was free to all regardless of insurance coverage.

While several inequalities increased from March to April, one waned. ZIP Codes with high Hispanic populations were associated with larger increases in vaccinations, adjusting for other demographic and socioeconomic factors. Still, accounting for socioeconomic distributions, Hispanic communities were left behind overall as vaccination eligibility expanded.

\section{Limitations}

This study has several limitations. Authorities published vaccination data by ZIP Code only. Because ZIP Codes are suboptimal units for measuring inequality, disparities may be understated in this analysis. Representing ZIP Codes as areal polygons is distortive, potentially leading to measurement error. ${ }^{145-152}$ Furthermore, while they afford more local vantage points than states and counties, ZIP Codes cannot reveal finer, neighborhood-level dynamics. Our units of analysis averaged 38,123 residents, and one-quarter exceeded 50,000. At this scale, observations had substantial within-unit variation and relatively low between-unit variation, likely obscuring disparities. ${ }^{52,86,89,153-158}$ We further discuss the analytical limitations of ZIP Codes in Section e3.1 of the online supplement.

The absence of individual-level data limited this analysis, but geographically aggregated data also presented advantages. It is difficult to determine how much our results reflected differential vaccine eligibility across ZIP Codes. We adjusted for key prioritized populations, however, and by mid-April eligibility was approaching universal among U.S. adults. In addition, the complete administrative data we used was more comprehensive than small surveys of self- 
reported behavior. Spatial analysis could also be optimal for guiding policy. Allocating resources geographically may be less resource-intensive than focusing on demographic subgroups. And, as we highlight above, spatial targeting is an effective tool for health equity.

\section{CONCLUSION}

Even as the number of vaccinated individuals increased by 7.1 million (34.7 percent) in the large U.S. cities we studied, COVID-19 vaccination lagged in marginalized communities from late March through mid-April 2021. Vaccination gaps increased between low- and highSES communities and between White or Asian and Black or Hispanic communities. The spatial clustering of unvaccinated individuals probably led to further public health issues.

Our findings suggest vaccination rollouts contributed to cumulative disadvantage at the community—and likely individual-level. Populations that experienced the highest burdens of infection and mortality from COVID-19 before vaccines were available had lower levels of vaccination during restricted vaccine eligibility. Gaps persisted or widened as eligibility first expanded. These disparities may have contributed to a bifurcated recovery in which advantaged communities began to move on from the COVID-19 pandemic while marginalized people continued to suffer. 
medRxiv preprint doi: https://doi.org/10.1101/2021.11.19.21266593; this version posted November 21, 2021. The copyright holder for this preprint (which was not certified by peer review) is the author/funder, who has granted medRxiv a license to display the preprint in perpetuity.

It is made available under a CC-BY-NC-ND 4.0 International license .

\section{TABLES AND FIGURES}

\section{Table 1. Vaccination data sources and coverage}

\begin{tabular}{llll}
\hline City & Source & Time 1 & Time 2 \\
\hline $\begin{array}{llll}\text { New York } \\
\text { Chicago }\end{array}$ & New York City Department of Health and Mental Hygiene & March 22, 2021 & April 13, 2021 \\
Houston & Chicago Department of Public Health & March 22, 2021 & April 13, 2021 \\
Phoenix & Arizona Department of Health Services & March 22, 2021 & April 11, 2021 \\
Philadelphia & Philadelphia Department of Public Health & March 22, 2021 & April 13, 2021 \\
San Antonio & Texas Department of State Health Services & March 21, 2021 & April 12, 2021 \\
San Diego & County of San Diego Health and Human Services Agency & March 21, 2021 & April 12, 2021 \\
Dallas & Texas Department of State Health Services & March 22, 2021 & April 11, 2021 \\
& & & \\
\hline
\end{tabular}


Table 2. Descriptive statistics on COVID-19 vaccination and population composition in ZIP Codes within and across eight large U.S. cities, March and April 2021

\begin{tabular}{|c|c|c|c|c|c|c|c|c|}
\hline & $M$ & $S D$ & & $M$ & $S D$ & & $M$ & $S D$ \\
\hline New York $(n=175)$ & & & Chicago $(n=53)$ & & & Houston $(n=99)$ & & \\
\hline \% vaccinated, March & 28.18 & 7.94 & \% vaccinated, March & 28.70 & 5.50 & \% vaccinated, March & 27.23 & 10.03 \\
\hline \% vaccinated, April & 43.60 & 11.71 & \% vaccinated, April & 45.08 & 9.46 & $\%$ vaccinated, April & 40.97 & 13.64 \\
\hline$\%$ vaccinated, difference & 15.42 & 5.24 & \% vaccinated, difference & 16.38 & 5.21 & $\%$ vaccinated, difference & 13.75 & 4.03 \\
\hline$\% 65+$ & 14.98 & 5.09 & $\% 65+$ & 12.55 & 4.06 & $\% 65+$ & 10.32 & 3.09 \\
\hline \% health care workers & 17.42 & 6.49 & $\%$ health care workers & 13.93 & 3.73 & \% health care workers & 10.81 & 3.31 \\
\hline \% under poverty line & 15.91 & 9.42 & \% under poverty line & 17.93 & 9.90 & \% under poverty line & 18.33 & 9.36 \\
\hline$\%$ w/ Medicaid, etc. & 16.61 & 9.96 & \% w/ Medicaid, etc. & 12.98 & 9.48 & \% w/ Medicaid, etc. & 6.35 & 4.13 \\
\hline \% w/o health insurance & 8.16 & 4.40 & \% w/o health insurance & 10.13 & 5.97 & \% w/o health insurance & 25.09 & 12.31 \\
\hline$\%$ w/o internet access & 14.62 & 6.47 & $\%$ w/o internet access & 16.34 & 9.10 & $\%$ w/o internet access & 16.51 & 10.85 \\
\hline \% Black & 19.82 & 23.39 & \% Black & 29.67 & 33.53 & \% Black & 22.73 & 18.63 \\
\hline \% Hispanic & 26.37 & 19.34 & \% Hispanic & 22.43 & 21.94 & \% Hispanic & 42.58 & 22.27 \\
\hline \% Asian & 14.77 & 13.96 & \% Asian & 7.87 & 8.61 & \% Asian & 6.56 & 6.23 \\
\hline Phoenix $(n=50)$ & & & Philadelphia $(n=46)$ & & & San Antonio $(n=48)$ & & \\
\hline ed, March & 27.78 & 11.00 & \% vaccinated, March & 23.30 & 7.65 & \% vaccinated, March & 29.10 & 9.04 \\
\hline \% vaccinated, April & 40.17 & 13.48 & \% vaccinated, April & 35.58 & 8.74 & \% vaccinated, April & 42.21 & 11.90 \\
\hline \% vaccinated, difference & 12.38 & 3.19 & \% vaccinated, difference & 12.28 & 2.01 & $\%$ vaccinated, difference & 13.11 & 3.33 \\
\hline$\% 65+$ & 11.32 & 4.35 & $\%$ 65+ & 14.18 & 4.61 & $\% 65+$ & 11.90 & 3.24 \\
\hline \% health care workers & 12.08 & 2.16 & \% health care workers & 20.63 & 4.38 & \% health care workers & 14.06 & 2.31 \\
\hline$\%$ under poverty line & 16.82 & 10.04 & \% under poverty line & 22.25 & 11.17 & \% under poverty line & 16.55 & 8.85 \\
\hline \% w/ Medicaid, etc. & 12.38 & 7.14 & \% w/ Medicaid, etc. & 15.52 & 9.37 & \% w/ Medicaid, etc. & 4.99 & 3.01 \\
\hline \% w/o health insurance & 14.37 & 8.32 & \% w/o health insurance & 8.74 & 3.58 & \% w/o health insurance & 18.89 & 8.42 \\
\hline$\%$ w/o internet access & 13.49 & 9.36 & $\%$ w/o internet access & 18.16 & 8.49 & \% w/o internet access & 15.69 & 9.88 \\
\hline \% Black & 6.04 & 4.29 & \% Black & 38.51 & 30.97 & \% Black & 7.13 & 7.67 \\
\hline \% Hispanic & 37.30 & 23.95 & \% Hispanic & 11.99 & 13.48 & \% Hispanic & 61.79 & 20.90 \\
\hline$\%$ Asian & 3.96 & 2.77 & $\%$ Asian & 6.96 & 5.82 & $\%$ Asian & 2.85 & 2.72 \\
\hline San Diego $(n=33)$ & & & Dallas $(n=48)$ & & & Overall $(n=552)$ & & \\
\hline \% vaccinated, March & 34.16 & 8.45 & \% vaccinated, March & 27.02 & 10.40 & \% vaccinated, March & 27.95 & 9.00 \\
\hline \% vaccinated, April & 50.30 & 10.81 & \% vaccinated, April & 42.04 & 13.92 & \% vaccinated, April & 42.44 & 12.34 \\
\hline \% vaccinated, difference & 16.13 & 3.45 & \% vaccinated, difference & 15.02 & 4.72 & \% vaccinated, difference & 14.48 & 4.56 \\
\hline$\% 65+$ & 13.18 & 4.36 & $\%$ 65+ & 10.55 & 5.72 & $\%$ 65+ & 12.75 & 4.81 \\
\hline \% health care workers & 12.87 & 2.00 & $\%$ health care workers & 11.22 & 2.42 & $\%$ health care workers & 14.58 & 5.45 \\
\hline$\%$ under poverty line & 11.98 & 6.68 & \% under poverty line & 17.11 & 9.02 & \% under poverty line & 17.08 & 9.64 \\
\hline \% w/ Medicaid, etc. & 9.63 & 7.17 & \% w/ Medicaid, etc. & 5.11 & 3.89 & \% w/ Medicaid, etc. & 11.52 & 9.04 \\
\hline \% w/o health insurance & 8.11 & 5.43 & \% w/o health insurance & 24.26 & 11.89 & \% w/o health insurance & 14.33 & 10.65 \\
\hline$\%$ w/o internet access & 7.03 & 5.30 & $\%$ w/o internet access & 18.29 & 12.72 & $\%$ w/o internet access & 15.28 & 9.26 \\
\hline \% Black & 5.34 & 4.40 & \% Black & 22.88 & 19.50 & \% Black & 19.89 & 23.32 \\
\hline \% Hispanic & 26.84 & 21.38 & \% Hispanic & 36.52 & 20.75 & \% Hispanic & 32.68 & 23.95 \\
\hline$\%$ Asian & 15.39 & 11.40 & \% Asian & 5.23 & 9.70 & \% Asian & 9.18 & 10.79 \\
\hline
\end{tabular}

Note: $N=552$ ZIP Codes across eight of the 10 most populous U.S. cities. "Health care workers" refers to individuals employed in health care and social assistance. "Medicaid, etc." refers to Medicaid or any other meanstested public health insurance. The "\% vaccinated" is the percent of the population age 15 and older with at least one dose of a COVID-19 vaccine. 
Table 3. Spatial error model (SEM) estimates of COVID-19 vaccination levels in the population age 15 and older of ZIP Codes across eight large U.S. cities, March and April 2021

\begin{tabular}{|c|c|c|c|}
\hline & $\begin{array}{c}\text { (1) } \\
\% \text { vaccinated, March }\end{array}$ & $\begin{array}{c}(2) \\
\% \text { vaccinated, April }\end{array}$ & $\begin{array}{c}(3) \\
\text { Difference } \\
\end{array}$ \\
\hline \multicolumn{4}{|c|}{ Vaccination priority populations } \\
\hline$\% 65+$ & $\begin{array}{c}0.593 * * * \\
(0.048)\end{array}$ & $\begin{array}{c}0.470 * * * \\
(0.075)\end{array}$ & $\begin{array}{c}-0.122^{*} \\
(0.054)\end{array}$ \\
\hline$\%$ health care workers & $\begin{array}{c}0.147 \\
(0.257)\end{array}$ & $\begin{array}{l}-0.063 \\
(0.309)\end{array}$ & $\begin{array}{c}-0.201^{* * *} \\
(0.055)\end{array}$ \\
\hline \multicolumn{4}{|l|}{ Socioeconomic composition } \\
\hline$\%$ under poverty line & $\begin{array}{c}-0.102 * \\
(0.051)\end{array}$ & $\begin{array}{c}-0.138^{* *} \\
(0.051)\end{array}$ & $\begin{array}{l}-0.039 \\
(0.023)\end{array}$ \\
\hline \% w/ Medicaid, etc. & $\begin{array}{c}-0.102 * * * \\
(0.024)\end{array}$ & $\begin{array}{c}-0.127^{* *} \\
(0.046)\end{array}$ & $\begin{array}{l}-0.021 \\
(0.029)\end{array}$ \\
\hline$\%$ w/o health insurance & $\begin{array}{c}-0.418 * * * \\
(0.039)\end{array}$ & $\begin{array}{c}-0.655 * * * \\
(0.053)\end{array}$ & $\begin{array}{c}-0.234^{* * *} \\
(0.023)\end{array}$ \\
\hline$\%$ w/o internet access & $\begin{array}{l}-0.040 \\
(0.051)\end{array}$ & $\begin{array}{l}-0.036 \\
(0.060)\end{array}$ & $\begin{array}{c}0.003 \\
(0.011)\end{array}$ \\
\hline \multicolumn{4}{|l|}{ Racial/ethnic composition } \\
\hline$\%$ Black & $\begin{array}{l}-0.111 \\
(0.061)\end{array}$ & $\begin{array}{l}-0.132 \\
(0.084)\end{array}$ & $\begin{array}{l}-0.021 \\
(0.025)\end{array}$ \\
\hline \% Hispanic & $\begin{array}{c}0.041 \\
(0.035)\end{array}$ & $\begin{array}{c}0.076 \\
(0.041)\end{array}$ & $\begin{array}{c}0.036^{* * * *} \\
(0.010)\end{array}$ \\
\hline$\%$ Asian & $\begin{array}{c}0.101 \\
(0.067)\end{array}$ & $\begin{array}{l}0.230^{*} \\
(0.103)\end{array}$ & $\begin{array}{c}0.127^{* * *} \\
(0.037)\end{array}$ \\
\hline \multicolumn{4}{|l|}{ Residual Moran's I } \\
\hline Standard linear model (SLM) & $0.250 * * *$ & $0.222 * * *$ & $0.202^{* * *}$ \\
\hline Spatial error model (SEM) & 0.027 & 0.014 & -0.015 \\
\hline
\end{tabular}

Note: SEMs estimated by maximum likelihood with row-standardized nearest-neighbor spatial weighting $(k=8)$. $N=552$ ZIP Codes across eight of the 10 most populous U.S. cities. City fixed effects (reference: New York) and constant terms not shown. Percentages scaled from zero to one. All models weighted by estimated population age 15 and older. Heteroskedasticity-robust standard errors clustered by state in parentheses. ${ }^{* * *} p<0.001$; ${ }^{* *} p<0.01$; $* p<0.05$. Moran's I $p$-values calculated by permutation bootstrap (9,999 iterations). "Health care workers" refers to individuals employed in health care and social assistance. "Medicaid, etc." refers to Medicaid or any other meanstested public health insurance. The "\% vaccinated" is the percent of the population age 15 and older with at least one dose of a COVID-19 vaccine. 
medRxiv preprint doi: https://doi.org/10.1101/2021.11.19.21266593; this version posted November 21, 2021. The copyright holder for this preprint (which was not certified by peer review) is the author/funder, who has granted medRxiv a license to display the preprint in perpetuity.

It is made available under a CC-BY-NC-ND 4.0 International license .

Figure 1. COVID-19 vaccination levels in the population age 15 and older of ZIP Codes in eight large U.S. cities, March and April 2021

March 2021

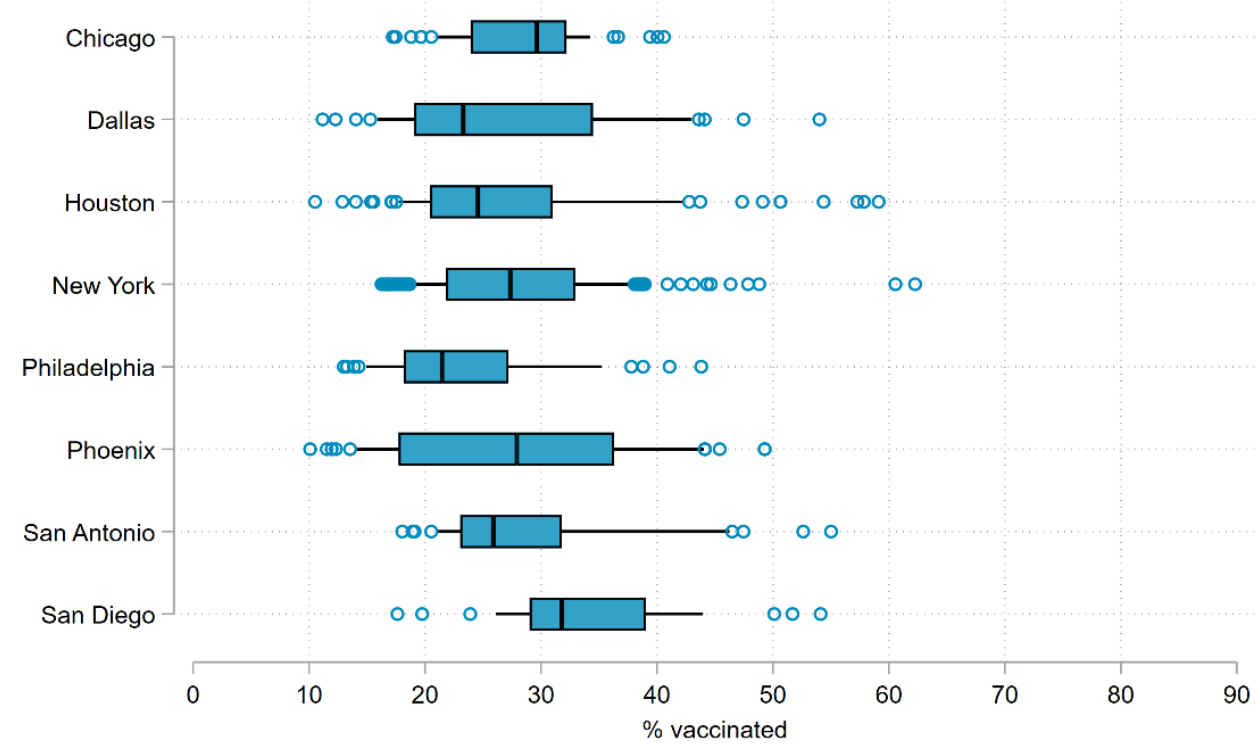

April 2021

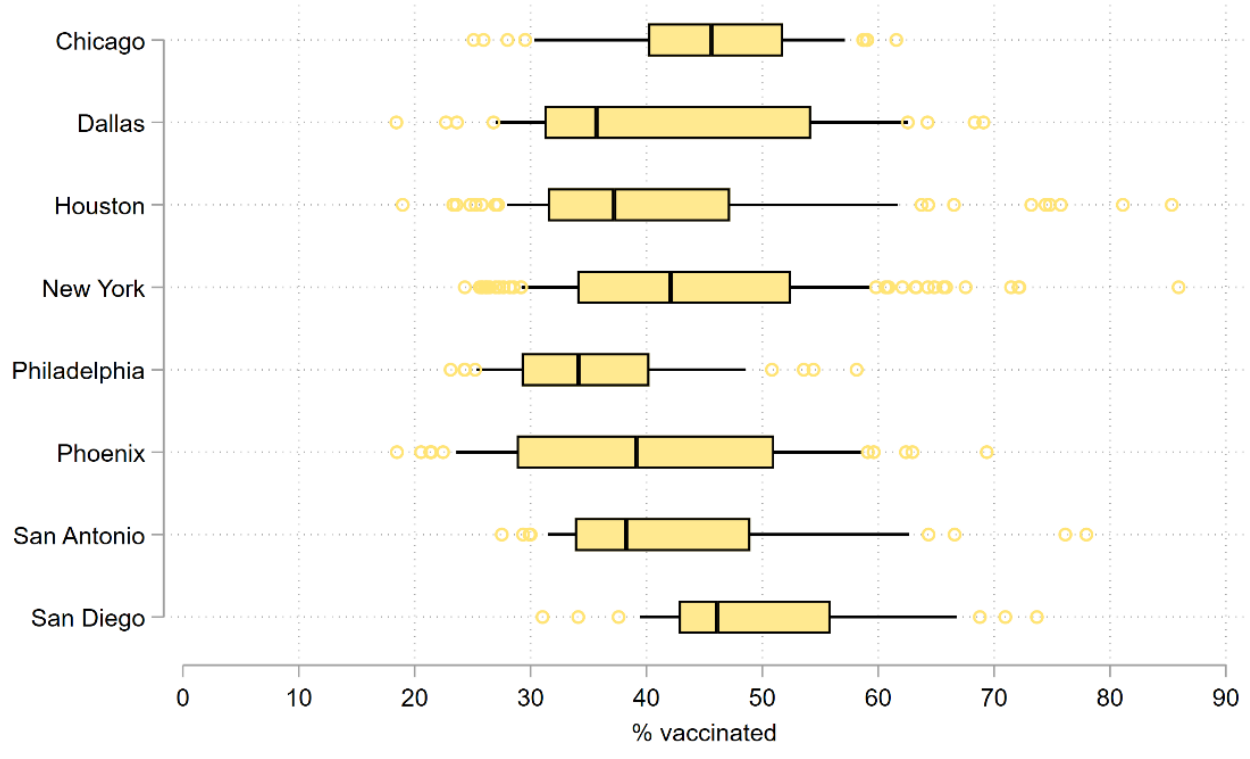

Note: Figures are box-and-whisker plots of vaccination levels in $N=552$ ZIP Codes across eight of the 10 most populous U.S. cities. The boxes represent interquartile ranges. The vertical lines represent medians. The horizontal lines extend from the 10th to the 90th percentiles. Circles represent observations below the 10th and above the 90th percentiles. The "\% vaccinated" is the percent of the population age 15 and older with at least one dose of a COVID19 vaccine. 
Figure 2. Simulated COVID-19 vaccination levels by racial/ethnic and socioeconomic composition in the population age 15 and older of ZIP Codes across eight large U.S. cities, March and April 2021

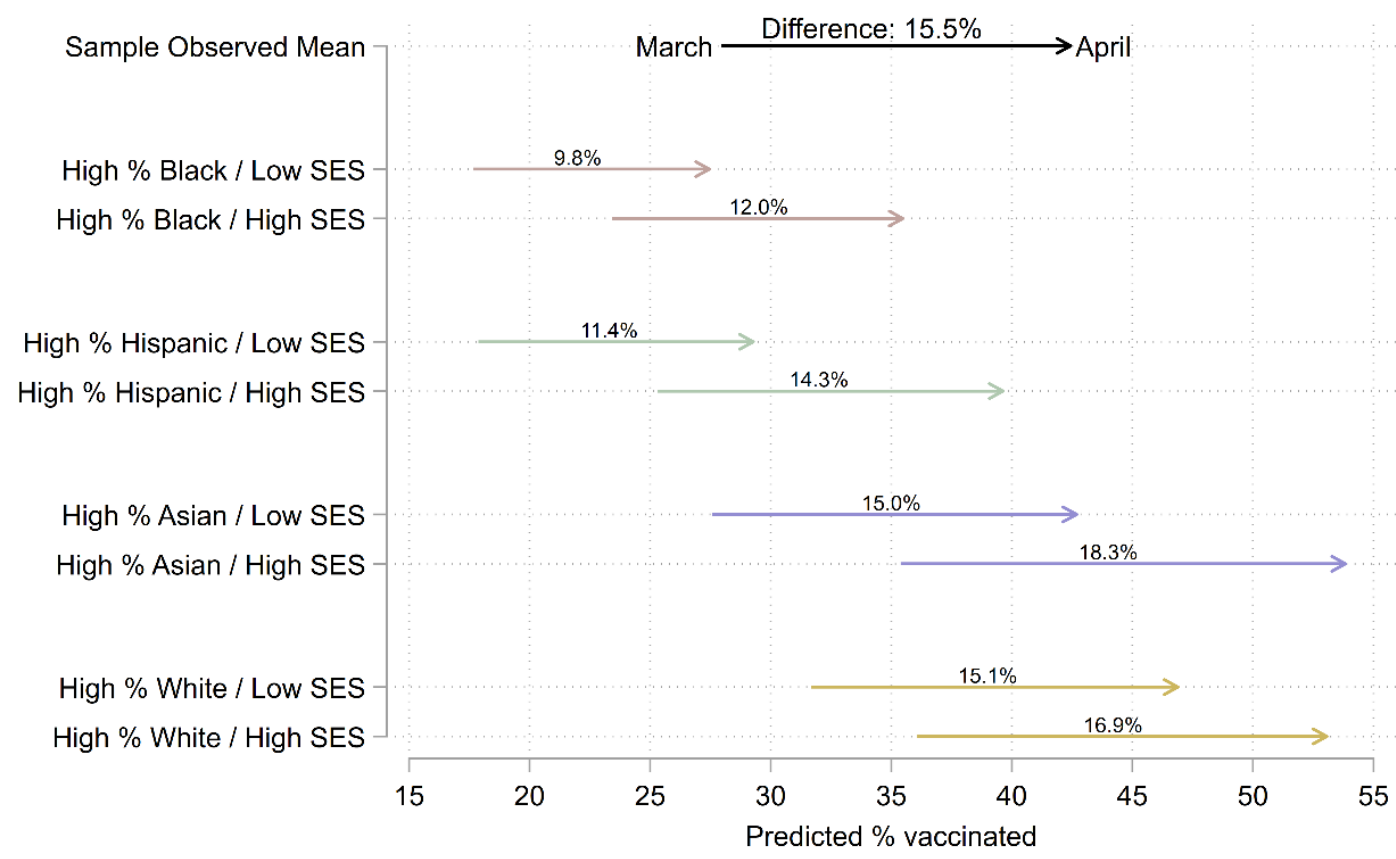

Note: This figure illustrates simulated sample-wide means assuming each ZIP Code had a given socioeconomic and racial/ethnic composition. We defined low and high levels as below the 10th and above the 90th within-city percentiles, respectively. We defined SES levels by setting all four SES variables to the same within-city percentiles within each scenario. We set other independent variables to within-city averages in each scenario. We include the true (observed) sample-wide average values of the dependent variable on the top row for comparison. The "\% vaccinated" is the percent of the population age 15 and older with at least one dose of a COVID-19 vaccine. 


\section{REFERENCES}

1. Understanding vaccination progress. Johns Hopkins Coronavirus Resource Center. Accessed May 11, 2021. https://coronavirus.jhu.edu/vaccines/us-states

2. Polack FP, Thomas SJ, Kitchin N, et al. Safety and efficacy of the BNT162b2 mRNA COVID-19 vaccine. $N$ Engl J Med. 2020;383(27):2603-2615. doi:10.1056/NEJMoa2034577

3. Baden LR, El Sahly HM, Essink B, et al. Efficacy and safety of the mRNA-1273 SARSCoV-2 vaccine. N Engl J Med. 2021;384(5):403-416. doi:10.1056/NEJMoa2035389

4. Thompson MG. Interim estimates of vaccine effectiveness of BNT162b2 and mRNA-1273 COVID-19 vaccines in preventing SARS-CoV-2 infection among health care personnel, first responders, and other essential and frontline workers - eight U.S. locations, December 2020-March 2021. Morb Mortal Wkly Rep. 2021;70(13):495-500. doi:10.15585/mmwr.mm7013e3

5. Shah ASV, Gribben C, Bishop J, et al. Effect of vaccination on transmission of SARS-CoV2. N Engl J Med. 2021;385(18):1718-1720. doi:10.1056/NEJMc2106757

6. Sahly HME, Baden LR, Essink B, et al. Efficacy of the mRNA-1273 SARS-CoV-2 vaccine at completion of blinded phase. $N$ Engl J Med. Published online September 22, 2021. doi:10.1056/NEJMoa2113017

7. Iheanacho CO, Eze UIH, Adida EA. A systematic review of effectiveness of BNT162b2 mRNA and ChAdOx1 adenoviral vector COVID-19 vaccines in the general population. Bull Natl Res Cent. 2021;45(1):150. doi:10.1186/s42269-021-00607-w

8. Lipsitch M, Kahn R. Interpreting vaccine efficacy trial results for infection and transmission. Vaccine. 2021;39(30):4082-4088. doi:10.1016/j.vaccine.2021.06.011

9. Gayle H, Foege W, Brown L, Kahn B, eds. Framework for Equitable Allocation of COVID19 Vaccine. National Academies Press; 2020.

10. Tanne JH. Covid-19: Biden buys 200 million doses of vaccines to tackle supply shortages across US. BMJ. 2021;372:n246. doi:10.1136/bmj.n246

11. Money L, Lin RG. Waves of Californians will be newly eligible for the vaccine. But getting it will be tough. Los Angeles Times (online). Published March 11, 2021. Accessed November 3, 2021. https://www.proquest.com/latimes/docview/2499986329/citation/8F6551B55F7D4C0APQ/ 15

12. Weise E. America could soon be swimming in COVID-19 vaccines: the shift from scarcity to surplus could bring its own problems. USA Today (online). Published March 9, 2021. Accessed November 3, 2021. 
https://www.usatoday.com/story/news/health/2021/03/09/covid-19-vaccine-us-surplusapril-coronavirus/4595458001/

13. Weekly COVID-19 vaccine allocations. Kaiser Family Foundation. Accessed November 3, 2021. https://www.kff.org/other/state-indicator/weekly-covid-19-vaccine-allocations/

14. Howard J. All 50 states now have expanded or will expand Covid vaccine eligibility to everyone 16 and up. CNN. Published April 5, 2021. Accessed April 23, 2021. https://www.cnn.com/2021/03/30/health/states-covid-19-vaccine-eligibility-bn/index.html

15. How to get a Covid-19 vaccine: a state-by-state guide. Wall Street Journal (online). Published April 15, 2021. Accessed September 5, 2021. https://www.wsj.com/articles/howto-get-a-covid-19-vaccine-a-state-by-state-guide-11611703769

16. COVID data tracker. Centers for Disease Control and Prevention. Accessed September 5, 2021. https://covid.cdc.gov/covid-data-tracker

17. Abedi V, Olulana O, Avula V, et al. Racial, economic, and health inequality and COVID-19 infection in the United States. J Racial Ethn Health Disparities. 2021;8:732-742. doi:10.1007/s40615-020-00833-4

18. Clouston SAP, Natale G, Link BG. Socioeconomic inequalities in the spread of coronavirus-19 in the United States: a examination of the emergence of social inequalities. Soc Sci Med. 2021;268:113554. doi:10.1016/j.socscimed.2020.113554

19. Do DP, Frank R. Unequal burdens: assessing the determinants of elevated COVID-19 case and death rates in New York City's racial/ethnic minority neighbourhoods. J Epidemiol Community Health. 2021;75(4):321-326. doi:10.1136/jech-2020-215280

20. Maroko AR, Nash D, Pavilonis BT. COVID-19 and inequity: a comparative spatial analysis of New York City and Chicago hot spots. J Urban Health. 2020;97(4):461-470. doi:10.1007/s11524-020-00468-0

21. Ransome Y, Ojikutu BO, Buchanan M, Johnston D, Kawachi I. Neighborhood social cohesion and inequalities in COVID-19 diagnosis rates by area-level Black/African American racial composition. J Urban Health. 2021;98(2):222-232. doi:10.1007/s11524021-00532-3

22. Kim B, Rundle AG, Goodwin ATS, et al. COVID-19 testing, case, and death rates and spatial socio-demographics in New York City: An ecological analysis as of June 2020. Health Place. 2021;68:102539. doi:10.1016/j.healthplace.2021.102539

23. Pierce JB, Harrington K, McCabe ME, et al. Racial/ethnic minority and neighborhood disadvantage leads to disproportionate mortality burden and years of potential life lost due to COVID-19 in Chicago, Illinois. Health Place. 2021;68:102540. doi:10.1016/j.healthplace.2021.102540 
24. Yang TC, Kim S, Zhao Y, Choi S won E. Examining spatial inequality in COVID-19 positivity rates across New York City ZIP codes. Health Place. 2021;69:102574. doi:10.1016/j.healthplace.2021.102574

25. Gu T, Mack JA, Salvatore M, et al. Characteristics associated with racial/ethnic disparities in COVID-19 outcomes in an academic health care system. JAMA Netw Open. 2020;3(10):e2025197-e2025197. doi:10.1001/jamanetworkopen.2020.25197

26. Yehia BR, Winegar A, Fogel R, et al. Association of race with mortality among patients hospitalized with Coronavirus Disease 2019 (COVID-19) at 92 US hospitals. JAMA Netw Open. 2020;3(8):e2018039. doi:10.1001/jamanetworkopen.2020.18039

27. Wrigley-Field E, Garcia S, Leider JP, Robertson C, Wurtz R. Racial disparities in COVID19 and excess mortality in Minnesota. Socius. 2020;6:2378023120980918. doi:10.1177/2378023120980918

28. Mackey K, Ayers CK, Kondo KK, et al. Racial and ethnic disparities in COVID-19-related infections, hospitalizations, and deaths. Ann Intern Med. 2021;174(3):362-373. doi:10.7326/M20-6306

29. Gershengorn HB, Patel S, Shukla B, et al. Association of race and ethnicity with COVID-19 test positivity and hospitalization is mediated by socioeconomic factors. Ann Am Thorac Soc. 2021;18(8):1326-1334. doi:10.1513/AnnalsATS.202011-1448OC

30. Lopez L, Hart LH, Katz MH. Racial and ethnic health disparities related to COVID-19. JAMA. 2021;325(8):719-720. doi:10.1001/jama.2020.26443

31. Shiels MS, Haque AT, Haozous EA, et al. Racial and ethnic disparities in excess deaths during the COVID-19 pandemic, March to December 2020. Ann Intern Med. Published online October 5, 2021. doi:10.7326/M21-2134

32. Smith AR. Emergency department visits for COVID-19 by race and ethnicity - 13 states, October-December 2020. Morb Mortal Wkly Rep. 2021;70(15):566-569. doi:10.15585/mmwr.mm7015e3

33. Chang MH, Moonesinghe R, Truman BI. COVID-19 hospitalization by race and ethnicity: association with chronic conditions among Medicare beneficiaries, January 1-September 30, 2020. J Racial Ethn Health Disparities. Published online January 8, 2021. doi:10.1007/s40615-020-00960-y

34. Renelus BD, Khoury NC, Chandrasekaran K, et al. Racial disparities in COVID-19 hospitalization and in-hospital mortality at the height of the New York City pandemic. $J$ Racial Ethn Health Disparities. 2021;8(5):1161-1167. doi:10.1007/s40615-020-00872-X

35. Persad G, Peek ME, Emanuel EJ. Fairly prioritizing groups for access to COVID-19 vaccines. JAMA. 2020;324(16):1601-1602. doi:10.1001/jama.2020.18513 
36. Schmidt H, Gostin LO, Williams MA. Is it lawful and ethical to prioritize racial minorities for COVID-19 vaccines? JAMA. 2020;324(20):2023. doi:10.1001/jama.2020.20571

37. Persad G. Against exclusive survivalism: preventing lost life and protecting the disadvantaged in resource allocation. Hastings Cent Rep. 2021;51(5):47-51. doi:10.1002/hast.1286

38. Dooling K. Phased allocation of COVID-19 vaccines. Presented at: Advisory Committee on Immunization Practices meeting; November 23, 2020.

https://www.cdc.gov/vaccines/acip/meetings/downloads/slides-2020-11/COVID-04Dooling.pdf

39. Goodnough A, Hoffman J. Up next: essential workers and people older than 74. New York Times. December 21, 2020:A.6.

40. Wilson WJ. The Truly Disadvantaged: The Inner City, the Underclass, and Public Policy. 2nd ed. University of Chicago Press; 2012.

41. Massey DS, Denton NA. American Apartheid: Segregation and the Making of the Underclass. Harvard University Press; 1993.

42. Entwisle B. Putting people into place. Demography. 2007;44(4):687-703. doi:10.1353/dem.2007.0045

43. Sampson RJ. Great American City: Chicago and the Enduring Neighborhood Effect. University of Chicago Press; 2012.

44. Sharkey P. Stuck in Place: Urban Neighborhoods and the End of Progress toward Racial Equality. University of Chicago Press; 2013.

45. Chetty R, Hendren N, Kline P, Saez E. Where is the land of opportunity?: the geography of intergenerational mobility in the United States. Q J Econ. 2014;129(4):1553-1623. doi:10.1093/qje/qju022

46. Gaddis SM, Ghoshal R. Arab American housing discrimination, ethnic competition, and the contact hypothesis. Ann Am Acad Pol Soc Sci. 2015;660(1):282-299. doi:10.1177/0002716215580095

47. Krysan M, Crowder K. Cycle of Segregation: Social Processes and Residential Stratification. Russell Sage Foundation; 2017.

48. Rothstein R. The Color of Law: A Forgotten History of How Our Government Segregated America. Liveright; 2017.

49. Galster G, Sharkey P. Spatial foundations of inequality: a conceptual model and empirical overview. RSF. 2017;3(2):1-33. doi:10.7758/rsf.2017.3.2.01 
50. Gaddis SM, Ghoshal R. Searching for a roommate: a correspondence audit examining racial/ethnic and immigrant discrimination among millennials. Socius.

2020;6:2378023120972287. doi:10.1177/2378023120972287

51. Gaddis SM, DiRago N, Ghoshal R. Moving to the city: an audit study examining the consequences of racial/ethnic discrimination on residential segregation. SSRN Sch Pap. 2020;2605853. doi:10.2139/ssrn.2605853

52. Wrigley-Field E, Kiang MV, Riley AR, et al. Geographically targeted COVID-19 vaccination is more equitable and averts more deaths than age-based thresholds alone. Sci Adv. 7(40):eabj2099. doi:10.1126/sciadv.abj2099

53. Kreps S, Prasad S, Brownstein JS, et al. Factors associated with US adults' likelihood of accepting COVID-19 vaccination. JAMA Netw Open. 2020;3(10):e2025594-e2025594. doi:10.1001/jamanetworkopen.2020.25594

54. King WC, Rubinstein M, Reinhart A, Mejia R. COVID-19 vaccine hesitancy January-May 2021 among 18-64 year old US adults by employment and occupation. Prev Med Rep. 2021;24:101569. doi:10.1016/j.pmedr.2021.101569

55. Latkin CA, Dayton L, Yi G, Konstantopoulos A, Boodram B. Trust in a COVID-19 vaccine in the U.S.: a social-ecological perspective. Soc Sci Med. 2021;270:113684.

doi:10.1016/j.socscimed.2021.113684

56. Fridman A, Gershon R, Gneezy A. COVID-19 and vaccine hesitancy: a longitudinal study. PLOS ONE. 2021;16(4):e0250123. doi:10.1371/journal.pone.0250123

57. Daly M, Jones A, Robinson E. Public trust and willingness to vaccinate against COVID-19 in the US from October 14, 2020, to March 29, 2021. JAMA. 2021;325(23):2397-2399. doi:10.1001/jama.2021.8246

58. Allen JD, Feng W, Corlin L, et al. Why are some people reluctant to be vaccinated for COVID-19?: a cross-sectional survey among U.S. adults in May-June 2020. Prev Med Rep. 2021;24:101494. doi:10.1016/j.pmedr.2021.101494

59. Agarwal R, Dugas M, Ramaprasad J, Luo J, Li G, Gao G. Socioeconomic privilege and political ideology are associated with racial disparity in COVID-19 vaccination. PNAS. 2021;118(33):e2107873118. doi:10.1073/pnas.2107873118

60. Guidry JPD, Laestadius LI, Vraga EK, et al. Willingness to get the COVID-19 vaccine with and without emergency use authorization. Am J Infect Control. 2021;49(2):137-142. doi:10.1016/j.ajic.2020.11.018

61. Khubchandani J, Sharma S, Price JH, Wiblishauser MJ, Sharma M, Webb FJ. COVID-19 vaccination hesitancy in the United States: a rapid national assessment. J Community Health. 2021;46(2):270-277. doi:10.1007/s10900-020-00958-x 
62. Kricorian K, Civen R, Equils O. COVID-19 vaccine hesitancy: misinformation and perceptions of vaccine safety. Hum Vaccines Immunother. Published online July 30, 2021. doi:10.1080/21645515.2021.1950504

63. Willis DE, Andersen JA, Bryant-Moore K, et al. COVID-19 vaccine hesitancy: race/ethnicity, trust, and fear. Clin Transl Sci. Published online July 2, 2021. doi:10.1111/cts.13077

64. Liu R, Li GM. Hesitancy in the time of coronavirus: temporal, spatial, and sociodemographic variations in COVID-19 vaccine hesitancy. SSM Popul Health. 2021;15:100896. doi:10.1016/j.ssmph.2021.100896

65. Hamel L, Lopes L, Sparks G, Stokes M, Brodie M. KFF COVID-19 Vaccine Monitor April 2021. Kaiser Family Foundation; 2021. Accessed May 12, 2021. https:/www.kff.org/coronavirus-covid-19/poll-finding/kff-covid-19-vaccine-monitor-april2021/

66. Merton RK. The Matthew Effect in science. Science. 1968;159(3810):56-63. doi:10.1126/science.159.3810.56

67. DiPrete TA, Eirich GM. Cumulative advantage as a mechanism for inequality: a review of theoretical and empirical developments. Annu Rev Sociol. 2006;32(1):271-297. doi:10.1146/annurev.soc.32.061604.123127

68. Sampson RJ, Morenoff JD, Gannon-Rowley T. Assessing “neighborhood effects:” social processes and new directions in research. Annu Rev Sociol. 2002;28(1):443-478. doi:10.1146/annurev.soc.28.110601.141114

69. Sampson RJ, Sharkey P, Raudenbush SW. Durable effects of concentrated disadvantage on verbal ability among African-American children. PNAS. 2008;105(3):845-852. doi:10.1073/pnas.0710189104

70. Wodtke GT, Harding DJ, Elwert F. Neighborhood effects in temporal perspective: the impact of long-term exposure to concentrated disadvantage on high school graduation. Am Sociol Rev. 2011;76(5):713-736. doi:10.1177/0003122411420816

71. Sharkey P, Elwert F. The legacy of disadvantage: multigenerational neighborhood effects on cognitive ability. Am J Sociol. 2011;116(6):1934-1981. doi:10.1086/660009

72. Sharkey P, Faber JW. Where, when, why, and for whom do residential contexts matter?: moving away from the dichotomous understanding of neighborhood effects. Annu Rev Sociol. 2014;40(1):559-579. doi:10.1146/annurev-soc-071913-043350

73. Barber S, Hickson DA, Kawachi I, Subramanian SV, Earls F. Neighborhood disadvantage and cumulative biological risk among a socioeconomically diverse sample of African American adults: an examination in the Jackson Heart Study. J Racial Ethn Health Disparities. 2016;3(3):444-456. doi:10.1007/s40615-015-0157-0 
medRxiv preprint doi: https://doi.org/10.1101/2021.11.19.21266593; this version posted November 21, 2021. The copyright holder for this preprint (which was not certified by peer review) is the author/funder, who has granted medRxiv a license to display the preprint in perpetuity.

It is made available under a CC-BY-NC-ND 4.0 International license .

74. Elías Alvarado S. Delayed disadvantage: neighborhood context and child development. Soc Forces. 2016;94(4):1847-1877. doi:10.1093/sf/sow020

75. Chetty R, Hendren N. The impacts of neighborhoods on intergenerational mobility I: childhood exposure effects. Q J Econ. 2018;133(3):1107-1162. doi:10.1093/qje/qjy007

76. Levy BL, Owens A, Sampson RJ. The varying effects of neighborhood disadvantage on college graduation: moderating and mediating mechanisms. Sociol Educ. 2019;92(3):269292. doi: $10.1177 / 0038040719850146$

77. Levy BL, Phillips NE, Sampson RJ. Triple disadvantage: neighborhood networks of everyday urban mobility and violence in U.S. cities. Am Sociol Rev. 2020;85(6):925-956. doi:10.1177/0003122420972323

78. Momplaisir F, Haynes N, Nkwihoreze H, Nelson M, Werner RM, Jemmott J. Understanding drivers of Coronavirus Disease 2019 vaccine hesitancy among Blacks. Clin Infect Dis. 2021;ciab102. doi:10.1093/cid/ciab102

79. Omer SB, Enger KS, Moulton LH, Halsey NA, Stokley S, Salmon DA. Geographic clustering of nonmedical exemptions to school immunization requirements and associations with geographic clustering of pertussis. Am J Epidemiol. 2008;168(12):1389-1396. doi:10.1093/aje/kwn263

80. Siddiqui M, Salmon DA, Omer SB. Epidemiology of vaccine hesitancy in the United States. Hum Vaccines Immunother. 2013;9(12):2643-2648. doi:10.4161/hv.27243

81. Salmon DA, Dudley MZ, Glanz JM, Omer SB. Vaccine hesitancy: causes, consequences, and a call to action. Vaccine. 2015;33:D66-D71. doi:10.1016/j.vaccine.2015.09.035

82. Lieu TA, Ray GT, Klein NP, Chung C, Kulldorff M. Geographic clusters in underimmunization and vaccine refusal. Pediatrics. 2015;135(2):280-289. doi:10.1542/peds.2014-2715

83. Phadke VK, Bednarczyk RA, Salmon DA, Omer SB. Association between vaccine refusal and vaccine-preventable diseases in the United States: a review of measles and pertussis. JAMA. 2016;315(11):1149-1158. doi:10.1001/jama.2016.1353

84. Moghadas SM, Vilches TN, Zhang K, et al. The impact of vaccination on COVID-19 outbreaks in the United States. Clin Infect Dis. 2021;ciab079. doi:10.1093/cid/ciab079

85. Liang LL, Kuo HS, Ho HJ, Wu CY. COVID-19 vaccinations are associated with reduced fatality rates: Evidence from cross-county quasi-experiments. $J$ Glob Health. 2021;11:05019. doi:10.7189/jogh.11.05019

86. Masters NB, Eisenberg MC, Delamater PL, Kay M, Boulton ML, Zelner J. Fine-scale spatial clustering of measles nonvaccination that increases outbreak potential is obscured by aggregated reporting data. PNAS. 2020;117(45):28506-28514.

doi:10.1073/pnas.2011529117 
87. Estep K, Greenberg P. Opting out: individualism and vaccine refusal in pockets of socioeconomic homogeneity. Am Sociol Rev. 2020;85(6):957-991.

doi:10.1177/0003122420960691

88. Gromis A, Liu KY. The emergence of spatial clustering in medical vaccine exemptions following California Senate Bill 277, 2015-2018. Am J Public Health. 2020;110(7):10841091. doi:10.2105/AJPH.2020.305607

89. Lei Y. Hyper focusing local geospatial data to improve COVID-19 vaccine equity and distribution. J Urban Health. 2021;98(4):453-458. doi:10.1007/s11524-021-00552-z

90. Chen X, Zou Y, Gao H. Role of neighborhood social support in stress coping and psychological wellbeing during the COVID-19 pandemic: Evidence from Hubei, China. Health Place. 2021;69:102532. doi:10.1016/j.healthplace.2021.102532

91. Glodeanu A, Gullón P, Bilal U. Social inequalities in mobility during and following the COVID-19 associated lockdown of the Madrid metropolitan area in Spain. Health Place. 2021;70:102580. doi:10.1016/j.healthplace.2021.102580

92. Guo Y, Yu H, Zhang G, Ma DT. Exploring the impacts of travel-implied policy factors on COVID-19 spread within communities based on multi-source data interpretations. Health Place. 2021;69:102538. doi:10.1016/j.healthplace.2021.102538

93. Hao F, Shao W, Huang W. Understanding the influence of contextual factors and individual social capital on American public mask wearing in response to COVID-19. Health Place. 2021;68:102537. doi:10.1016/j.healthplace.2021.102537

94. Mayen Huerta C, Utomo A. Evaluating the association between urban green spaces and subjective well-being in Mexico city during the COVID-19 pandemic. Health Place. 2021;70:102606. doi:10.1016/j.healthplace.2021.102606

95. Robertson LS. Predictors of COVID-19-confirmed cases and fatalities in 883 US counties with a population of 50,000 or more: estimated effect of initial prevention policies. $J$ Urban Health. 2021;98(2):205-210. doi:10.1007/s11524-021-00514-5

96. Slavik CE, Darlington JC, Buttle C, Sturrock SL, Yiannakoulias N. Has public health messaging during the COVID-19 pandemic reflected local risks to health?: a content analysis of tweeting practices across Canadian geographies. Health Place. 2021;69:102568. doi:10.1016/j.healthplace.2021.102568

97. Reitsma MB, Goldhaber-Fiebert JD, Salomon JA. Quantifying and benchmarking disparities in COVID-19 vaccination rates by race and ethnicity. JAMA Netw Open. 2021;4(10):e2130343. doi:10.1001/jamanetworkopen.2021.30343

98. Cardona S, Felipe N, Fischer K, Sehgal NJ, Schwartz BE. Vaccination disparity: quantifying racial inequity in COVID-19 vaccine administration in Maryland. $J$ Urban Health. 2021;98(4):464-468. doi:10.1007/s11524-021-00551-0 
medRxiv preprint doi: https://doi.org/10.1101/2021.11.19.21266593; this version posted November 21, 2021. The copyright holder for this preprint (which was not certified by peer review) is the author/funder, who has granted medRxiv a license to display the preprint in perpetuity.

It is made available under a CC-BY-NC-ND 4.0 International license .

99. Sacarny A, Daw JR. Inequities in COVID-19 vaccination rates in the 9 largest US cities. JAMA Health Forum. 2021;2(9):e212415. doi:10.1001/jamahealthforum.2021.2415

100. Siegel M, Critchfield-Jain I, Boykin M, et al. Racial/ethnic disparities in state-level COVID-19 vaccination rates and their association with structural racism. J Racial Ethn Health Disparities. Published online October 28, 2021. doi:10.1007/s40615-021-01173-7

101. DiRago NV. Replication data for: "COVID-19 vaccine rollouts and the reproduction of urban spatial inequality: disparities within large U.S. cities in March and April 2021 by racial/ethnic and socioeconomic composition.” Harvard Dataverse. Published November 1, 2021. doi:10.7910/DVN/O6EVCZ

102. Jacobsen LA, Mather M, Jarosz B, et al. Understanding and Using American Community Survey Data: What All Data Users Need to Know. U.S. Census Bureau; 2020. https://www.census.gov/programs-surveys/acs/guidance/handbooks/general.html

103. 2019 TIGER/Line Shapefiles Technical Documentation. U.S. Census Bureau; 2019. https://www.census.gov/programs-surveys/geography/technical-documentation/completetechnical-documentation/tiger-geo-line.2019.html

104. Lam NSN. Spatial interpolation methods: a review. Am Cartogr. 1983;10(2):129-150. doi:10.1559/152304083783914958

105. Hawley K, Moellering H. A comparative analysis of areal interpolation methods. Cartogr Geogr Inf Sci. 2005;32(4):411-423. doi:10.1559/152304005775194818

106. Reibling N, Ariaans M, Wendt C. Worlds of healthcare: a healthcare system typology of OECD countries. Health Policy. 2019;123(7):611-620. doi:10.1016/j.healthpol.2019.05.001

107. Lozano R, Fullman N, Mumford JE, et al. Measuring universal health coverage based on an index of effective coverage of health services in 204 countries and territories, 1990-2019: a systematic analysis for the Global Burden of Disease Study 2019. Lancet. 2020;396(10258):1250-1284. doi:10.1016/S0140-6736(20)30750-9

108. Gee GC, Ford CL. Structural racism and health inequities: old issues, new directions. Bois Rev Soc Sci Res Race. 2011;8(1):115-132. doi:10.1017/S1742058X11000130

109. Krieger N. Methods for the scientific study of discrimination and health: an ecosocial approach. Am J Public Health. 2012;102(5):936-944. doi:10.2105/AJPH.2011.300544

110. Phelan JC, Link BG. Is racism a fundamental cause of inequalities in health? Annu Rev Sociol. 2015;41(1):311-330. doi:10.1146/annurev-soc-073014-112305

111. Bailey ZD, Krieger N, Agénor M, Graves J, Linos N, Bassett MT. Structural racism and health inequities in the USA: evidence and interventions. Lancet. 2017;389(10077):14531463. doi:10.1016/S0140-6736(17)30569-X 
medRxiv preprint doi: https://doi.org/10.1101/2021.11.19.21266593; this version posted November 21, 2021. The copyright holder for this preprint (which was not certified by peer review) is the author/funder, who has granted medRxiv a license to display the preprint in perpetuity.

It is made available under a CC-BY-NC-ND 4.0 International license .

112. Hicken MT, Kravitz-Wirtz N, Durkee M, Jackson JS. Racial inequalities in health: framing future research. Soc Sci Med. 2018;199:11-18. doi:10.1016/j.socscimed.2017.12.027

113. Cogburn CD. Culture, race, and health: implications for racial inequities and population health. Milbank Q. 2019;97(3):736-761. doi:10.1111/1468-0009.12411

114. Williams DR, Lawrence JA, Davis BA. Racism and health: evidence and needed research. Annu Rev Public Health. 2019;40(1):105-125. doi:10.1146/annurev-publhealth-040218043750

115. Laster Pirtle WN. Racial capitalism: a fundamental cause of novel coronavirus (COVID-19) pandemic inequities in the United States. Health Educ Behav. 2020;47(4):504-508. doi:10.1177/1090198120922942

116. Bonilla-Silva E. Rethinking racism: toward a structural interpretation. Am Sociol Rev. 1997;62(3):465-480. doi:10.2307/2657316

117. Zuberi T. Deracializing social statistics: problems in the quantification of race. Ann Am Acad Pol Soc Sci. 2000;568:172-185. doi:10.1177/000271620056800113

118. Holland PW. Causation and race. In: Zuberi T, Bonilla-Silva E, eds. White Logic, White Methods: Racism and Methodology. Rowman \& Littlefield; 2008:93-109.

119. Gaddis SM. An introduction to audit studies in the social sciences. In: Gaddis SM, ed. Audit Studies: Behind the Scenes with Theory, Method, and Nuance. Springer; 2018:3-44.

120. Ray V. A theory of racialized organizations. Am Sociol Rev. 2019;84(1):26-53. doi:10.1177/0003122418822335

121. Omi M, Winant H. Racial Formation in the United States. 3rd ed. Routledge; 2015.

122. Link BG, Phelan J. Social conditions as fundamental causes of disease. J Health Soc Behav. 1995;35:80-94. doi:10.2307/2626958

123. Stewart QT, Sewell AA. Quantifying race: on methods for analyzing social inequality. In: Stanfield JH, ed. Rethinking Race and Ethnicity in Research Methods. Routledge; 2011:209-234.

124. Reskin B. The race discrimination system. Annu Rev Sociol. 2012;38(1):17-35. doi:10.1146/annurev-soc-071811-145508

125. Kohler-Hausmann I. Eddie Murphy and the dangers of counterfactual causal thinking about detecting racial discrimination. Northwest Univ Law Rev. 2019;113(5):1163-1228. https://scholarlycommons.law.northwestern.edu/nulr/vol113/iss5/6

126. Rosen E, Garboden PME, Cossyleon JE. Racial discrimination in housing: how landlords use algorithms and home visits to screen tenants. Am Sociol Rev. 2021;86(5):787-822. doi:10.1177/00031224211029618 
medRxiv preprint doi: https://doi.org/10.1101/2021.11.19.21266593; this version posted November 21, 2021. The copyright holder for this preprint (which was not certified by peer review) is the author/funder, who has granted medRxiv a license to display the preprint in perpetuity.

It is made available under a CC-BY-NC-ND 4.0 International license .

127. Solon G, Haider SJ, Wooldridge JM. What are we weighting for? J Hum Resour. 2015;50(2):301-316. doi:10.3368/jhr.50.2.301

128. Ord K. Estimation methods for models of spatial interaction. J Am Stat Assoc. 1975;70(349):120-126. doi:10.1080/01621459.1975.10480272

129. Anselin L. Spatial Econometrics: Methods and Models. Springer; 1988.

130. LeSage JP, Pace RK. Introduction to Spatial Econometrics. Chapman \& Hall/CRC; 2009.

131. Pace RK, LeSage JP. Omitted variable biases of OLS and spatial lag models. In: Páez A, Le Gallo J, Buliung RN, Dall'erba S, eds. Progress in Spatial Analysis: Methods and Applications. Springer; 2010:17-28.

132. Golgher AB, Voss PR. How to interpret the coefficients of spatial models: spillovers, direct and indirect effects. Spat Demogr. 2016;4(3):175-205. doi:10.1007/s40980-015-0016-y

133. Rüttenauer T. Spatial regression models: a systematic comparison of different model specifications using Monte Carlo experiments. Sociol Methods Res. Published online November 29, 2019. doi:10.1177/0049124119882467

134. Schabenberger O, Gotway CA. Statistical Methods for Spatial Data Analysis. Chapman \& Hall/CRC; 2005.

135. Anselin L, Bera AK, Florax R, Yoon MJ. Simple diagnostic tests for spatial dependence. Reg Sci Urban Econ. 1996;26(1):77-104. doi:10.1016/0166-0462(95)02111-6

136. Tiefelsdorf M, Griffith DA, Boots B. A variance-stabilizing coding scheme for spatial link matrices. Environ Plan A. 1999;31(1):165-180. doi:10.1068/a310165

137. Dubin R. Spatial weights. In: Fotheringham AS, Rogerson P, eds. The SAGE Handbook of Spatial Analysis. SAGE; 2009:125-157.

138. Smith TE. Notebook on Spatial Data Analysis. School of Engineering and Applied Science, University of Pennsylvania; 2014.

https://www.seas.upenn.edu/ tesmith/NOTEBOOK/index.html

139. Gormley TA, Matsa DA. Common errors: how to (and not to) control for unobserved heterogeneity. Rev Financ Stud. 2014;27(2):617-661. doi:10.1093/rfs/hht047

140. Cameron AC, Miller DL. A practitioner's guide to cluster-robust inference. J Hum Resour. 2015;50(2):317-372. doi:10.3368/jhr.50.2.317

141. Brambor T, Clark WR, Golder M. Understanding interaction models: improving empirical analyses. Polit Anal. 2006;14(1):63-82. doi:10.1093/pan/mpi014

142. Pepinsky TB. Visual heuristics for marginal effects plots. Res Polit. 2018;5(1). doi:10.1177/2053168018756668 
143. Bivand R. Spatial econometrics functions in R: classes and methods. J Geogr Syst. 2002;4(4):405-421. doi:10.1007/s101090300096

144. Goulard M, Laurent T, Thomas-Agnan C. About predictions in spatial autoregressive models: optimal and almost optimal strategies. Spat Econ Anal. 2017;12(2-3):304-325. doi:10.1080/17421772.2017.1300679

145. Krieger N, Waterman P, Chen JT, Soobader MJ, Subramanian SV, Carson R. ZIP Code caveat: bias due to spatiotemporal mismatches between ZIP Codes and US Census-defined geographic areas. Am J Public Health. 2002;92(7):1100-1102. doi:10.2105/AJPH.92.7.1100

146. Grubesic TH, Matisziw TC. On the use of ZIP Codes and ZIP Code Tabulation Areas (ZCTAs) for the spatial analysis of epidemiological data. Int J Health Geogr. 2006;5(58). doi:10.1186/1476-072X-5-58

147. Grubesic TH. ZIP Codes and spatial analysis: problems and prospects. Socioecon Plann Sci. 2008;42(2):129-149. doi:10.1016/j.seps.2006.09.001

148. Beyer KMM, Schultz AF, Rushton G. Using ZIP Codes as geocodes in cancer research. In: Rushton G, Armstrong MP, Gittler J, et al., eds. Geocoding Health Data: The Use of Geographic Codes in Cancer Prevention and Control, Research, and Practice. CRC; 2008:37-68.

149. Liu K. Measurement error and its impact on partial correlation and multiple linear regression analyses. Am J Epidemiol. 1988;127(4):864-874. doi:10.1093/oxfordjournals.aje.a114870

150. Hausman J. Mismeasured variables in econometric analysis: problems from the right and problems from the left. J Econ Perspect. 2001;15(4):57-67. doi:10.1257/jep.15.4.57

151. Hutcheon JA, Chiolero A, Hanley JA. Random measurement error and regression dilution bias. BMJ. 2010;340:c2289. doi:10.1136/bmj.c2289

152. Loken E, Gelman A. Measurement error and the replication crisis. Science. 2017;355(6325):584-585. doi:10.1126/science.aal3618

153. Krieger N, Chen JT, Waterman PD, Soobader MJ, Subramanian SV, Carson R. Geocoding and monitoring of US socioeconomic inequalities in mortality and cancer incidence: does the choice of area-based measure and geographic level matter? Am J Epidemiol. 2002;156(5):471-482. doi:10.1093/aje/kwf068

154. Thomas AJ, Eberly LE, Davey Smith G, Neaton JD. ZIP-Code-based versus tract-based income measures as long-term risk-adjusted mortality predictors. Am J Epidemiol. 2006;164(6):586-590. doi:10.1093/aje/kwj234

155. Schuurman N, Bell N, Dunn JR, Oliver L. Deprivation indices, population health and geography: an evaluation of the spatial effectiveness of indices at multiple scales. $J$ Urban Health. 2007;84(4):591-603. doi:10.1007/s11524-007-9193-3 
medRxiv preprint doi: https://doi.org/10.1101/2021.11.19.21266593; this version posted November 21, 2021. The copyright holder for this preprint (which was not certified by peer review) is the author/funder, who has granted medRxiv a license to display the preprint in perpetuity.

It is made available under a CC-BY-NC-ND 4.0 International license .

156. Rey G, Jougla E, Fouillet A, Hémon D. Ecological association between a deprivation index and mortality in France over the period 1997 - 2001: variations with spatial scale, degree of urbanicity, age, gender and cause of death. BMC Public Health. 2009;9(1):33.

doi:10.1186/1471-2458-9-33

157. Parenteau MP, Sawada MC. The modifiable areal unit problem (MAUP) in the relationship between exposure to $\mathrm{NO}_{2}$ and respiratory health. Int J Health Geogr. 2011;10(1):58. doi:10.1186/1476-072X-10-58

158. Halonen JI, Vahtera J, Oksanen T, et al. Socioeconomic characteristics of residential areas and risk of death: is variation in spatial units for analysis a source of heterogeneity in observed associations? BMJ Open. 2013;3(4):e002474. doi:10.1136/bmjopen-2012-002474 


\title{
COVID-19 vaccine rollouts and the reproduction of urban spatial inequality: disparities within large U.S. cities in March and April 2021 by racial/ethnic and socioeconomic composition
}

\section{Online supplement}

\author{
Nicholas V. DiRago, ${ }^{\text {a,b }}$ Meiying Li, ${ }^{\mathrm{c}}$ Thalia Tom, ${ }^{\mathrm{c}}$ \\ Will Schupmann, ${ }^{\mathrm{a}}$ Yvonne Carrillo, ${ }^{\mathrm{a}}$ Colleen M. Carey, ${ }^{\mathrm{d}}$ \\ and S. Michael Gaddis ${ }^{\mathrm{a}, \mathrm{b}, *}$ \\ a Department of Sociology, University of California, Los Angeles (UCLA) \\ b California Center for Population Research, UCLA \\ c Department of Sociology, University of Southern California \\ d Department of Policy Analysis and Management, Cornell University \\ *Corresponding author; direct correspondence to mgaddis@soc.ucla.edu.
}

Forthcoming at Journal of Urban Health

4 November 2021 
It is made available under a CC-BY-NC-ND 4.0 International license .

\section{e1 Introduction}

In this supplement to the main text of our study, "COVID-19 vaccine rollouts and the reproduction of urban spatial inequality: disparities within large U.S. cities in March and April 2021 by racial/ethnic and socioeconomic composition," we clarify our approach and contributions by detailing our data and methods. We used spatial quantitative methods to analyze a novel data set that harmonized previously incompatible administrative, demographic, and geospatial data. These data and methods enabled us to test for socioeconomic and racial/ethnic disparities in COVID-19 vaccination across jurisdictions and reporting agencies.

The main purpose of this supplement is to elaborate on the rationale and decisions that led to the final study. In addition to this document, interested readers can access online code and data to replicate our analysis. ${ }^{1}$ We gathered, wrangled, interpolated, and analyzed data using version 4.0.4 of the $\mathrm{R}$ statistical programming language and software environment, ${ }^{2}$ making extensive use of the Tidyverse. ${ }^{3}$ Throughout this supplement, we cite other $\mathrm{R}$ packages that we used. We created Figures e3.1 and e4.1 in $\mathrm{R}^{4}$ and all other figures using version 16.1 of Stata/MP software. ${ }^{5}$

Another purpose of this supplement is to argue that, in addition to the study's empirical findings, our data and methods are substantial contributions. Because of inconsistent reporting, considerable analysis and computation were necessary to compile a high-quality data set measuring local vaccination outcomes across jurisdictions. Once we created the data set, the need to model spatial patterns became evident. Administrative obstacles and empirical dynamics expanded the study's scope beyond the routine boundaries of observational quantitative research.

Even with appropriate adjustments, however, the absence of true neighborhood-level or other hyperlocal data from public sources limited our analysis. Conducted at the ZIP Code level, the study is the best feasible alternative to our original aim of analyzing disparities across jurisdictions by neighborhood - rather than by states or counties, which predominated in media coverage of vaccination rates at the time we began the analysis. Substantial, unnecessary barriers to measuring local inequality in COVID-19 vaccination were in place during the pandemic. Policymakers and administrators should work to reduce them. Reporting data across agencies at the same hyperlocal scale would better support analysis and resource allocation as long as vaccination disparities persist. It would also improve the reporting infrastructure for public health and other sociologically pertinent data.

The rest of this supplement is divided into four sections. In Section e2, we detail the sources, coverage, and definitions of the raw data we collected. We also specify the constructs we sought to measure, define the variables we created accordingly, and assess validity and limitations. In Section e3, we discuss the spatial scale of the study and resulting analytical obstacles and limitations, including measurement error, and detail the interpolation procedures we used to harmonize incompatible raw data. In Section e4, we explain our modeling and estimation strategy, including how we detected and accommodated spatial relationships, and explain the simulation-based approach we used to facilitate interpretation. 
medRxiv preprint doi: https://doi.org/10.1101/2021.11.19.21266593; this version posted November 21, 2021. The copyright holder for this preprint (which was not certified by peer review) is the author/funder, who has granted medRxiv a license to display the preprint in perpetuity.

It is made available under a CC-BY-NC-ND 4.0 International license .

Table e2.1: Vaccination data sources and coverage (expanded)

\begin{tabular}{|c|c|c|c|c|}
\hline City & Source & \multicolumn{2}{|c|}{ As of (year 2021) } & Universe \\
\hline New York & $\begin{array}{l}\text { New York City Department of } \\
\text { Health and Mental Hygiene }\end{array}$ & 22 March & 13 April & $\begin{array}{l}\text { New York City residents } \\
\text { of MODZCTA }\end{array}$ \\
\hline Chicago & $\begin{array}{l}\text { Chicago Department of Public } \\
\text { Health }\end{array}$ & 22 March & 13 April & $\begin{array}{l}\text { Chicago residents } \\
\text { of ZIP Code }\end{array}$ \\
\hline Houston & $\begin{array}{l}\text { Texas Department of State } \\
\text { Health Services }\end{array}$ & 22 March & 11 April & $\begin{array}{l}\text { Texas residents } \\
\text { of ZIP Code }\end{array}$ \\
\hline Phoenix & $\begin{array}{l}\text { Arizona Department of Health } \\
\text { Services }\end{array}$ & 22 March & 13 April & $\begin{array}{l}\text { Arizona residents } \\
\text { of ZIP Code }\end{array}$ \\
\hline Philadelphia & $\begin{array}{l}\text { Philadelphia Department of } \\
\text { Public Health }\end{array}$ & 21 March & 12 April & $\begin{array}{l}\text { Philadelphia residents } \\
\text { of ZIP Code }\end{array}$ \\
\hline San Antonio & $\begin{array}{l}\text { Texas Department of State } \\
\text { Health Services }\end{array}$ & 22 March & 11 April & $\begin{array}{l}\text { Texas residents } \\
\text { of ZIP Code }\end{array}$ \\
\hline San Diego & $\begin{array}{l}\text { County of San Diego Health } \\
\text { and Human Services Agency }\end{array}$ & 21 March & 12 April & $\begin{array}{l}\text { San Diego County } \\
\text { residents of ZIP Code }\end{array}$ \\
\hline Dallas & $\begin{array}{l}\text { Texas Department of State } \\
\text { Health Services }\end{array}$ & 22 March & 11 April & $\begin{array}{l}\text { Texas residents } \\
\text { of ZIP Code }\end{array}$ \\
\hline
\end{tabular}

\section{e2 Data}

\section{e2.1 Administrative records}

From online public databases maintained by state and local public health authorities, we gathered official counts of individuals with at least one dose of a COVID-19 vaccine in March and April 2021. We secured these data for eight of the 10 most populous U.S. cities: New York, Chicago, Houston, Phoenix, Philadelphia, San Antonio, San Diego, and Dallas (in descending order of population). Suitable data were unavailable for Los Angeles and San José, the second and 10th most populous cities, respectively. We summarize the sources and other details of the vaccination data in Table e2.1. ${ }^{\mathrm{e}}$

Only geographically aggregated data were publicly available. For each city except New York, agencies reported vaccination counts aggregated by ZIP Codes (U.S. postal codes) of residence, or by related units known as ZIP Code Tabulation Areas (ZCTAs). ${ }^{\text {f }}$ For New York, data were aggregated by Modified ZIP Code Tabulation Areas (MODZCTAs), proprietary spatial units that merge less populous ZCTAs with adjacent ZCTAs "to allow more stable estimates of population size for rate calculation." ${ }^{6}$ Using an official crosswalk file, ${ }^{7}$ we harmonized data released by ZIP Code or ZCTA with the MODZCTAs.

\footnotetext{
'We detail how we interpolated units of analysis that could be meaningfully compared given agencies' diverging reporting practices in Section e3.2.

${ }^{\mathrm{f}}$ We further introduce ZCTAs in Section e3.1.
} 


\section{e2.2 Demographic surveys}

The 2015-2019 American Community Survey (ACS) Five-Year Estimates were the source of all demographic data in the analysis. Fielded annually by the U.S. Census Bureau (USCB), the ACS provides current, reliable, and representative estimates of population characteristics at various geographic scales. ${ }^{8}$ In preparation for the spatial processing detailed in Section e3.2, we collected all ACS tables listed in Table e2.2 by census block group (CBG). ${ }^{\mathrm{g}}$ We also collected table B01001 by city and by ZCTA. ${ }^{\text {h }}$ We used the USCB application programming interface (API) to gather the ACS estimates. ${ }^{9}$

We detail the demographic variables we calculated from the ACS Table e2.2. ${ }^{\mathrm{i}}$ In addition to the denominator for the outcome variables and the population weights, we used ACS data to compute all independent variables, which measured vaccine priority populations, socioeconomic composition, and racial/ethnic composition.

\section{Socioeconomic status (SES) and health care}

We conceptualized socioeconomic status (SES) through the conventional sociological lens of life chances, ${ }^{10,11}$ or individuals' likelihood of "gaining access to scarce and valued outcomes." $12(\mathrm{p} 32)$ In this analysis, the scarce and valued outcome - COVID-19 vaccination - was health-related and facilitated by internet access. We adjusted for corresponding SES variables, in addition to poverty levels and vaccine priority populations.

Several independent variables measured relationships to the health care system. We partially accounted for the effects of vaccination priority regulations by adjusting for the population of health care workers. Population estimates were unavailable for this exact group, but ACS data allowed us to closely approximate them. We adjusted for the percent of the civilian employed population age 16 or older that worked in "health care and social assistance." 13 This category included employees of hospitals, medical practices, chiropractic practices, dental practices, optometry practices, outpatient and home health care services, nursing and residential care facilities, and other health settings. It also included employees of social service providers, child care services, and other "social assistance" professions. These social assistance workers were typically excluded from early priority groups for vaccination. The population employed in "health care and social assistance" industries was the best available proxy for health care workers, but our variable is effectively an estimate with error.

We also included two independent variables measuring health insurance status. The first was the percent of the population enrolled in Medicaid or other means-tested public health insurance. This variable comprised individuals who had "Medicaid, Medical Assistance, or any kind of government-assistance plan for those with low incomes or a disability." ${ }^{14 p 73}$ It included individuals who had one of these types of insurance in combination with one or more other types of health insurance. The second insurance-related variable was the percent of individuals without health insurance coverage. Together, these two variables captured populations that were among the least integrated into the U.S. health care system.

\footnotetext{
'We introduce CBGs in Section e3.2.

${ }^{\mathrm{h}}$ We introduce ZCTAs in Section e3.1.

${ }^{i}$ As the third column of Table e2.2 shows, the ACS tables were sampled from different sub-populations. Variation in the universes was slight and unproblematic for our analysis.
} 
medRxiv preprint doi: https://doi.org/10.1101/2021.11.19.21266593; this version posted November 21, 2021. The copyright holder for this preprint (which was not certified by peer review) is the author/funder, who has granted medRxiv a license to display the preprint in perpetuity.

It is made available under a CC-BY-NC-ND 4.0 International license .

Table e2.2: Variables calculated from 2015-2019 American Community Survey (ACS) FiveYear Estimates

\begin{tabular}{|c|c|c|c|c|}
\hline Variable & Table & Universe & Numerator & Denominator \\
\hline Population & B01001 & Total population & Column 1 & None \\
\hline $\begin{array}{l}\text { Population age } 15 \text { or } \\
\text { older }\end{array}$ & B01001 & Total population & $\begin{array}{l}\text { Sum of columns } \\
6-25 \text { and } 30-49\end{array}$ & None \\
\hline Percent age 65 or older & B01001 & Total population & $\begin{array}{l}\text { Sum of columns } \\
20-25 \text { and } 44- \\
49\end{array}$ & Column 1 \\
\hline $\begin{array}{l}\text { Percent employed in } \\
\text { health care or social } \\
\text { assistance }\end{array}$ & $\mathrm{C} 24030$ & $\begin{array}{l}\text { Civilian } \\
\text { employed } \\
\text { population age } \\
16 \text { or older }\end{array}$ & $\begin{array}{l}\text { Sum of columns } \\
23 \text { and } 50\end{array}$ & Column 1 \\
\hline $\begin{array}{l}\text { Percent under poverty } \\
\text { line }\end{array}$ & C17002 & $\begin{array}{l}\text { Population for } \\
\text { whom poverty } \\
\text { status is } \\
\text { determined }\end{array}$ & $\begin{array}{l}\text { Sum of columns } \\
2-3\end{array}$ & Column 1 \\
\hline $\begin{array}{l}\text { Percent with Medicaid } \\
\text { or other means-tested } \\
\text { public health insurance }\end{array}$ & B27010 & $\begin{array}{l}\text { Civilian non- } \\
\text { institutionalized } \\
\text { population }\end{array}$ & $\begin{array}{l}\text { Sum of columns } \\
23,29,39,46, \\
\text { and } 62\end{array}$ & Column 1 \\
\hline $\begin{array}{l}\text { Percent without health } \\
\text { insurance }\end{array}$ & B27010 & $\begin{array}{l}\text { Civilian non- } \\
\text { institutionalized } \\
\text { population }\end{array}$ & $\begin{array}{l}\text { Sum of columns } \\
33,50, \text { and } 66\end{array}$ & Column 1 \\
\hline $\begin{array}{l}\text { Percent without } \\
\text { internet access }\end{array}$ & B28002 & Households & Column 13 & Column 1 \\
\hline Percent Black & B03002 & Total population & Column 4 & Column 1 \\
\hline Percent Hispanic & B03002 & Total population & Column 12 & Column 1 \\
\hline Percent Asian & B03002 & Total population & Column 6 & Column 1 \\
\hline Percent White & B03002 & Total population & Column 3 & Column 1 \\
\hline
\end{tabular}


We adjusted for income, a key component of SES, by including the percent of the population that was below the poverty line:

The data on poverty status of households were derived from answers to the income questions. Since poverty is defined at the family level and not the household level, the poverty status of the household is determined by the poverty status of the householder. Households are classified as poor when the total income of the householder's family is below the appropriate poverty threshold. (For nonfamily householders, their own income is compared with the appropriate threshold.) The income of people living in the household who are unrelated to the householder is not considered when determining the poverty status of a household, nor does their presence affect the family size in determining the appropriate threshold. The poverty thresholds vary depending on three criteria: size of family, number of related children, and, for 1 - and 2-person families, age of householder. ${ }^{14 \mathrm{p} 30}$

Percent without internet access was an important independent variable because making appointments online was often the most effective way to secure a vaccine. This variable was the only variable measured at the household level. In the ACS, internet access is defined as "whether or not someone in the household uses or can connect to the internet, regardless of whether or not they pay for the service." 14 p13 Households are designated as having internet access if at least one member can access the internet through a computer or mobile device.

\section{Race/ethnicity}

We use the term "race/ethnicity" rather than "race," "ethnicity," or "race and ethnicity." In the 2015-2019 ACS, USCB considered Hispanic, Latino, and Spanish origins as indicators of ethnicity and other origins as indicators of race. ${ }^{14}$ USCB racial/ethnic definitions change over time and are often unaligned with popular understandings of race/ethnicity, academic definitions of race/ethnicity, or analytically appropriate racial/ethnic schemes for a research question or site. ${ }^{15-22} \mathrm{~A}$ sharp distinction between race and ethnicity does not reflect the processes of stratification in which we were interested in this analysis. The combined term "race/ethnicity" communicates the construct of interest and the structure of the data we used to measure it.

From ACS data, ${ }^{8,14}$ we created variables measuring the estimated populations of four mutually exclusive, non-exhaustive racial/ethnic groups: Black, Hispanic, Asian, and White. We defined Hispanic as Hispanic, Latino, or Spanish origin, of any race(s). We defined Black, Asian, and White as Black or African American alone, Asian alone, and White alone, respectively, and non-Hispanic. This approach implies a fifth category comprised of non-Hispanic individuals of multiple races or of any other race alone, including American Indians, native Alaskans and Hawaiians, and Pacific Islanders. The four racial/ethnic variables did not sum to one (100 percent) unless the estimated population of the fifth category was zero.

Thoroughly accounting for limitations stemming from USCB racial/ethnic categories was outside the scope of our analysis, but attending to the definitions of racial/ethnic categories aids in interpreting our findings. In the ACS,

The terms "Hispanic," "Latino," and "Spanish" are used interchangeably. Some respondents identify with all three terms while others may identify with only 
one of these three specific terms. Hispanics or Latinos who identify with the terms "Hispanic," "Latino," or "Spanish" are those who classify themselves in one or more of the specific Hispanic, Latino, or Spanish categories listed on the questionnaire ("Mexican," "Puerto Rican," or "Cuban") as well as those who indicate that they are "another Hispanic, Latino, or Spanish origin." .. P People who identify their origin as Hispanic, Latino, or Spanish may be of any race. ${ }^{14 p 76}$

The ACS classifies individuals as White if they report "origins in any of the original peoples of Europe, the Middle East, or North Africa," including people who "report entries such as Irish, German, Italian, Lebanese, Arab, Moroccan, or Caucasian." ${ }^{14 p 114}$ It classifies individuals as Black or African American if they report "origins in any of the Black racial groups of Africa," including people who "report entries such as African American, Kenyan, Nigerian, or Haitian." ${ }^{14 p 114}$ It classifies individuals as Asian if they report "origins in any of the original peoples of the Far East, Southeast Asia, or the Indian subcontinent including, for example, Cambodia, China, India, Japan, Korea, Malaysia, Pakistan, the Philippine Islands, Thailand, and Vietnam."14p115

\section{e2.3 Geospatial data}

We used several geospatial vector datasets from the USCB 2019 TIGER/Line Shapefiles (TLS). The TLS are extracts of official USCB geographic and cartographic data. ${ }^{23}$ We collected the following TLS data from the USCB API: ${ }^{24}$ city boundaries from the Place State-Based Shapefiles; ZCTA boundaries from the Five-Digit ZCTA National Shapefile; CBG boundaries from the Block Group State-Based Shapefiles; the boundaries of bodies of water from the Area Hydrography County-Based Shapefiles; and the boundaries of USCBdesignated landmarks from the Area Landmark State-Based Shapefiles. The coordinate reference system (CRS) for the TLS data was the North American Datum of 1983 (NAD83), an ellipsoidal system that uses geodetic latitude and longitude (not a Cartesian plane).

\section{e3 Spatial processing}

\section{e3.1 ZIP Codes, ZIP Code Tabulation Areas (ZCTAs), and vac- cination records}

For brevity and interpretability, in the main paper we refer to our units of analysis as ZIP Codes, the official and colloquial name for postal codes in the U.S. ZIP Codes were the bases of the units of analysis but themselves were not viable analytical units. ZIP Codes are lists of discrete postal addresses, not areal units. More specifically, they are

administrative units established by the United States Postal Service (USPS) for the distribution of mail. ZIP Codes serve addresses for the most efficient delivery of mail, and therefore generally do not respect political or census statistical area boundaries. ZIP Codes usually do not have clearly identifiable boundaries, often serve a continually changing area, are changed periodically to meet postal requirements, and do not cover all the land area of the United States. ${ }^{25 \mathrm{pA}-13}$ 
It is made available under a CC-BY-NC-ND 4.0 International license .

Table e3.1: Population distribution of ZIP Code Tabulation Areas (ZCTAs) within and across eight large U.S. cities, 2015-2019

\begin{tabular}{|c|c|c|c|c|c|c|c|c|c|c|c|c|c|}
\hline \multirow[t]{2}{*}{ City } & \multirow[t]{2}{*}{ ZCTAs } & \multicolumn{4}{|c|}{ Population } & \multicolumn{4}{|c|}{ Area } & \multicolumn{4}{|c|}{ Population density } \\
\hline & & $M$ & $S D$ & $10 \%$ & $90 \%$ & $M$ & $S D$ & $10 \%$ & $90 \%$ & $M$ & $S D$ & $10 \%$ & $90 \%$ \\
\hline New York & 196 & 44,673 & 27,176 & 9,151 & 83,574 & 4.4 & 4.2 & 0.9 & 8.2 & 16,237 & 12,669 & 3,209 & 35,127 \\
\hline Chicago & 87 & 40,687 & 25,148 & 11,559 & 79,690 & 11.8 & 8.5 & 2.6 & 20.2 & 4,825 & 3,617 & 1,378 & 9,804 \\
\hline Houston & 145 & 37,194 & 21,173 & 16,170 & 59,835 & 43.9 & 60.7 & 9.7 & 97.3 & 1,518 & 968 & 410 & 2,789 \\
\hline Phoenix & 67 & 36,025 & 17,375 & 10,064 & 60,657 & 52.1 & 85.6 & 10.4 & 107.5 & 1,500 & 1,004 & 255 & 2,794 \\
\hline Philadelphia & 68 & 28,603 & 18,284 & 6,158 & 53,988 & 9.6 & 7.8 & 3.3 & 17.6 & 4,269 & 3,163 & 863 & 8,371 \\
\hline San Antonio & 69 & 28,439 & 19,865 & 4,818 & 56,665 & 49.1 & 50.1 & 5.8 & 106.7 & 1,043 & 777 & 74 & 2,092 \\
\hline San Diego & 58 & 38,047 & 22,312 & 4,431 & 64,465 & 34.6 & 59.8 & 7.9 & 59.7 & 1,921 & 1,267 & 432 & 3,764 \\
\hline Dallas & 86 & 33,483 & 19,757 & 8,188 & 56,424 & 33.1 & 34.7 & 8.8 & 67.4 & 1,523 & 955 & 467 & 2,629 \\
\hline Overall & 776 & 37,495 & 23,203 & 8,754 & 69,876 & 26.6 & 47.8 & 2.1 & 57.5 & 5,835 & 9,016 & 495 & 16,875 \\
\hline
\end{tabular}

We operationalized ZIP Codes as ZCTAs. For each ZIP Code, the USCB delimits a corresponding ZCTA that approximates the ZIP Code as a polygonal areal unit. The area of each ZCTA is mutually exclusive with those of all other ZCTAs. ${ }^{23}$ ZIP Codes and ZCTAs are related and frequently used interchangeably in research, but ZCTAs are suboptimal units for spatial and quantitative analysis.

ZCTAs are distortive and error-prone. ZIP Codes do not have objective, non-overlapping areal boundaries, which often makes converting from ZIP Codes to ZCTAs uncertain. Public health scholars, epidemiologists, and spatial analysts consistently find mismatches between observations' true locations and recorded ZCTAs. ${ }^{26-29}$ Despite the well-known risk of inducing measurement error, however, most state and local authorities published COVID-19 vaccination data aggregated by ZIP Code. Some failed to indicate whether data were aggregated by ZIP Code or ZCTA. These reporting decisions left researchers without a feasible alternative to using ZCTAs to define areal boundaries consistently across cities.

We summarize the population distribution of each ZCTA that intersected the eight cities proper in Table e3.1. The average ZCTA had 37,495 estimated inhabitants and spanned 26.6 square kilometers, an area nearly half the size of Manhattan or roughly twice the size of Los Angeles International or London Heathrow Airports. In addition, ZCTAs' physical and population sizes varied widely. Over 20 percent of ZCTAs had fewer than 10,000 or more than 70,000 estimated inhabitants. Some were as small as two square kilometers, just over half the size of Central Park in Manhattan; others approached or exceeded 60 square kilometers, an area larger than that of Manhattan and about one-third the size of Washington, DC.

ZCTAs have much larger geographical areas and populations than colloquial and academic definitions of neighborhoods, which limits their utility for studying inequality. Using ZCTAs as units of analysis complicates making connections with the voluminous literature on neighborhood effects, ${ }^{30,31}$ which usually uses finer spatial units. For example, census tracts - the most common areal units in analyses of neighborhood inequality in the U.S.- average 4,000 residents and rarely have more than 8,000.,32 ZIP Codes and ZCTAs also differ substantially from subjective neighborhood boundaries, ${ }^{33-37}$ activity spaces, ${ }^{38-41}$ and other, analytically sounder local units. ${ }^{4-47}$ Aggregating person-level observations to a scale as wide as ZCTAs increases variation within units and decreases variation between them. Statistical analysis may therefore mischaracterize disparities or fail to detect them al- 
together. ${ }^{48-53}$ For these reasons, we avoid the term "neighborhood" when describing our units and findings, and our study's evidence of inequality is partial and potentially understated.

Issues of spatial mismatch and scale aside, ZIP Codes and ZCTAs are inconvenient reporting units for comparing outcomes across administrative jurisdictions. ZIP Codes and ZCTAs overlap neighborhoods, municipalities, counties, and states. ${ }^{8}$ As the rightmost column of Table e2.1 shows, the jurisdictions of some agencies that reported vaccination data also overlapped political boundaries, frequently excluding part of the territory of some ZCTAs. Several sources of data extended only to the populations of cities proper, excluding vaccinations administered to residents of other municipalities who lived in ZIP Codes that straddled city borders. Other agencies' vaccination counts included all individuals with a given ZIP Code, regardless of the municipality in which they resided, within a particular state or county. The administrative and demographic data required adjustment before we could meaningfully compare trends among units.

\section{e3.2 Spatial interpolation}

To create consistent, comparable units of analysis given reporting irregularities in the vaccination data, we restricted the analysis to the geographical limits of the eight cities proper. We excluded populations residing outside the cities, even if they shared a ZIP Code with some city residents. Because only aggregated administrative and demographic data were available, we relied on spatial interpolation to approximate the within-city values of variables for ZCTAs that spanned city borders.

We used the overlay or areal weighting method of spatial interpolation. ${ }^{54,55}$ This method estimates the value of a variable in a target zone based on the proportion of smaller source zones that intersect it. Formally,

$$
\tilde{C}_{t}=\sum_{s} C_{s} \frac{A_{s \cap t}^{*}}{A_{s}^{*}},
$$

where $C$ was the observed value of a count variable; $\tilde{C}$ was the interpolated value of a count variable; $A_{i}^{*}$ approximated the geographic area of unit $i$ that could be populated; $\cap$ denoted geometric intersection; and $s$ and $t$ denoted the source and target zones, respectively. We conducted the interpolation using the NAD83 CRS and square kilometers as the areal unit of measure. ${ }^{56,57}$

The target zones were the geometric intersections between 776 ZCTAs and the eight cities proper. (For ZCTAs that were completely inside city limits, the target zone was the entire ZCTA). The source zones were 16,283 CBGs that intersected the cities proper. The most local areal units for which the USCB releases ACS estimates, CBGs' populations typically range from 600 to 3,000 people. $^{8}$ The area of $90 \%$ of CBGs that intersected the cities was 1.33 square kilometers or less. The typical CBG was 0.93 square kilometers - less than four percent of the area of the typical ZCTA in the study.

The overlay method had several benefits for this study. It also entailed one nontrivial assumption. Overlay interpolation accounts for uneven population density within target zones at the level of source zones. In addition, it is intuitive, computationally inexpensive, and does not require supplemental data. Using the overlay method required us to assume, however, 
Table e3.2: Population distribution of census block groups (CBGs) within and across eight large U.S. cities, 2015-2019

\begin{tabular}{|c|c|c|c|c|c|c|c|c|c|c|c|c|c|}
\hline \multirow[t]{2}{*}{ City } & \multirow[t]{2}{*}{ CBGs } & \multicolumn{4}{|c|}{ Population } & \multicolumn{4}{|c|}{ Area } & \multicolumn{4}{|c|}{ Population density } \\
\hline & & $M$ & $S D$ & $10 \%$ & $90 \%$ & $M$ & $S D$ & $10 \%$ & $90 \%$ & $M$ & $S D$ & $10 \%$ & $90 \%$ \\
\hline New York & 6,507 & 1,305 & 692 & 615 & 2,136 & 0.14 & 0.53 & 0.02 & 0.23 & 24,284 & 21,247 & 4,479 & 52,754 \\
\hline Chicago & 2,344 & 1,246 & 642 & 599 & 1,992 & 0.32 & 0.81 & 0.09 & 0.50 & 7,970 & 9,083 & 2,064 & 13,989 \\
\hline Houston & 1,951 & 2,342 & 2,796 & 844 & 3,701 & 2.32 & 6.84 & 0.31 & 4.03 & 2,629 & 2,601 & 639 & 5,012 \\
\hline Phoenix & 1,064 & 1,705 & 815 & 876 & 2,714 & 2.17 & 11.45 & 0.32 & 2.61 & 2,612 & 1,980 & 626 & 5,045 \\
\hline Philadelphia & 1,402 & 1,185 & 585 & 555 & 1,963 & 0.33 & 0.91 & 0.06 & 0.55 & 8,645 & 5,755 & 2,223 & 16,333 \\
\hline San Antonio & 1,007 & 1,796 & 1,213 & 759 & 3,153 & 2.68 & 9.95 & 0.35 & 3.66 & 2,098 & 1,304 & 574 & 3,731 \\
\hline San Diego & 924 & 1,789 & 1,572 & 764 & 2,750 & 1.95 & 10.37 & 0.16 & 1.90 & 4,125 & 3,307 & 946 & 8,029 \\
\hline Dallas & 1,084 & 1,553 & 927 & 711 & 2,584 & 1.48 & 3.40 & 0.21 & 2.68 & 2,987 & 3,078 & 627 & 6,173 \\
\hline Overall & 16,283 & 1,511 & 1,296 & 657 & 2,462 & 0.93 & 5.32 & 0.04 & 1.33 & 12,644 & 17,088 & 1,064 & 33,315 \\
\hline
\end{tabular}

that populations were uniformly distributed within CBGs. This assumption was modest for such small units.

We nonetheless took steps to mitigate potential inaccuracies. As Equation e3.1 indicates, we interpolated $\tilde{C}_{t}$ from $A^{*}$ rather than from $A$. Formally,

$$
A_{i}^{*}=A_{i}-A_{i \cap(B \cup L)}
$$

where $A_{i}$ was the total area of unit $i$; $\cup$ denoted geometric union; $B$ was the set of USCBdesignated bodies of water; and $L$ was a subset of USCB-designated landmarks. $B$ and $L$ overlapped in many locations. $B$ included the area of "perennial and intermittent ... ponds, lakes, oceans, swamps, glaciers, and ... large streams." 23 p3-34 We list the types of landmarks included in $L$ in Table e3.3. By excluding from areal calculations parts of source zones that were unlikely to contribute population to the target zones, the adjustment in Equation e3.2 made it more plausible to assume uniform population density within CBGs.

We visualize the overlay interpolation process in Figure e3.1. We used overlay interpolation to estimate the target zones' numerators and denominators for all variables listed in Table e2.2-including the population age 15 and older, the outcome variable's denominator.

Calculating the numerator for the outcome variable - the number of individuals with at least dose of a COVID-19 vaccine - required a separate interpolation procedure. For New York, Chicago, and Philadelphia, agencies' counts included only vaccinated individuals living inside the cities proper. In these cases, we could adopt the reported total directly as the numerator for the outcome variable. Elsewhere, reporting agencies' counts for ZIP Codes intersecting the cities included vaccinated individuals residing outside the cities proper. We resolved this discrepancy by adjusting the reported counts using multipler $m$. The value of $m$ was one for observations in New York, Chicago, and Philadelphia; otherwise, it was the ratio between the estimated populations of the target zone and its corresponding reporting unit. Formally, 
medRxiv preprint doi: https://doi.org/10.1101/2021.11.19.21266593; this version posted November 21, 2021. The copyright holder for this preprint (which was not certified by peer review) is the author/funder, who has granted medRxiv a license to display the preprint in perpetuity.

It is made available under a CC-BY-NC-ND 4.0 International license .

Table e3.3: U.S. Census Bureau (USCB)-designated landmarks excluded from area calculations

\begin{tabular}{ll}
\hline Code & Description \\
\hline C3026 & Quarry or mine \\
C3077 & Solar farm \\
K2180 & Park \\
K2181 & National park, forest, etc. \\
K2182 & Other federal land \\
K2183 & Tribal park, forest, etc. \\
K2184 & State park, forest, etc. \\
K2185 & Regional park, forest, etc. \\
K2186 & County park, forest, etc. \\
K2187 & Civil division park, forest, etc. \\
K2188 & Municipal park, forest, etc. \\
K2189 & Private park, forest, etc. \\
K2190 & Other park, forest, etc. \\
K2362 & Industrial building or park \\
K2424 & Marina \\
K2432 & Pier or dock \\
K2451 & Airport \\
K2452 & Train station \\
K2453 & Bus terminal \\
K2454 & Marine terminal \\
K2455 & Seaplane anchorage \\
K2456 & Airport terminals \\
K2457 & Airport grounds \\
K2458 & Park-and-ride facility \\
K2459 & Airport runway \\
K2460 & Helicopter landing \\
K2561 & Golf course \\
K2564 & Amusement park \\
K2582 & Cemetery \\
K2586 & Zoo \\
\hline Cores & \\
\hline
\end{tabular}

Codes are USCB MAF/TIGER Feature

Class Codes $^{23}$. 
medRxiv preprint doi: https://doi.org/10.1101/2021.11.19.21266593; this version posted November 21, 2021. The copyright holder for this preprint (which was not certified by peer review) is the author/funder, who has granted medRxiv a license to display the preprint in perpetuity.

It is made available under a CC-BY-NC-ND 4.0 International license .

Figure e3.1: Summary of overlay interpolation by city

New York
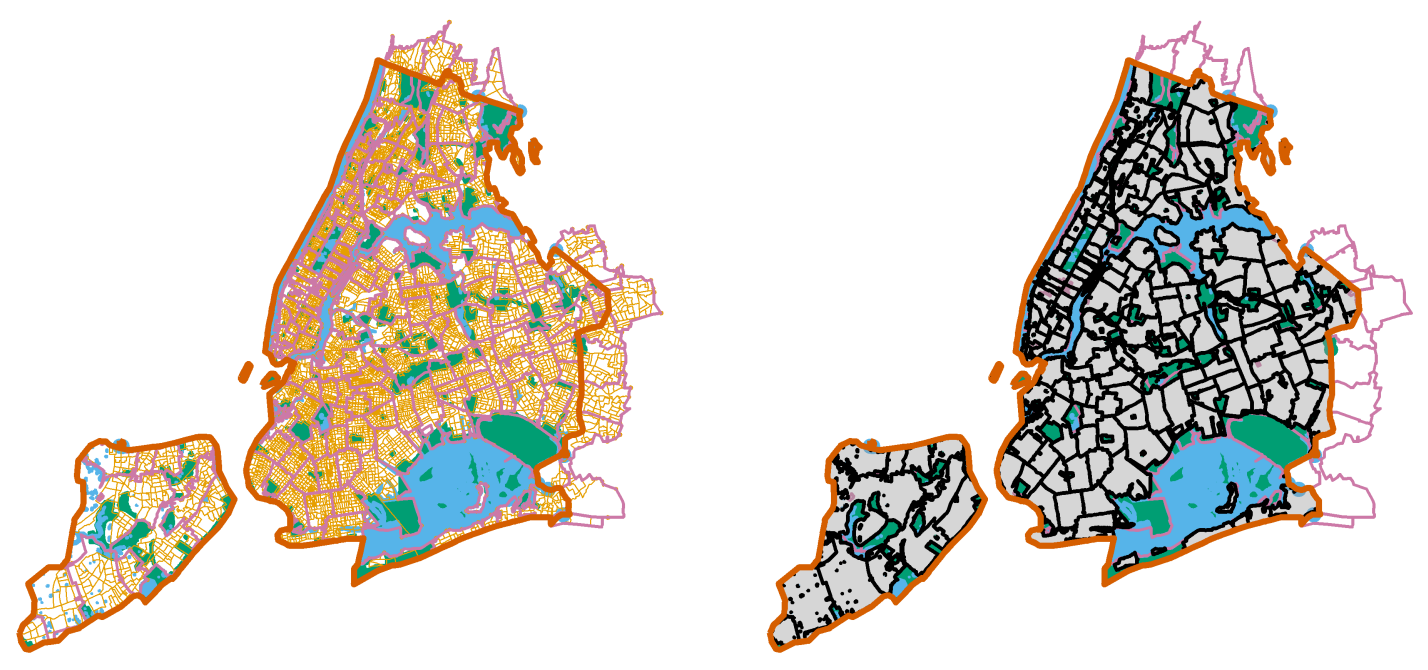

Chicago
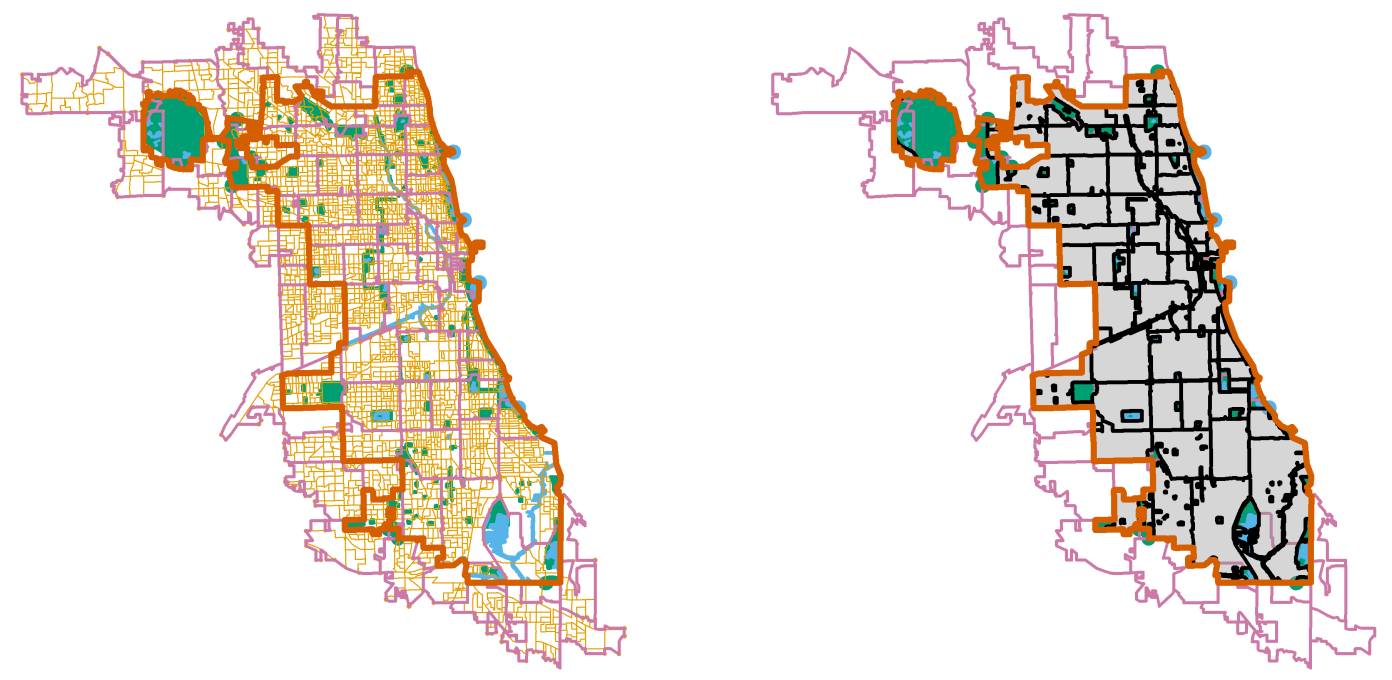

\begin{tabular}{l|l|l|l} 
Bodies of water & Limits of city proper & Zip Code Tabulation Areas (ZCTAs) \\
Other landmarks & Census Block Groups (CBGs)
\end{tabular}$\quad$\begin{tabular}{l} 
Units of analysis \\
\hline
\end{tabular}

Scales differ. All ZCTAs that intersect cities shown. 
medRxiv preprint doi: https://doi.org/10.1101/2021.11.19.21266593; this version posted November 21, 2021. The copyright holder for this preprint (which was not certified by peer review) is the author/funder, who has granted medRxiv a license to display the preprint in perpetuity.

It is made available under a CC-BY-NC-ND 4.0 International license .

Figure e3.1: Summary of overlay interpolation by city

\section{Houston}
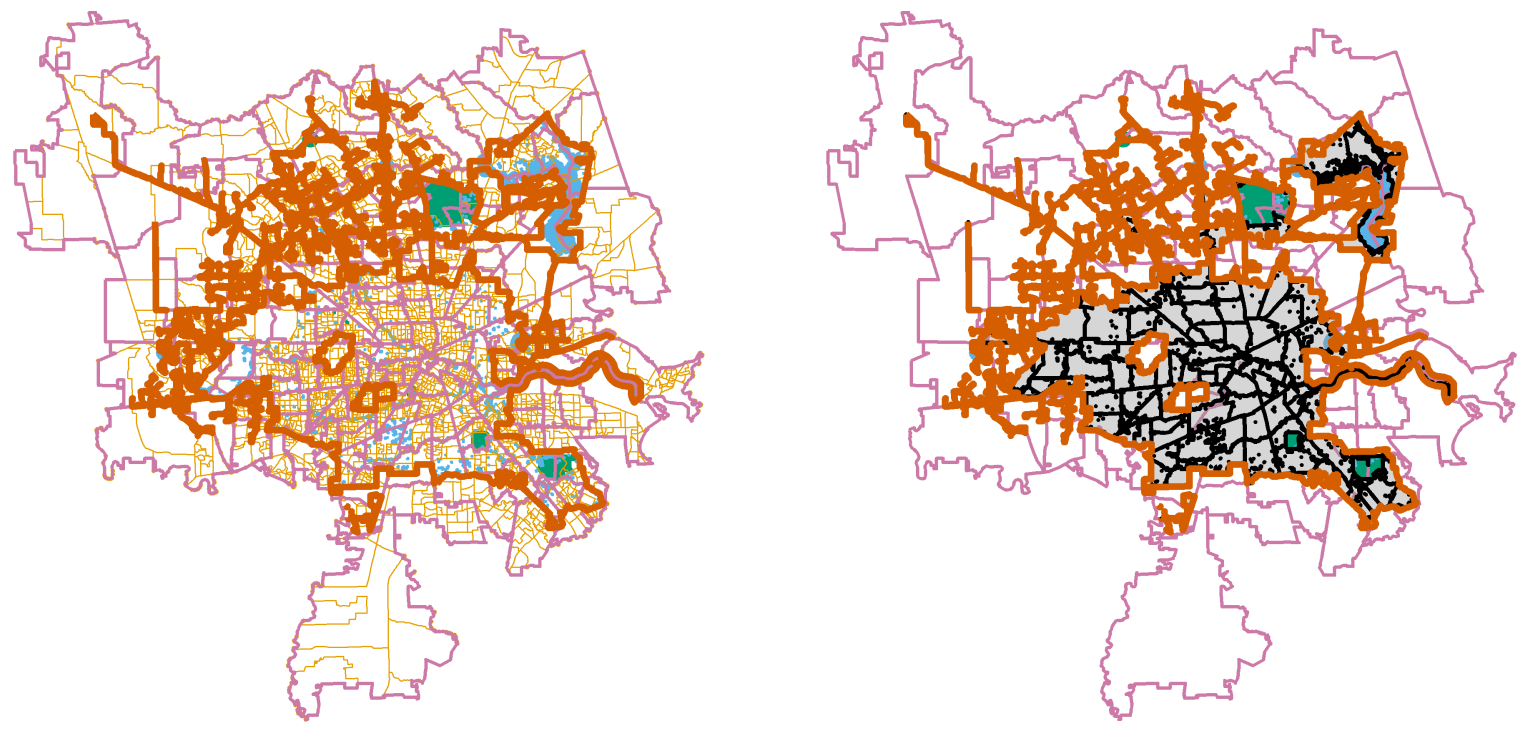

Phoenix
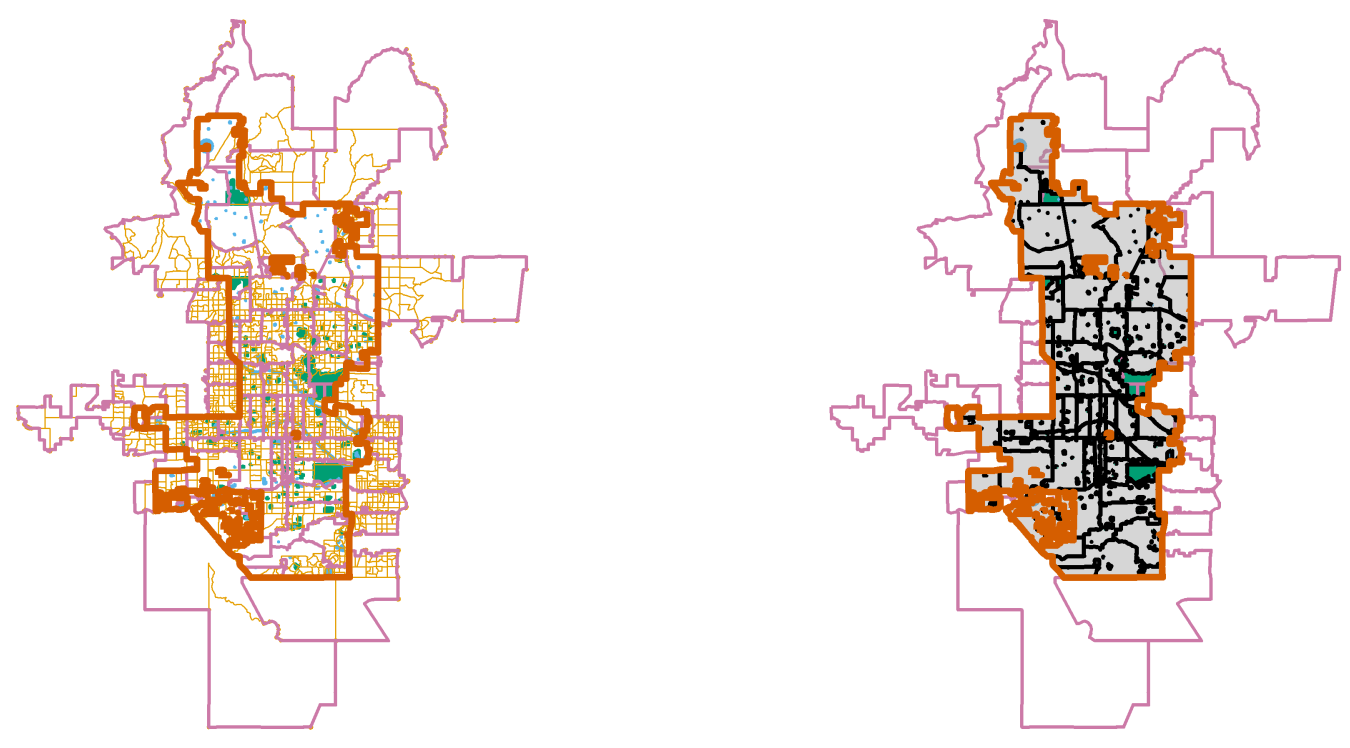

\begin{tabular}{l|l|l|l} 
Bodies of water & Limits of city proper \\
Other landmarks & Census Block Groups (CBGs) & Zip Code Tabulation Areas (ZCTAs) \\
Units of analysis
\end{tabular}

Scales differ. All ZCTAs that intersect cities shown. 
medRxiv preprint doi: https://doi.org/10.1101/2021.11.19.21266593; this version posted November 21, 2021. The copyright holder for this preprint (which was not certified by peer review) is the author/funder, who has granted medRxiv a license to display the preprint in perpetuity.

It is made available under a CC-BY-NC-ND 4.0 International license .

Figure e3.1: Summary of overlay interpolation by city

\section{Philadelphia}
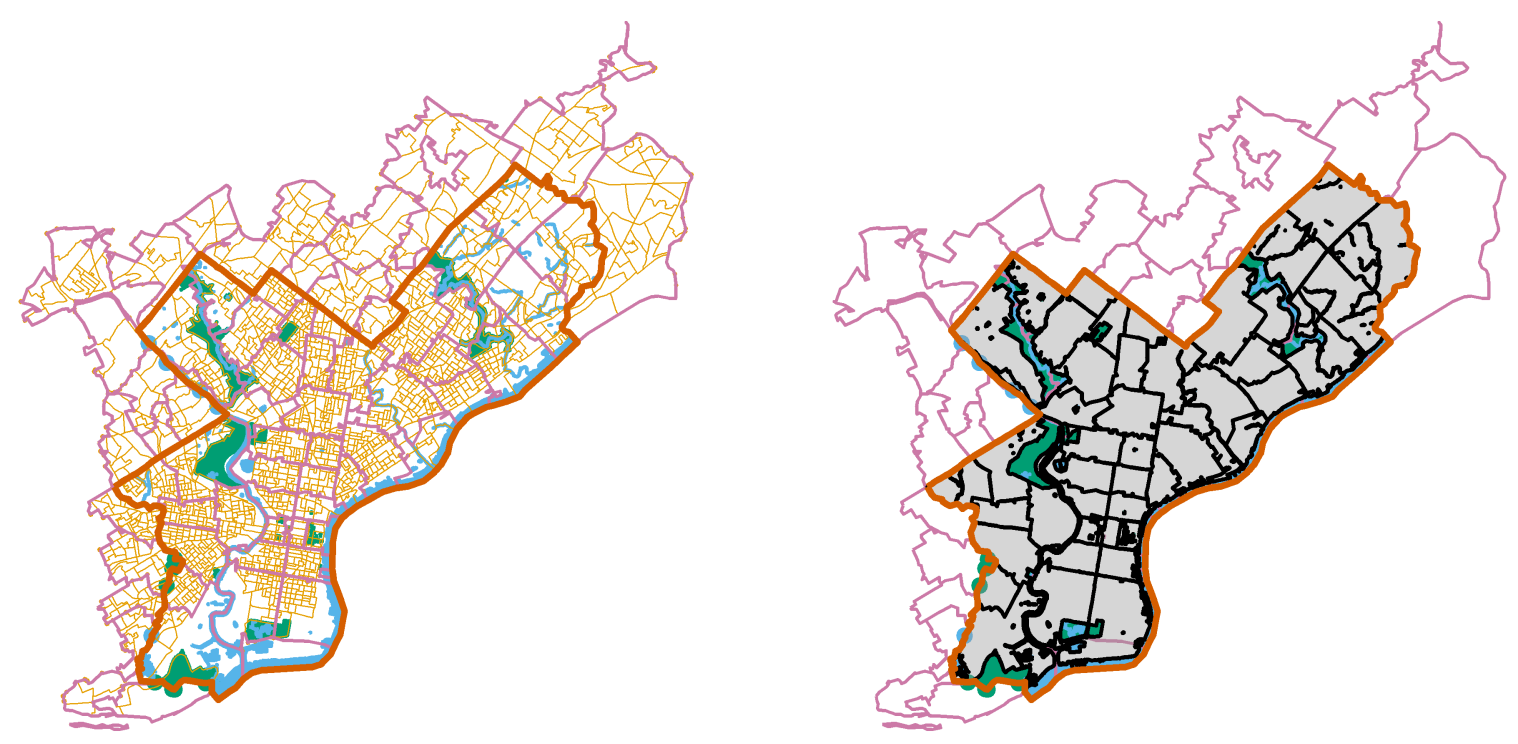

San Antonio
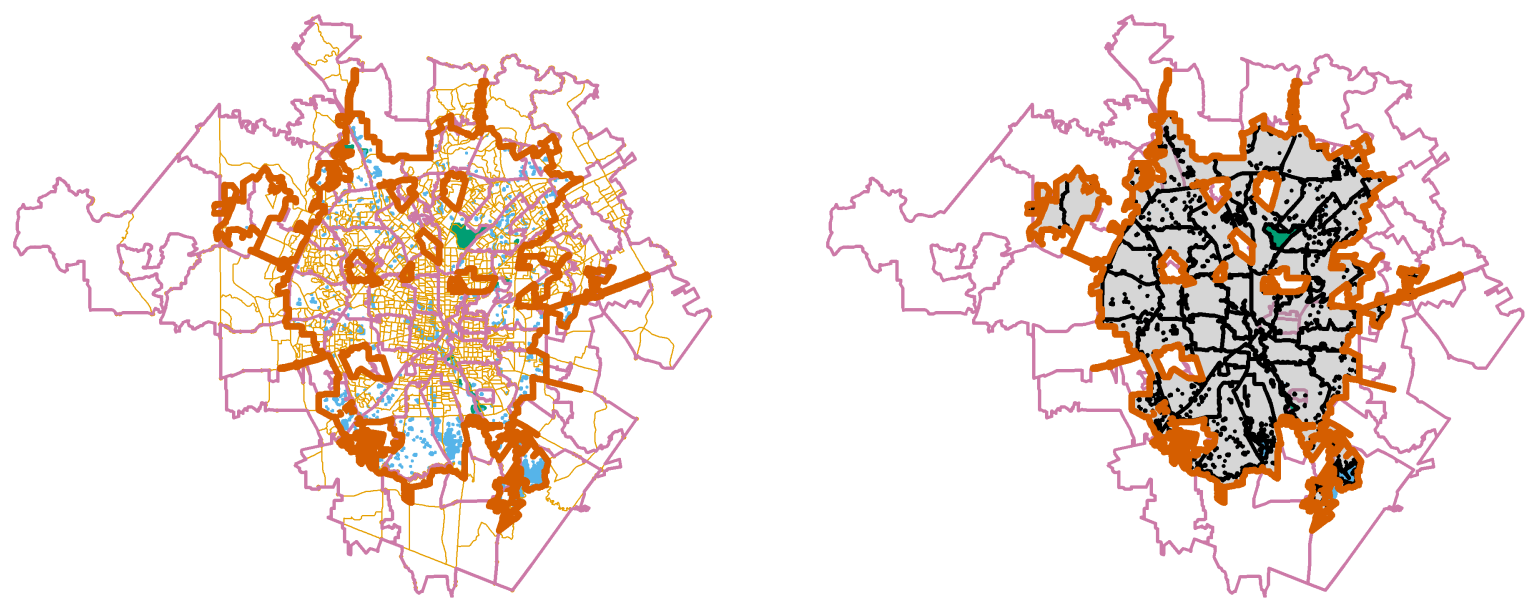

\begin{tabular}{l|l|l|l} 
Bodies of water & Limits of city proper \\
Other landmarks & Census Block Groups (CBGs) & Zip Code Tabulation Areas (ZCTAs) \\
Units of analysis
\end{tabular}

Scales differ. All ZCTAs that intersect cities shown. 
medRxiv preprint doi: https://doi.org/10.1101/2021.11.19.21266593; this version posted November 21, 2021. The copyright holder for this preprint (which was not certified by peer review) is the author/funder, who has granted medRxiv a license to display the preprint in perpetuity.

It is made available under a CC-BY-NC-ND 4.0 International license .

Figure e3.1: Summary of overlay interpolation by city

San Diego
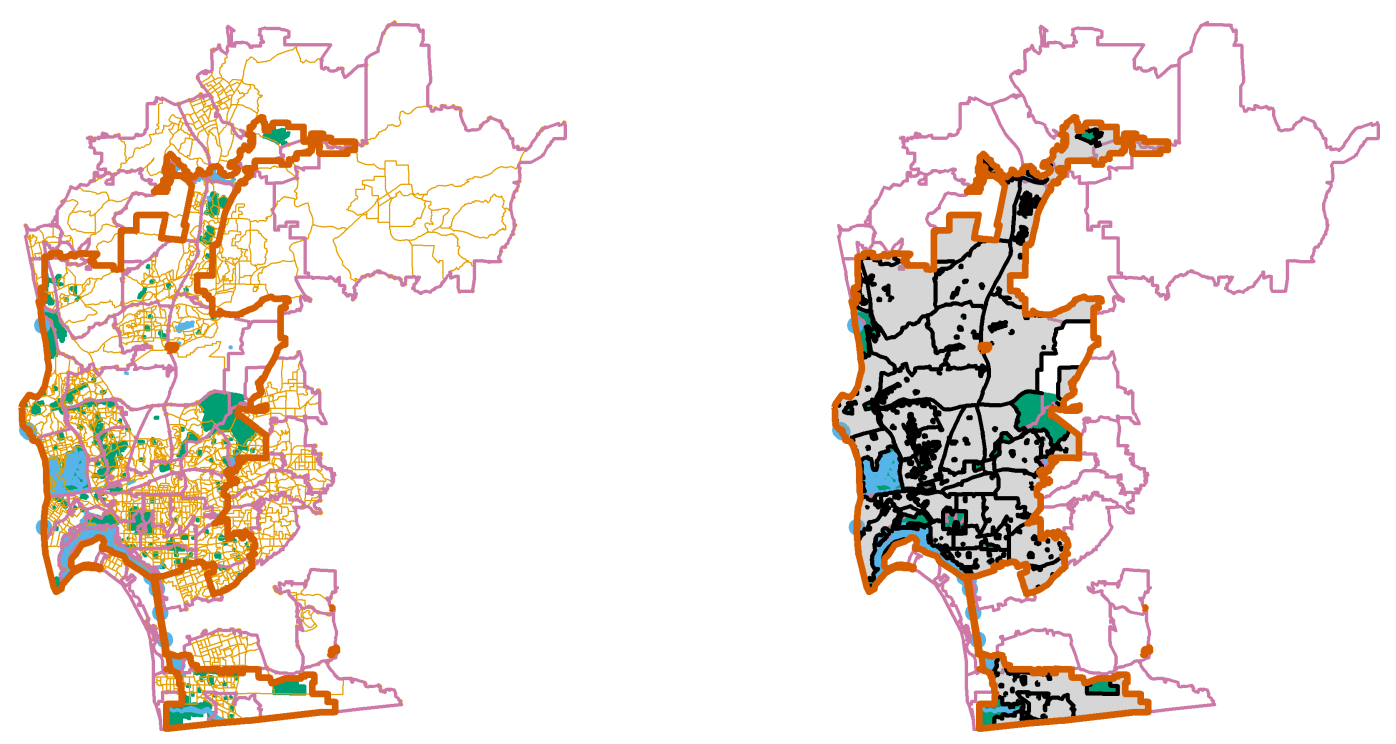

Dallas
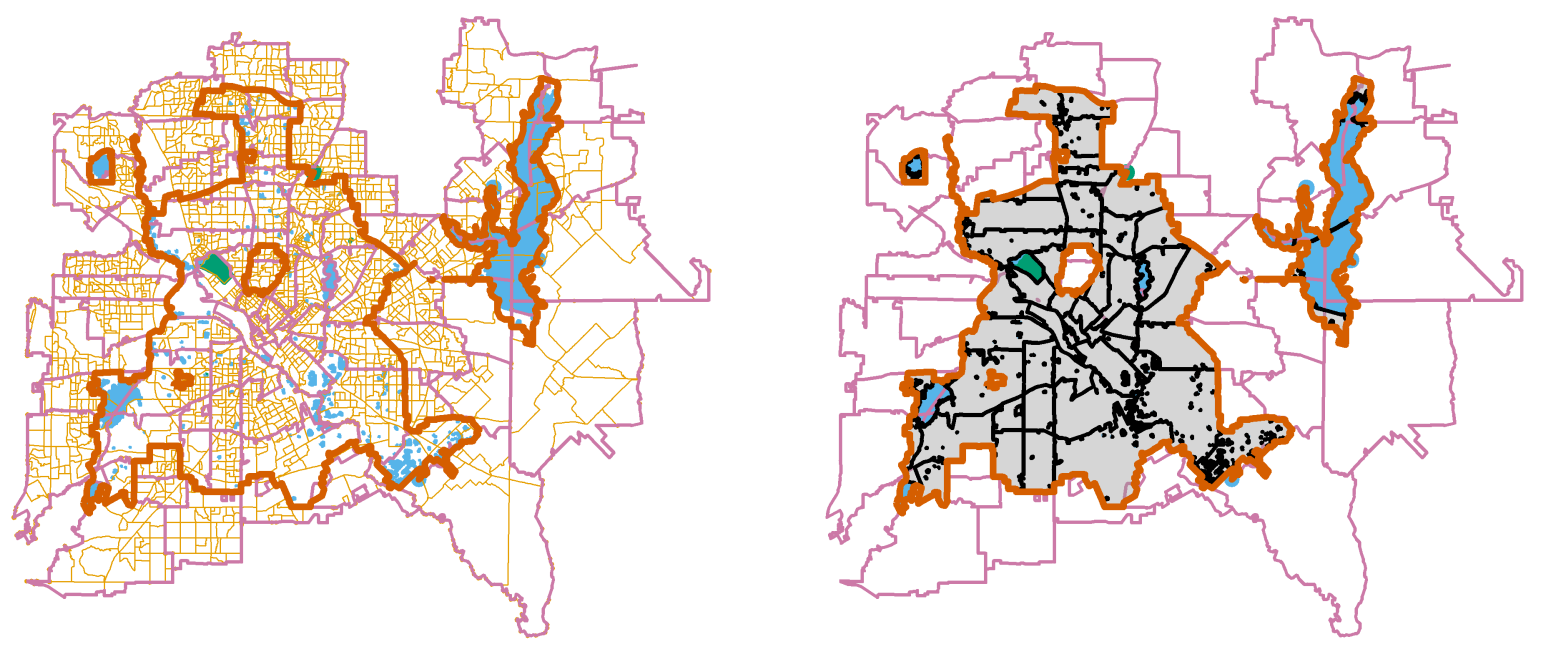

\begin{tabular}{l|l|l|l}
\hline Bodies of water & Limits of city proper & Zip Code Tabulation Areas (ZCTAs) \\
Other landmarks & Census Block Groups (CBGs) & Units of analysis
\end{tabular}

Scales differ. All ZCTAs that intersect cities shown. 
It is made available under a CC-BY-NC-ND 4.0 International license .

Table e3.4: Population distribution of interpolated units of analysis within and across eight large U.S. cities, 2015-2019

\begin{tabular}{|c|c|c|c|c|c|c|c|c|c|c|c|c|c|}
\hline \multirow[t]{2}{*}{ City } & \multirow[t]{2}{*}{ Units } & \multicolumn{4}{|c|}{ Population } & \multicolumn{4}{|c|}{ Area } & \multicolumn{4}{|c|}{ Population density } \\
\hline & & $M$ & $S D$ & $10 \%$ & $90 \%$ & $M$ & $S D$ & $10 \%$ & $90 \%$ & $M$ & $S D$ & $10 \%$ & $90 \%$ \\
\hline New York & 175 & 48,078 & 26,244 & 18,050 & 84,458 & 3.6 & 3.3 & 1.0 & 6.2 & 18,864 & 12,726 & 5,443 & 36,182 \\
\hline Chicago & 53 & 51,131 & 24,084 & 21,882 & 86,091 & 9.7 & 8.3 & 2.2 & 16.6 & 7,376 & 4,215 & 3,271 & 13,798 \\
\hline Houston & 99 & 24,998 & 15,270 & 6,933 & 43,964 & 16.0 & 9.1 & 5.4 & 28.4 & 1,708 & 928 & 745 & 2,830 \\
\hline Phoenix & 50 & 32,331 & 17,292 & 7,825 & 53,528 & 25.7 & 20.6 & 5.6 & 54.0 & 1,707 & 990 & 360 & 3,035 \\
\hline Philadelphia & 46 & 34,328 & 17,463 & 12,436 & 59,943 & 7.1 & 4.3 & 2.4 & 13.6 & 5,965 & 2,899 & 2,295 & 9,673 \\
\hline San Antonio & 48 & 31,560 & 17,439 & 6,984 & 56,254 & 25.9 & 15.4 & 7.1 & 48.1 & 1,392 & 704 & 482 & 2,360 \\
\hline San Diego & 33 & 42,400 & 18,163 & 22,666 & 67,742 & 22.1 & 16.4 & 8.8 & 46.8 & 2,603 & 1,487 & 947 & 4,690 \\
\hline Dallas & 48 & 27,830 & 20,596 & 4,760 & 56,793 & 18.2 & 15.5 & 4.1 & 38.7 & 1,857 & 1,035 & 734 & 3,592 \\
\hline Overall & 552 & 38,123 & 23,314 & 9,166 & 72,696 & 13.0 & 13.8 & 1.7 & 31.1 & 8,085 & 10,555 & 901 & 22,545 \\
\hline
\end{tabular}

$$
\begin{aligned}
\tilde{v}_{t} & =m_{t} v_{z}, \\
m_{t} & = \begin{cases}1 & z_{t} \equiv t \\
\tilde{q_{t}} / q_{z_{t}} & z_{t} \neq \equiv t\end{cases}
\end{aligned}
$$

where $v_{i}$ and $\tilde{v}_{i}$ were the observed and interpolated numbers of individuals with at least one vaccine dose in unit $i$, respectively; $q_{i}$ and $\tilde{q}_{i}$ were the observed and interpolated total populations of unit $i$, respectively; and $z_{t}$ denoted the area covered by the reporting unit corresponding to target zone $t$. This adjustment assumed that, within ZCTAs that straddled city borders, vaccinated individuals were distributed proportionally to the total population.

We made two final adjustments to the interpolated units of analysis. The interpolation yielded several target zones with very small estimated populations. To minimize the effects of outliers and reduce variation in the size of the units, we merged target zones with unusually low populations into adjacent zones such that no unit of analysis had fewer than 3,000 estimated residents. In addition, in a small number cases, implausible or extreme values surfaced in the interpolated vaccination outcome variables. These values suggested spatial mismatch occurred in the ZIP Code-level data, or that the interpolation was particularly illsuited to the spatial contours of a portion of the study area. To smooth out mismatches and discrepancies in these instances, we merged sets of contiguous zones that visual inspection suggested were susceptible to administrative mismatch or inaccurate interpolation. Due to these adjustments, there were 776 target zones but only 552 final units of analysis.

We summarize the population distribution of the 552 ZIP Code-based units of analysis in Table e3.4, and we illustrate them in the right-hand panels of Figure e3.1. The average unit of analysis had an interpolated total population of 38,123, roughly equivalent to the average population of the ZCTAs that were the bases of the target zones. Units' populations varied considerably. About one-quarter had more than 50,000 estimated inhabitants; another quarter had fewer than 20,000. Because the units excluded bodies of water, landmarks, and area outside city limits, however, the average physical size of the units of analysis was roughly half that of the average ZCTA. Furthermore, the area of the units of analysis exhibited significantly less variation than the raw ZCTAs. On the whole, the interpolated spatial units 
medRxiv preprint doi: https://doi.org/10.1101/2021.11.19.21266593; this version posted November 21, 2021. The copyright holder for this preprint (which was not certified by peer review) is the author/funder, who has granted medRxiv a license to display the preprint in perpetuity.

It is made available under a CC-BY-NC-ND 4.0 International license .

Table e3.5: Official vs. interpolated estimates of the populations of eight large U.S. cities, $2015-2019$

\begin{tabular}{lrrr}
\hline & Official & Interpolated & Difference \\
\hline New York & $8,419,316$ & $8,413,650$ & $-0.1 \%$ \\
Chicago & $2,709,534$ & $2,709,943$ & $+0.0 \%$ \\
Houston & $2,310,432$ & $2,474,802$ & $+7.1 \%$ \\
Phoenix & $1,633,017$ & $1,616,550$ & $-1.0 \%$ \\
Philadelphia & $1,579,075$ & $1,579,088$ & $+0.0 \%$ \\
San Antonio & $1,508,083$ & $1,514,880$ & $+0.5 \%$ \\
San Diego & $1,409,573$ & $1,399,200$ & $-0.7 \%$ \\
Dallas & $1,330,612$ & $1,335,840$ & $+0.4 \%$ \\
\hline Overall & $\mathbf{2 0 , 8 9 9 , 6 4 2}$ & $\mathbf{2 1 , 0 4 3 , 9 5 3}$ & $+\mathbf{0 . 7 \%}$ \\
\hline
\end{tabular}

Official estimates from ACS (2015-2019)

table B01001, column 1.

provided more viable bases for analysis and comparison than were available in the raw data. Yet they generally remained susceptible to the analytical pitfalls of ZIP Codes and ZCTAs that we discuss in Section e3.1. We present descriptive statistics for observations on the analysis variables for the interpolated units of analysis in Table e3.6.

\section{e3.3 Measurement error and information bias}

In regression analysis, information bias arises when variables are measured inaccurately. ${ }^{58}$ If outcome variables are measured with error, regression coefficients are unbiased but confidence intervals too wide. ${ }^{59,60}$ Researchers might consequently accept null hypotheses they should reject. If independent variables are measured with error, the direction of information bias is case-specific, determined by the covariance of the variables in question. ${ }^{59,61}$ Typically, regression coefficients are biased towards zero when independent variables are measured with error. ${ }^{60,62}$ As a result, researchers are vulnerable to understating the magnitude of associations. Measurement error often makes regression inference more conservative.

The nature of available data for this study made some information bias likely. The demographic data were estimates with margins of error. ${ }^{8}$ The administrative records were vulnerable to spatial mismatch between individuals' ZIP Codes and assigned ZCTAs. Even careful variable construction from these data also probably introduced some measurement error because available quantities were not always aligned with the theoretical quantity of interest. Similarly, as an estimation process based on aggregated observations, overlay interpolation contributed some measurement error.

It is unlikely that these sources of information bias seriously jeopardized our findings. The direction and magnitude of bias from measurement error are difficult to predict, but information bias probably only made our analysis more cautious. The quality of the data was high overall. We used established methods to calculate variables that tracked closely with theoretical variables of interest. Moreover, because information bias typically makes regression findings more conservative, false negatives (Type II errors) were more likely than false positives (Type I errors). The most plausible effect of information bias in this study 
medRxiv preprint doi: https://doi.org/10.1101/2021.11.19.21266593; this version posted November 21, 2021. The copyright holder for this preprint (which was not certified by peer review) is the author/funder, who has granted medRxiv a license to display the preprint in perpetuity.

It is made available under a CC-BY-NC-ND 4.0 International license .

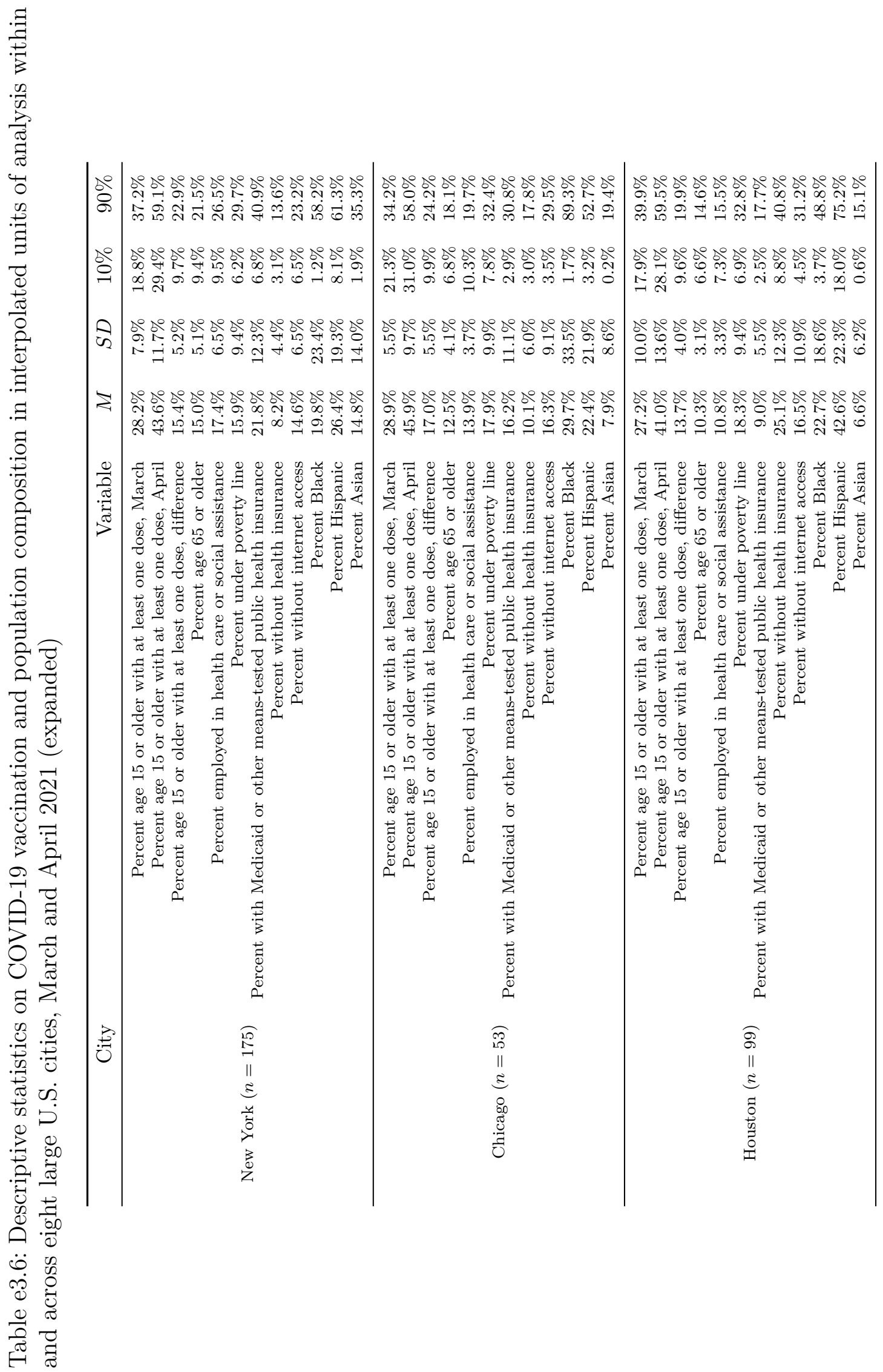


medRxiv preprint doi: https://doi.org/10.1101/2021.11.19.21266593; this version posted November 21, 2021. The copyright holder for this preprint (which was not certified by peer review) is the author/funder, who has granted medRxiv a license to display the preprint in perpetuity.

It is made available under a CC-BY-NC-ND 4.0 International license .

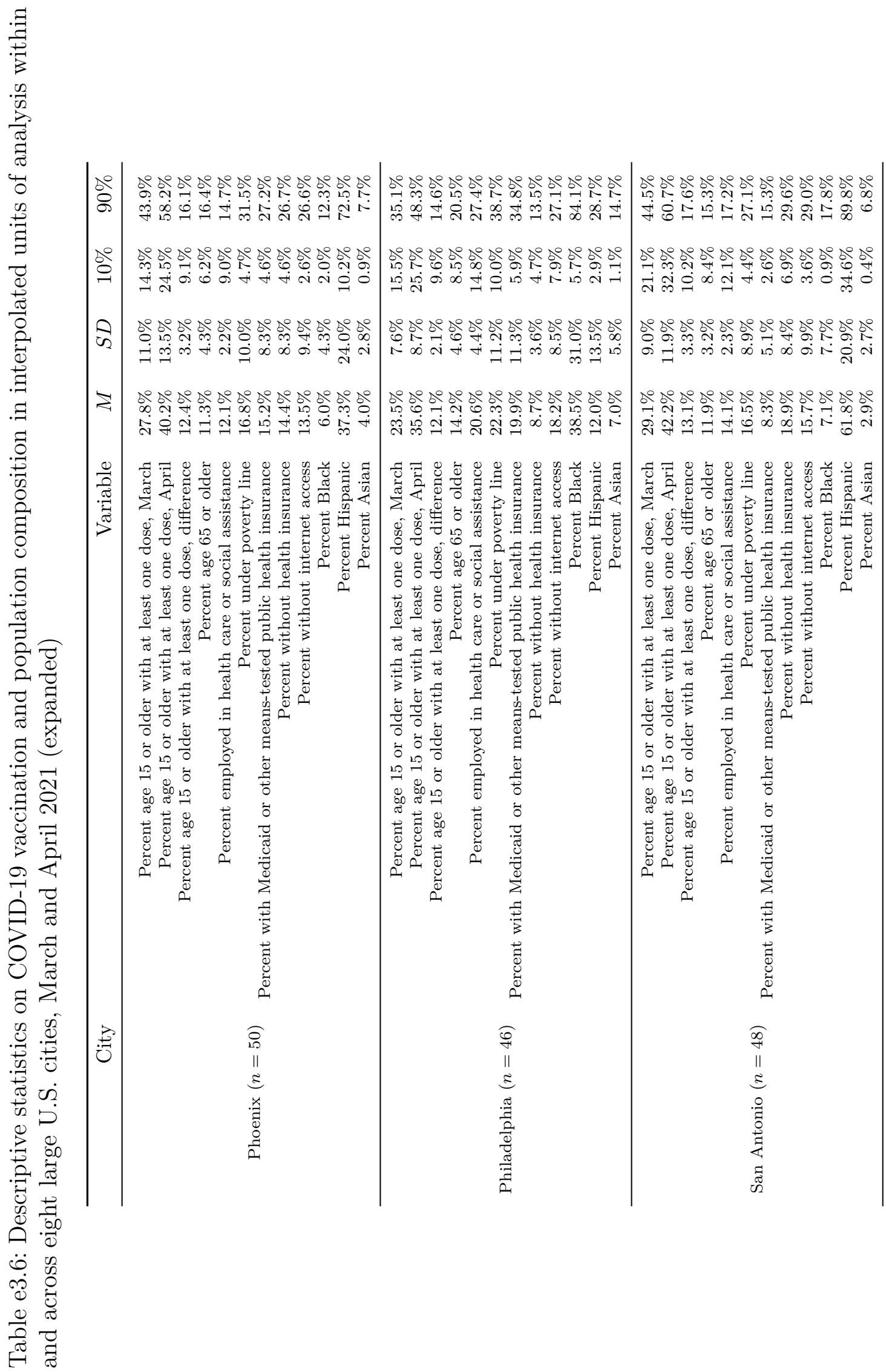


medRxiv preprint doi: https://doi.org/10.1101/2021.11.19.21266593; this version posted November 21, 2021. The copyright holder for this preprint (which was not certified by peer review) is the author/funder, who has granted medRxiv a license to display the preprint in perpetuity.

It is made available under a CC-BY-NC-ND 4.0 International license .

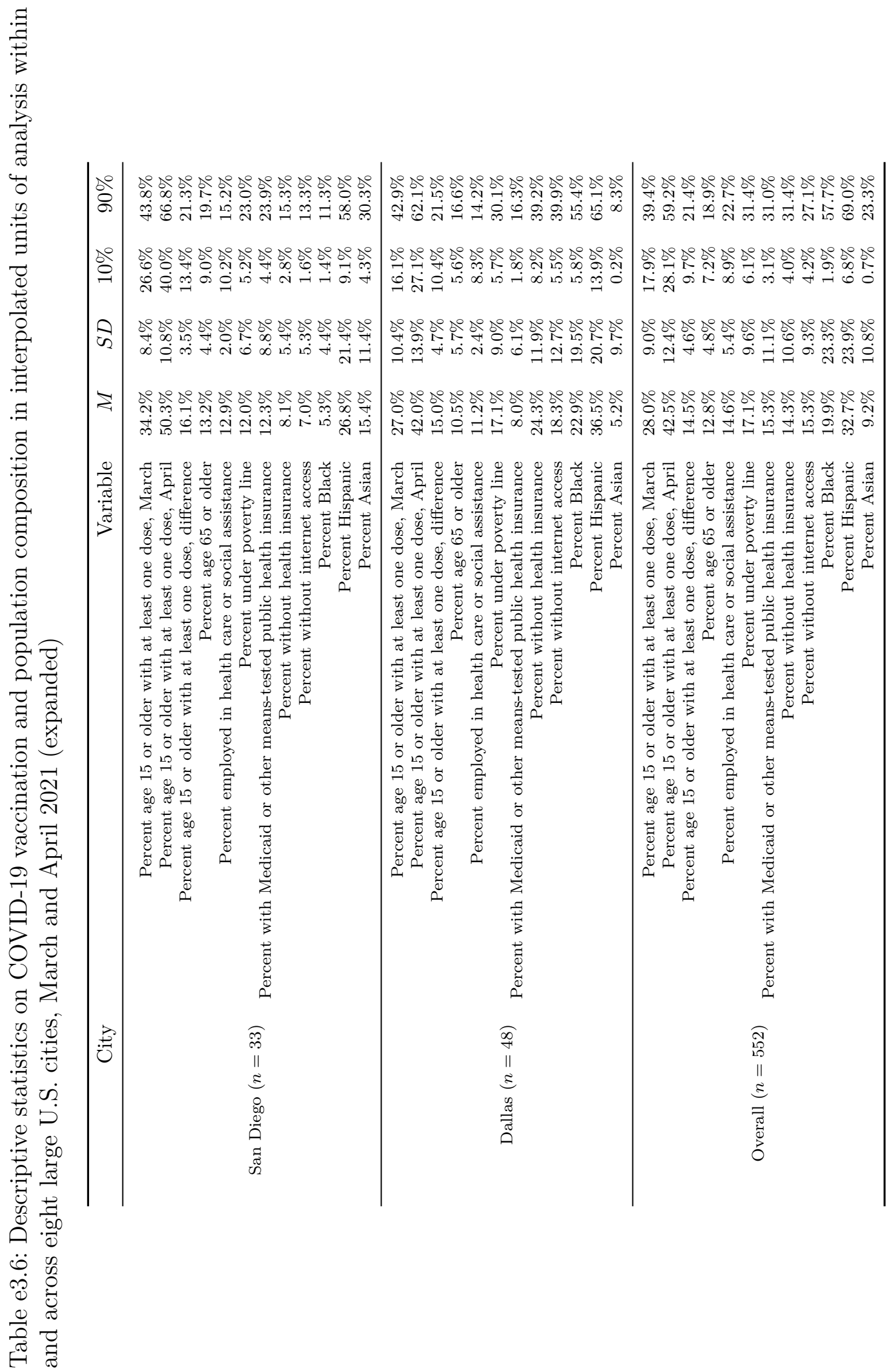


was to compound the effects of spatial scale that we discuss in Section e3.1: underestimating associations and disparities.

Table e3.5 provides a partial assessment of the level of measurement error stemming from spatial interpolation. The table compares the official ACS population estimates with the sums of the interpolated populations of the target zones. For all cities except Houston and for the eight cities combined, the interpolated population was within one percent of the official estimate. The much greater difference between the estimates for Houston is probably attributable to its irregular physical boundaries, as illustrated in Figure e3.1. This layout would be challenging for any method of spatial interpolation. On average, however, Table e3.5 suggests our overlay interpolation procedure distributed populations with considerable accuracy. This comparison is insufficient to rule out information bias from the interpolation, but it suggests the biasing effects of resulting measurement error were minor overall.

\section{e4 Analytical approach}

\section{e4.1 Model specification and estimation}

We estimated standard linear models (SLMs) by weighted least squares (LS) and spatial error models (SEMs) with nearest-neighbor spatial weights by maximum likelihood. ${ }^{63-67}$ Formally, for observations of $n=552$ units on $\rho$ independent variables and $k=8$ nearest neighbors, the SLM was

$$
Q y=Q \alpha+Q X \beta+Q \varepsilon
$$

and the SEM was

$$
\begin{aligned}
Q y & =Q \alpha+Q X \beta+Q u \\
& =Q \alpha+Q X \beta+Q(\lambda W u+\varepsilon) \\
& =Q \alpha+Q X \beta+Q\left(I_{n}-\lambda W\right)^{-1} \varepsilon
\end{aligned}
$$

with

$$
\begin{gathered}
Q=\left(\begin{array}{cccc}
q_{1}^{15+} & 0 & \cdots & 0 \\
0 & q_{2}^{15+} & \cdots & 0 \\
\vdots & \vdots & \ddots & \vdots \\
0 & 0 & \cdots & q_{n}^{15+}
\end{array}\right)^{1 / 2} ; \\
W=\left(\begin{array}{cccc}
\sum_{j=1}^{n} g_{1 j} & 0 & \cdots & 0 \\
0 & \sum_{j=1}^{n} g_{2 j} & \cdots & 0 \\
\vdots & \vdots & \ddots & \vdots \\
0 & 0 & \cdots & \sum_{j=1}^{n} g_{n j}
\end{array}\right)^{-1} \quad G=\frac{G}{k} ;
\end{gathered}
$$




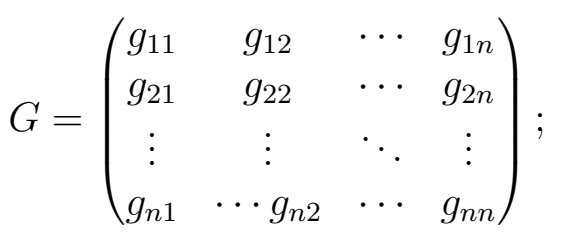

$$
\begin{aligned}
& g_{i j}=\left\{\begin{array}{ll}
1 & j \in h_{i} \\
0 & j \notin h_{i}
\end{array} ;\right.
\end{aligned}
$$

where $y$ was an $n \times 1$ vector of observations on the outcome variable; $X$ was an $n \times \rho$ matrix of observations on the independent variables; $I_{n}$ was an identity matrix of size $n$; $q_{i}^{15+}$ was the estimated population age 15 and older of unit $i ; h_{i}$ indexed the $k$ units closest to unit $i ; \alpha$ was the intercept (constant) parameter to be estimated; $\beta$ was a $1 \times \rho$ vector of coefficients to be estimated; $\varepsilon$ was an $n \times 1$ vector of disturbances; $\lambda$ was a scalar parameter to be estimated measuring average spatial autocorrelation in $\varepsilon$, conditional on $W$; and population weights matrix $Q$, spatial weights matrix $W$, and spatial links matrix $G$ were square, of order $n$.

We report expanded step-wise results of both sets of models in Tables e4.1 and e4.2, and we compare the estimates between the SEMs and SLMs that included all independent variables in Figure e4.1. For the March and April outcomes, the coefficient estimates differed significantly or very nearly significantly between the models for three of the SES indicators. The magnitudes of the coefficients for the insurance-related variables decreased from the SLM to the SEM but remained negative, while the coefficient for the poverty variable changed from slightly positive to slightly negative.

\section{e4.2 Spatial heterogeneity and modeling strategy}

\section{Testing for and modeling spatial effects}

Estimating SLMs by LS, the most common tool for analyzing high-dimensional relationships among variables, is unbiased and efficient in many settings. ${ }^{64}$ In the presence of spatial effects, however, LS estimates are inaccurate and/or require larger samples to model relationships. ${ }^{65,66,68,69}$ There are two basic classes of spatial effects: spatial heterogeneity and spatial dependence.

Spatial heterogeneity "is related to the lack of stability over space of the ... relationships under study. More precisely, this implies that functional forms and parameters vary with location and are not homogeneous throughout the data set." ${ }^{65} \mathrm{p} 9$ It was plausible that the relationships among vaccination, priority population composition, socioeconomic composition, and racial/ethnic composition varied from unit to unit but were spatially clustered, even within cities. In principle, the likely sources of spatial heterogeneity could be modeled as independent variables; in practice, they were unobserved. Potential unmeasurable sources of spatial heterogeneity included past levels of exposure to COVID-19, hyperlocal idiosyncrasies in the effects or implementation of vaccination policies, and cultural influences.

Spatial dependence, which includes spillover effects or externalities, is "the existence of a functional relationship between what happens at one point in space and what happens elsewhere." ${ }^{25 p 11}$ Spatial dependence seemed less likely to contaminate this analysis, but it 
medRxiv preprint doi: https://doi.org/10.1101/2021.11.19.21266593; this version posted November 21, 2021. The copyright holder for this preprint (which was not certified by peer review) is the author/funder, who has granted medRxiv a license to display the preprint in perpetuity.

It is made available under a CC-BY-NC-ND 4.0 International license .

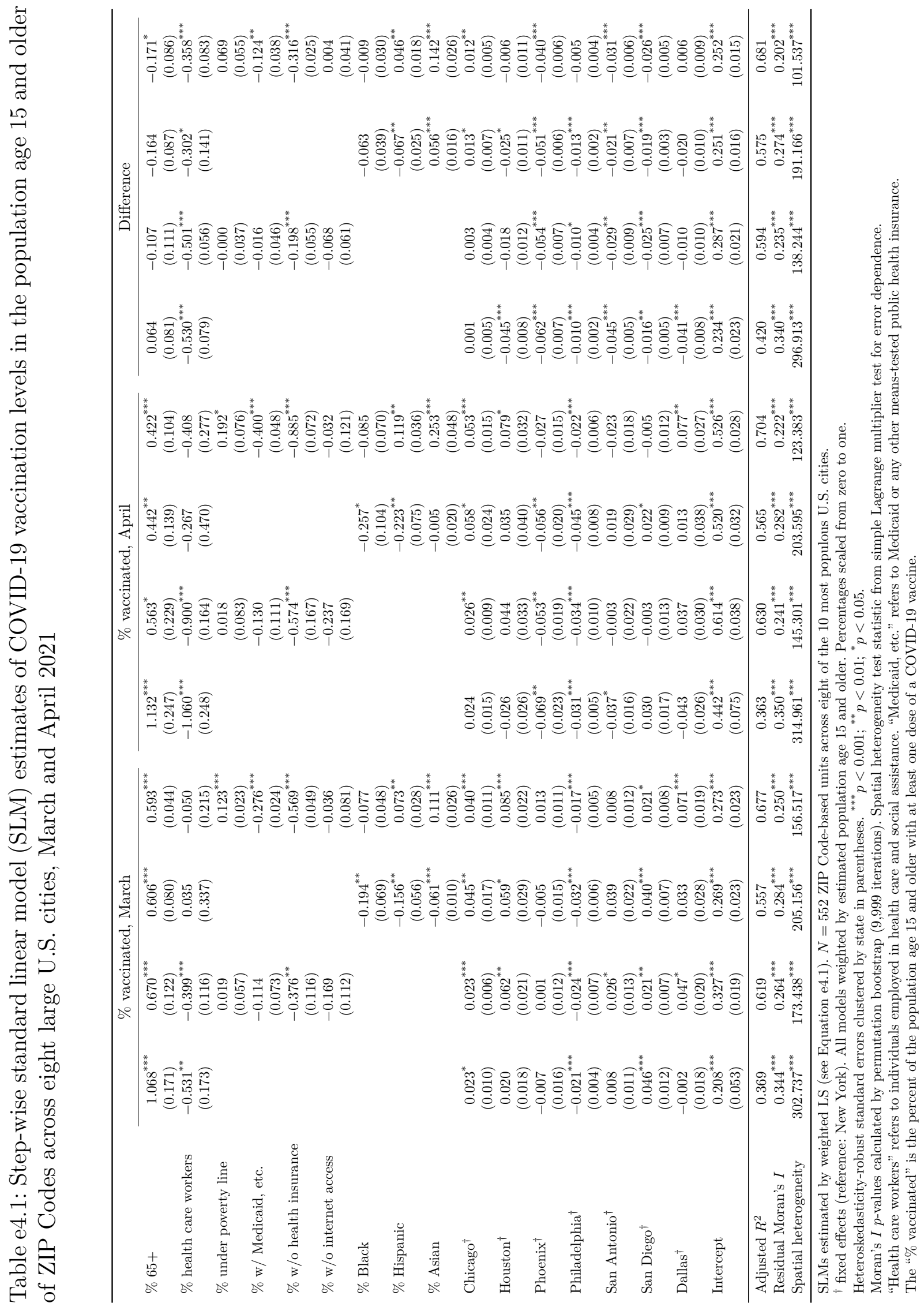


medRxiv preprint doi: https://doi.org/10.1101/2021.11.19.21266593; this version posted November 21, 2021. The copyright holder for this preprint (which was not certified by peer review) is the author/funder, who has granted medRxiv a license to display the preprint in perpetuity.

It is made available under a CC-BY-NC-ND 4.0 International license .

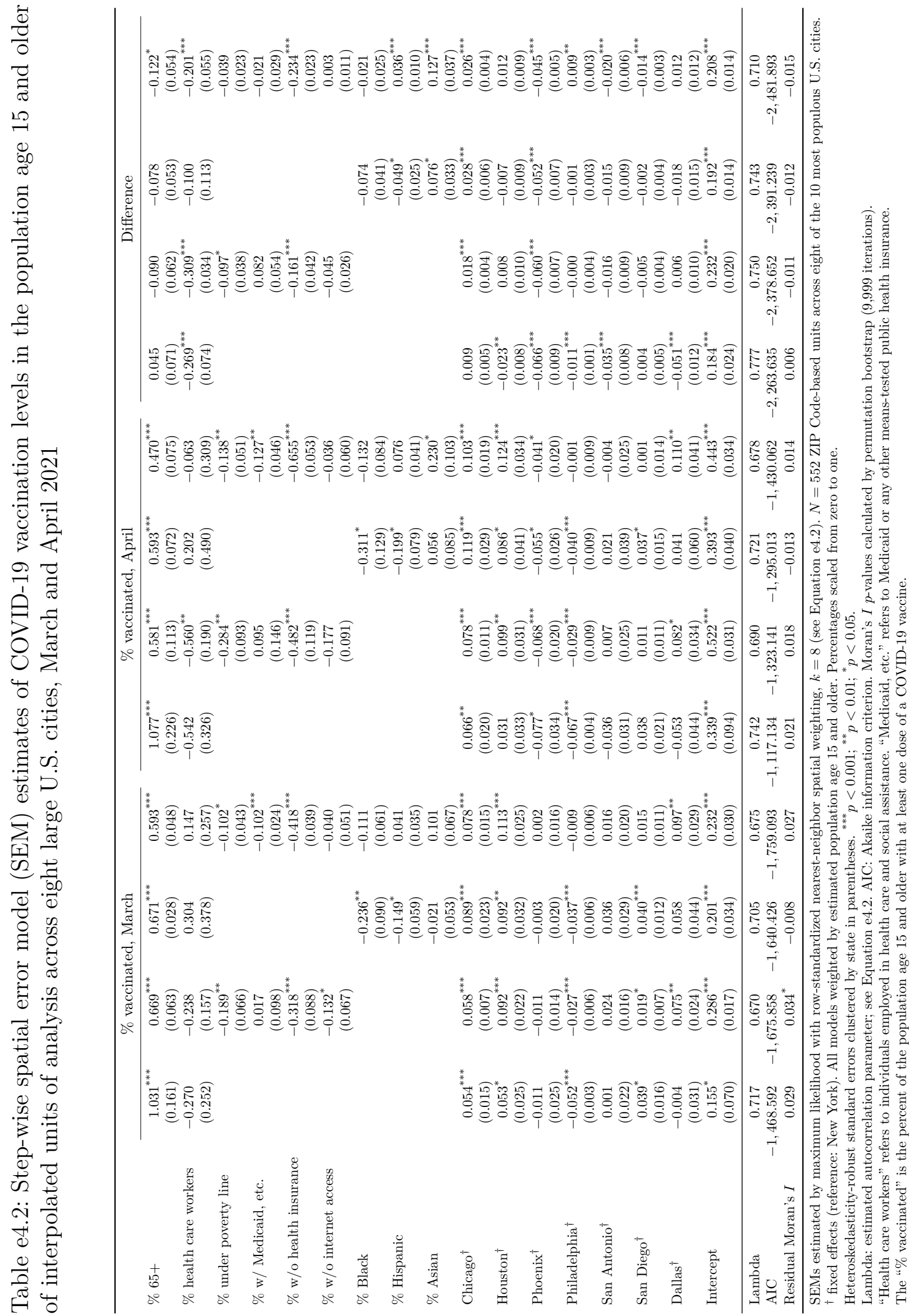


medRxiv preprint doi: https://doi.org/10.1101/2021.11.19.21266593; this version posted November 21, 2021. The copyright holder for this preprint (which was not certified by peer review) is the author/funder, who has granted medRxiv a license to display the preprint in perpetuity.

It is made available under a CC-BY-NC-ND 4.0 International license .
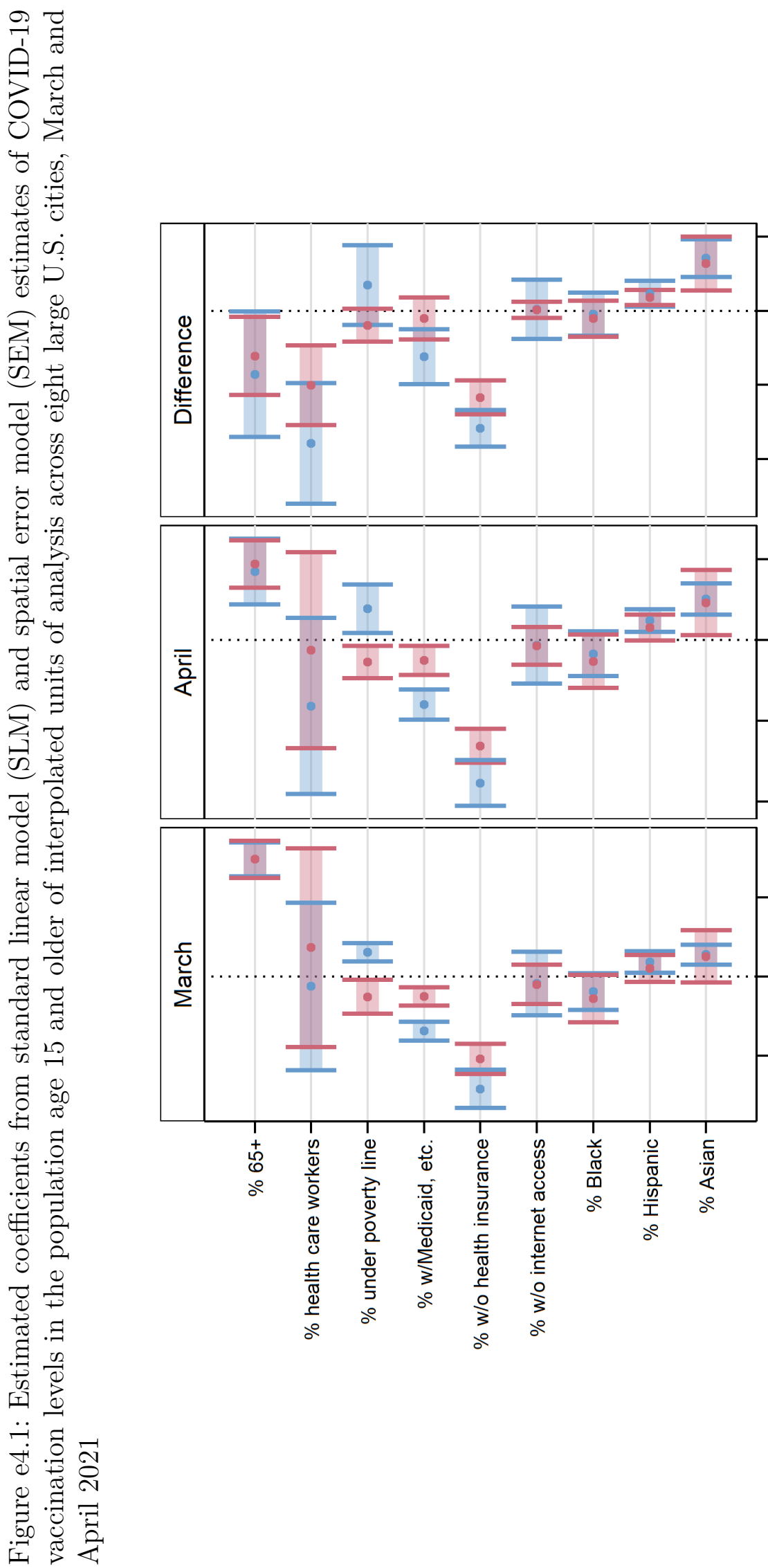

ㅇํㅇ
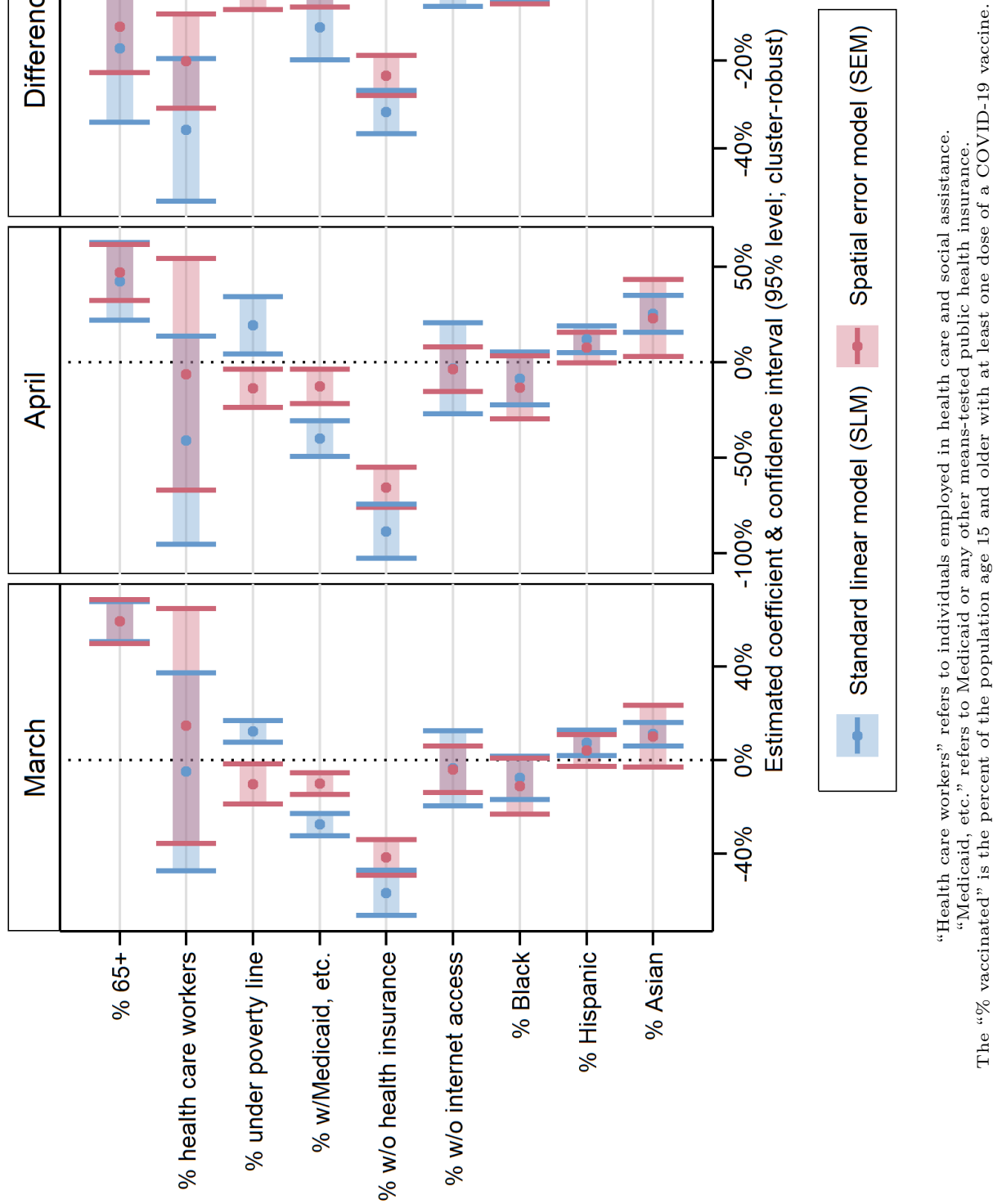
was not implausible. For example, zero-sum dynamics could have emerged between neighboring units when vaccine doses were scarce. Similarly, peer-effects might have caused uneven diffusion of vaccination across space.

Testing for and modeling spatial effects requires the researcher to specify the structure of spatial relationships. This structure is conventionally represented in matrix form as in Equation e4.4. ${ }^{70-72}$ We evaluated various common spatial weight matrix specifications, including adjacency ("queen" and "rook" contiguity), inverse distance, power distance, exponential distance, and nearest-neighbor weighting. We defined distance between units as the number of kilometers between their geometric centers, or centroids. ${ }^{57,73}$

We ultimately used a row-standardized $k$ nearest-neighbors scheme, with $k=8$. With this specification of $W$, we assumed relationships were best measured relative to the eight other units closest to each unit. Each unit's eight nearest-neighbors contributed equally to the spatial influence on it, and each unit's spatial weights summed to one; each nearest-neighbor contributed one-eighth of the spatial influence on unit $i$.

In our multi-city analysis, nearest-neighbor weighting produced more consistent weights than contiguity- or distance-based weighting. The units of analysis were irregularly sized and sometimes physically discontinuous within cities, and density and sprawl varied considerably across cities (see Figure e3.1 and Table e3.4). Nearest-neighbor weighting ensured each unit was weighted relative to the same number of other units. It also avoided fluctuations from the varying spatial distributions of cities' populations and the arbitrary boundaries of ZCTAs. Compared to contiguity-based weights, the nearest-neighbor approach was particularly advantageous for units on the edges of cities' boundaries and units with few or zero adjacent neighbors (such as islands). Compared to distance-based weights, it avoided skew that could result from atypically large units that received artificially low weights due to their exaggerated inter-centroid distances with other units. Overall, nearest-neighbor weights with $k=8$ struck an effective balance between the more rigid assumptions of contiguity-based weights and the perhaps overly-encompassing assumptions of distance-based weights.

We first tested for spatial effects by evaluating clustering in the SLM residuals using Moran's $I .{ }^{74}$ A spatial complement to the conventional correlation coefficient, I measures spatial autocorrelation on a scale from negative one to one. To determine whether $I$ was statistically distinguishable from zero, we ran permutation tests with 9, 999 iterations. ${ }^{73}$ We report Moran's I for the SLMs that included all independent variables in the first row of Table e4.3. For each model, $I$ was positive and highly significant, indicating units closer to one another had more similar residuals than units farther from one another (positive spatial autocorrelation). The Moran's I test on the SLM residuals provided strong preliminary evidence of spatial effects, suggesting LS estimation was suboptimal in our setting.

Whereas $I$ is a generic test statistic for spatial autocorrelation, Lagrange multiplier tests for SLM residuals help distinguish between types of spatial effects - i.e., to determine whether models exhibit spatial heterogeneity, dependence, or both. ${ }^{75}$ We summarize the results of the Lagrange multiplier tests for the SLM residuals in the bottom four rows of Table e4.3. ${ }^{73}$ The tests rejected the null hypothesis that the SLMs were free of spatial heterogeneity at $p<0.001$. They retained the null hypothesis that the models were free of spatial dependence. These results held when testing for heterogeneity and dependence alone (simple tests) and when accounting for the simultaneous possibility of the other (robust tests). Lagrange multiplier tests strongly suggested the spatial relationships among our independent and dependent 
It is made available under a CC-BY-NC-ND 4.0 International license .

Table e4.3: Tests for spatial effects in residuals of standard linear model (SLM) estimates of COVID-19 vaccination levels in the population age 15 and older of ZIP Codes across eight large U.S. cities, March and April 2021

\begin{tabular}{lccc}
\hline Test & March & April & Difference \\
\hline Moran's I & $0.250^{* * *}$ & $0.222^{* * *}$ & $0.202^{* * *}$ \\
Spatial heterogeneity (simple) & $156.517^{* * *}$ & $123.383^{* * *}$ & $101.537^{* * *}$ \\
Spatial dependence (simple) & 2.879 & 1.990 & 2.001 \\
Spatial heterogeneity (robust) & $153.982^{* * *}$ & $121.680^{* * *}$ & $99.808^{* * *}$ \\
Spatial dependence (robust) & 0.345 & 0.286 & 0.278 \\
\hline
\end{tabular}

${ }^{* * *} p<0.001 ;{ }^{* *} p<0.01 ;{ }^{*} p<0.05$.

Moran's I $p$-values from permutation bootstrap (9,999 iterations).

Simple Lagrange multiplier tests evaluate one spatial effect.

Robust Lagrange multiplier tests allow for simultaneous effects.

variables were heterogeneous across space, but no evidence emerged for dependence among nearby units.

When spatial heterogeneity is present and spatial dependence absent, the SEM is a standard modeling approach. ${ }^{65,66,72}$ SEMs account for unobserved, spatially clustered independent variables - spatial autoccorelation in the disturbances - that lead to spatial clustering in the associations among observed variables. LS estimation cannot capture these spatial dynamics. SEMs yield reliable estimates in the absence of spillover effects and reduce bias from confounding variables. ${ }^{69}$ Another advantage of SEMs is interpretability. Unlike other spatial models, the independent variables are identical between SLMs and corresponding SEMs. The difference between SLMs and SEMs instead lies in the specification of the disturbances: SEMs introduce a spatially correlated vector of random effects, $u$ in Equation e4.2. Interpreting SEM parameter estimates is thus comparable to interpreting SLM coefficients. ${ }^{76}$ By estimating SEMs, we assumed that $u$ was independent of $X$-i.e., that unmeasured spatially clustered variables were uncorrelated with the observed independent variables.

\section{City fixed effects, population weights, and cluster-robust standard errors}

There were three other key components to our modeling strategy. First, we included city fixed effects. Because state and local authorities oversaw vaccine distribution and local political contexts varied dramatically, potential sources of city-level heterogeneity abounded. The fixed effects adjusted for unobserved characteristics that units shared within cities. ${ }^{77}$ They accounted for the possibility that average outcomes varied by city and purged associated confounding.

Second, we weighted the units of analysis by population using matrix $Q$. Population weighting addressed heteroskedasticity stemming from associations between the variance in vaccination outcomes and the number of residents of each unit. ${ }^{78}$ The substantive assumption of unweighted models would have been that each unit represented an equal share of the process of vaccine distribution and uptake. Estimating sample-wide average associations among the independent and dependent variables required weighting by the population of each unit that could receive the vaccine. ${ }^{79-81}$ Due to the weighting, more populous units 
and cities influenced estimation more than less populous counterparts, consistent with their greater share of the sampled population. Table e3.5 contextualizes the relative influence of each city.

Third, we assessed statistical significance using heteroskedasticity-robust standard errors clustered by state (cluster-robust standard errors). While fixed effects netted out city-level unobserved heterogeneity, disturbances for units in the same state were vulnerable to clustering. (Of the eight cities, three were in Texas). We addressed this issue by computing standard errors using the product of the conventional "sandwich" estimator" and

$$
\frac{\mu(n-1)}{(\mu-1)(n-\rho)},
$$

where $\mu=6$ was the number of clusters. ${ }^{83,84}$ (This adjustment to the "sandwich" estimator is the default in many Stata commands). Calculated in this way, the standard errors were robust to within-state residual correlation.

\section{e4.3 Simulations}

\section{Motivation}

To illustrate relationships among the independent and dependent variables, we used a simulation approach. It was similar to conventional marginal effects analyses, which contextualize associations by visualizing the outcome that a model would predict given relevant values of the independent variables. ${ }^{85,86}$ Because SEMs account for unobserved, spatially clustered variables, it is effectively impossible for researchers to identify appropriate points in the distribution at which to analyze trends and to predict the corresponding outcomes. ${ }^{87,88}$ One approach would be to ignore the spatial structure of the disturbances and compute unitlevel predictions for hypothetical observations, effectively treating the SEM as a SLM. This approach, however, distorts the modeled relationships.

Our simulations accounted for the spatial structure of the data. Instead of an estimate for individual hypothetical units as in marginal effects analyses, we derived sample-wide average estimated outcomes under instructive hypothetical conditions. We assumed every observation in the sample took on representative values at points of interest in the within-city distributions of the independent variables. We could thereby answer a simple counterfactual question: if every unit sat at the same place in its city's population distribution and were subject to the trends suggested by the SEM estimation, how would average vaccination outcomes compare to the observed averages? Figure e4.2 illustrates expanded results of the simulations.

As we indicate in Section e2.2, this simulation approach contextualized disparities more comprehensively than interpreting coefficients alone. Table e4.2 and Figure e4.1 show that the outcomes' estimated associations with percents Black and Hispanic were statistically insignificant in March and April; average vaccination outcomes did not change systematically with Black and Hispanic populations, conditional on vaccine priority populations, socioeconomic composition, and the spatial relationships specified in $W$. In isolation, these results suggest that economimc - not racial/ethnic - inequality explained variation in vaccination outcomes. By accounting for unequal distributions of SES and vaccine priority pop- 
medRxiv preprint doi: https://doi.org/10.1101/2021.11.19.21266593; this version posted November 21, 2021. The copyright holder for this preprint (which was not certified by peer review) is the author/funder, who has granted medRxiv a license to display the preprint in perpetuity.

It is made available under a CC-BY-NC-ND 4.0 International license .

Figure e4.2: Simulated COVID-19 vaccination levels by racial/ethnic and socioeconomic composition in the population age 15 and older of ZIP Codes across eight large U.S. cities, March and April 2021 (expanded)

\section{March and April 2021}

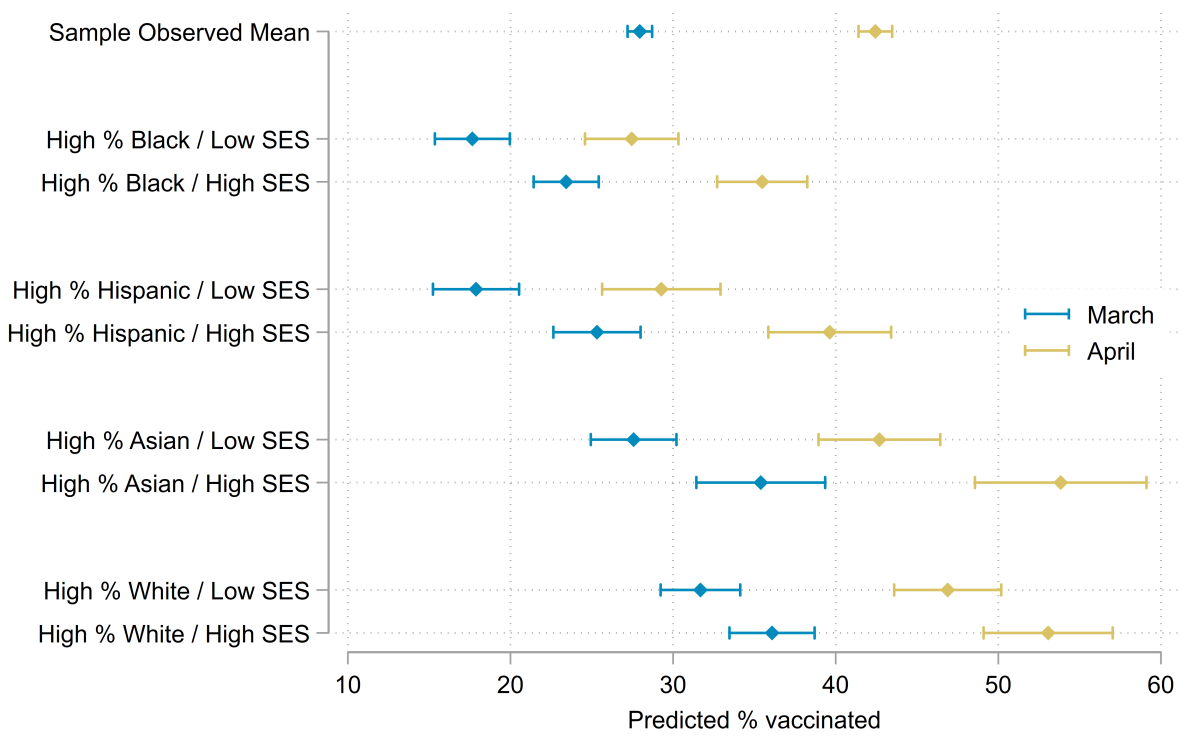

Difference between March and April 2021

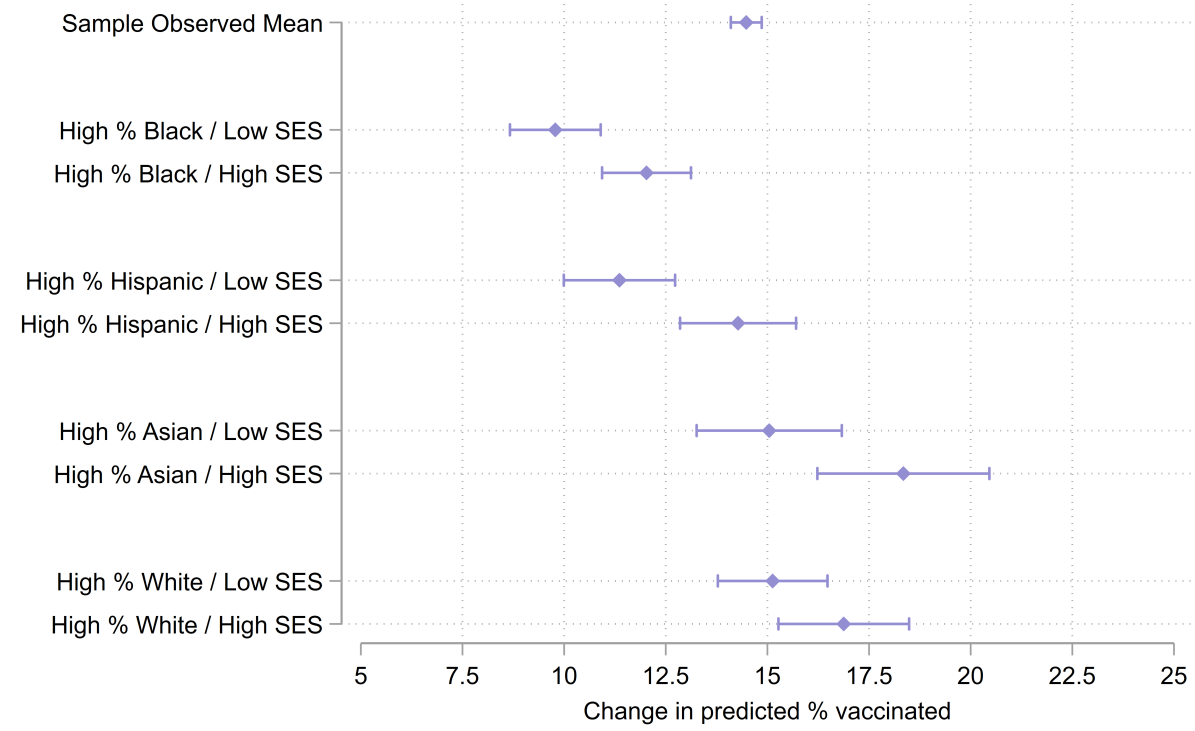

Dots represent simulated sample-wide means assuming each ZIP Code had a given socioeconomic and racial/ethnic composition. Bars represent bootstrapped confidence intervals ( $95 \%$ level). We defined low and high levels as below the 10th and above the 90 th within-city percentiles, respectively. We defined SES levels by setting all four SES variables to the same within-city percentiles within each scenario. We set other independent variables to within-city averages in each scenario. We include the true (observed) sample-wide average values of the dependent variable on the top row for comparison. The "\% vaccinated" is the percent of the population age 15 and older with at least one dose of a COVID-19 vaccine. 
medRxiv preprint doi: https://doi.org/10.1101/2021.11.19.21266593; this version posted November 21, 2021. The copyright holder for this preprint (which was not certified by peer review) is the author/funder, who has granted medRxiv a license to display the preprint in perpetuity.

It is made available under a CC-BY-NC-ND 4.0 International license .




medRxiv preprint doi: https://doi.org/10.1101/2021.11.19.21266593; this version posted November 21, 2021. The copyright holder for this preprint (which was not certified by peer review) is the author/funder, who has granted medRxiv a license to display the preprint in perpetuity.

It is made available under a CC-BY-NC-ND 4.0 International license .

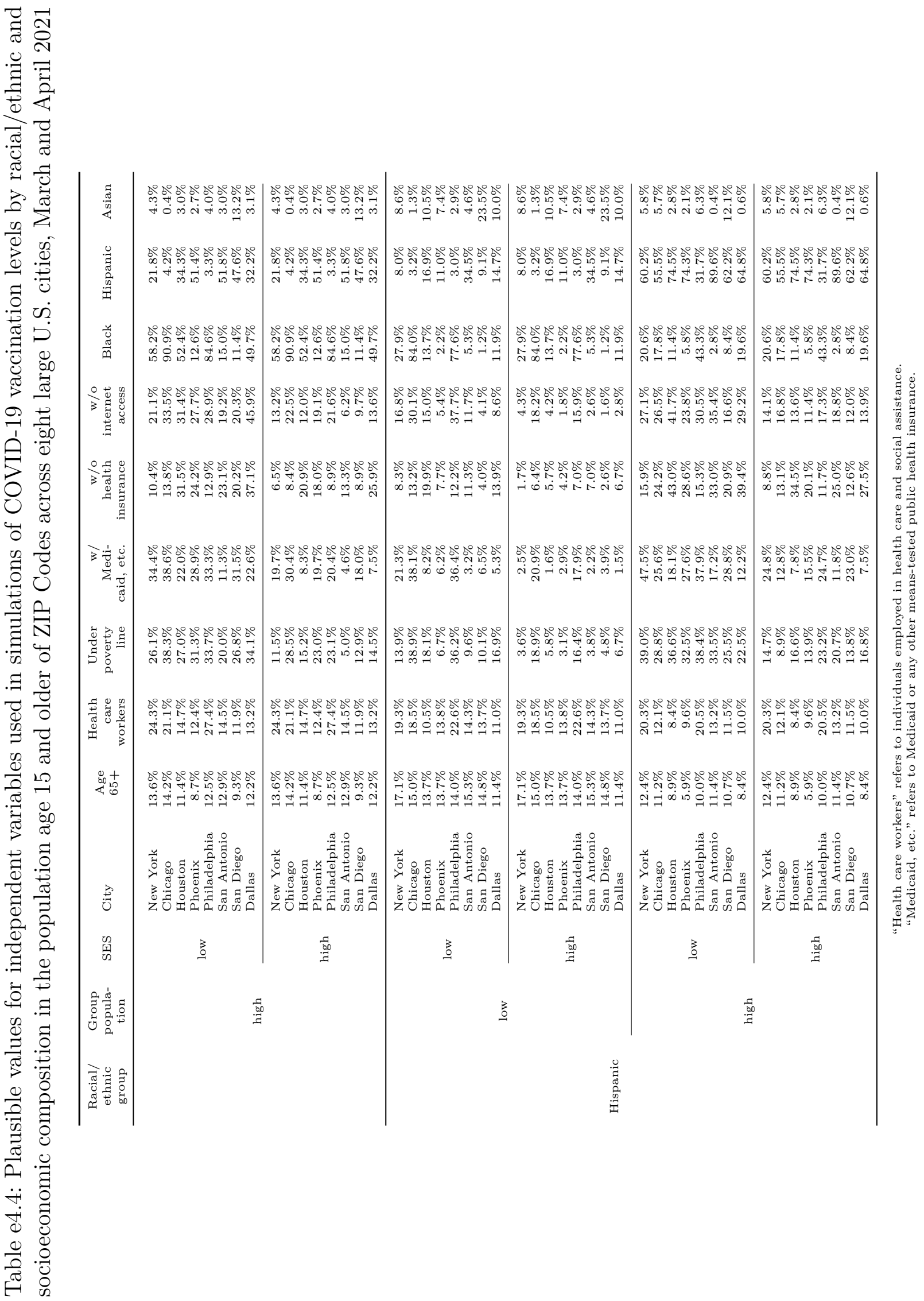


medRxiv preprint doi: https://doi.org/10.1101/2021.11.19.21266593; this version posted November 21, 2021. The copyright holder for this preprint (which was not certified by peer review) is the author/funder, who has granted medRxiv a license to display the preprint in perpetuity.

It is made available under a CC-BY-NC-ND 4.0 International license .

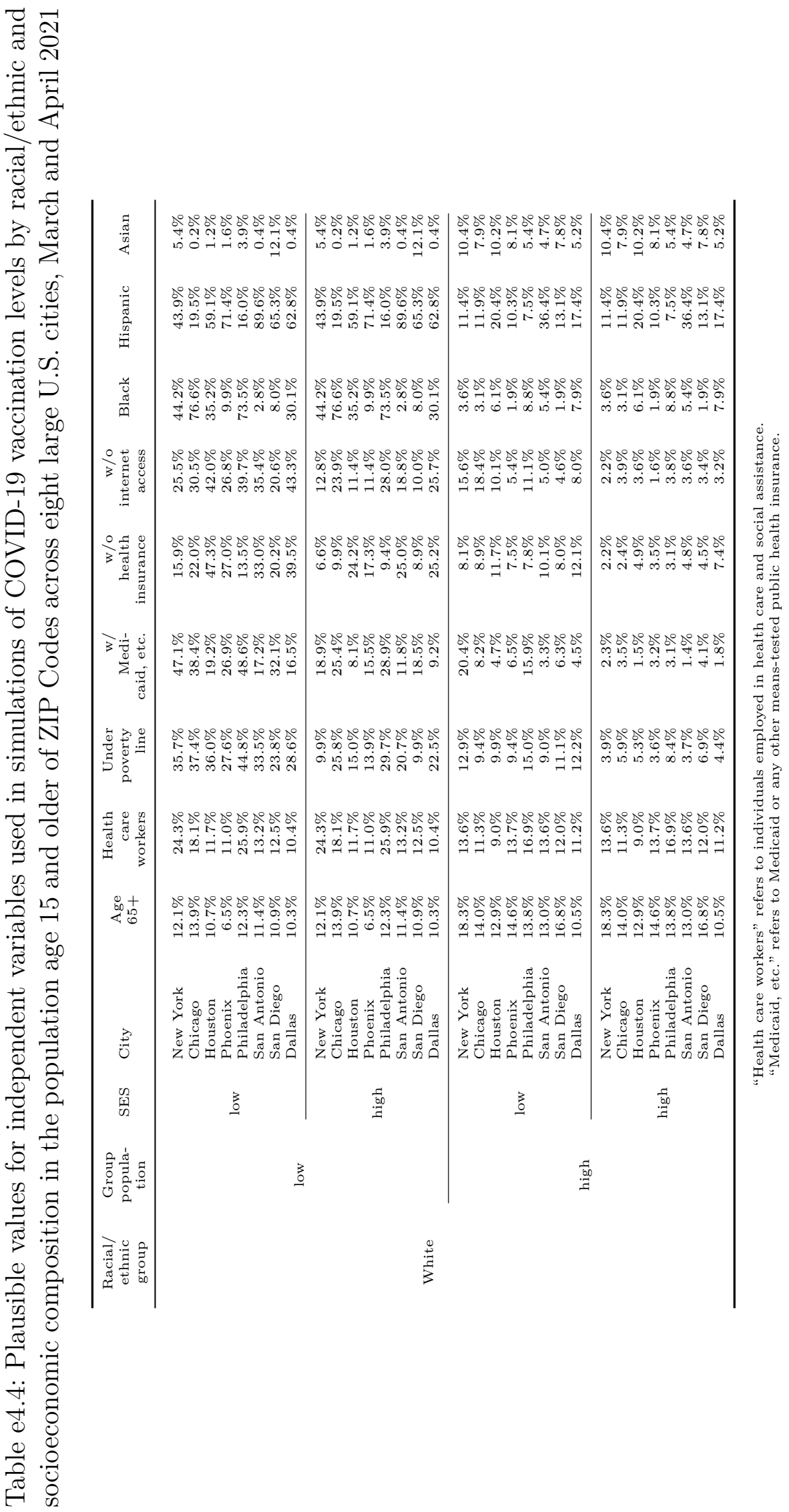


ulations across racial/ethnic groups, however, the simulations revealed that the explanation is more complicated. Because economic inequality is racialized, areas with high Black and Hispanic populations lagged behind areas with high Asian and White populations - even though the coefficients for percents Black and Hispanic were insignificant and the latter was even slightly positive. Attending to direct and indirect channels of structural racism more accurately represented the inequality-generating process than focusing only on average conditional racial/ethnic disparities.

\section{Implementation}

We first identified plausible values of the independent variables, listed in Table e4.4. Within each city, we identified low and high levels (the 10th and 90th percentiles) of Black, Hispanic, Asian, and White populations. Given these racial/ethnic compositions, we set plausible low and high values of the four SES variables. We identified the within-city 10th and 90th percentiles of the SES variables among units with populations within five percentile points of the within-city low and high levels for the given racial/ethnic group (the fifth through 15th and 85th through 95th percentiles). We set all other independent variables to their weighted averages within the same ranges. For example, in the iteration identified in Figure e4.2 as "High \% Black / Low SES," we assigned all units low values (10th percentile) for the SES variables and average values of other independent variables, among units with high Black populations (85th through 95th percentiles) within their respective cities.

Next, we simulated outcomes given the plausible values of the independent variables. For each combination of racial/ethnic and socioeconomic compositions, we set the variables for each unit in our data set to the corresponding within-city values in Table e4.4. (We assigned every unit within each city the same values for each independent variable in each iteration). For each unit, we then calculated the estimated values of the outcome under each scenario, using the parameter estimates from the full models in Table e4.2. We computed population-weighted means for the three outcomes under each hypothetical scenario.

Finally, we bootstrapped confidence intervals for the simulated sample means. We obtained 1,000 resamples of our original data set by sampling it with replacement. ${ }^{89}$ We then adjusted the spatial weights matrix $W$ accordingly for each resample. We assigned nearest neighbors according to $h_{i}$ in the original sample, which maintained the spatial structure of the data across iterations. Next, we re-estimated the SEMs on each of the resamples. We simulated the outcome variables under each hypothetical population composition of interest by assigning each unit the corresponding value in Table e4.4 in the same manner as above. From the distribution of the 1,000 resulting population-weighted resample means for each outcome, we calculated pivot confidence intervals at the $95 \%$ level. ${ }^{90}$ This bootstrap procedure yielded a non-parametric approximation of the uncertainty in the hypothetical outcomes. 


\section{e5 References}

1. DiRago NV. Replication Data for: "COVID-19 Vaccine Rollouts and the Reproduction of Urban Spatial Inequality: Disparities Within Large U.S. Cities in March and April 2021 by Racial/Ethnic and Socioeconomic Composition”. Harvard Dataverse; 2021. doi:10.7910/DVN/O6EVCZ.

2. Bates D, Chambers J, Dalgaard P, et al. R: A Language and Environment for Statistical Computing. Version 4.0.4. R Foundation for Statistical Computing; 2021. https://www.R-project.org/.

3. Wickham H, Averick M, Bryan J, et al. Welcome to the Tidyverse. JOSS. 2019;4(43):1686. doi:10.21105/joss.01686.

4. Wickham H. ggplot2: Elegant Graphics for Data Analysis. 2nd ed. Springer; 2016.

5. Stata Statistical Software. Version 16.1. StataCorp; 2020.

6. Montesano M, Slutsker J, Pezeshki G. NYC Coronavirus Disease 2019 (COVID-19)

Data. New York City Department of Health and Mental Hygiene; 2021.

https://github.com/nychealth/coronavirusdata/blob/68acaed9e700aca48294d20129d4ae0551a27561/README.md.

7. Montesano M. ZCTA to MODZCTA. New York City Department of Health and Mental Hygiene; 2020. https://github.com/nychealth/coronavirusdata/blob/68acaed9e700aca48294d20129d4ae0551a27561/Geographyresources/ZCTA-to-MODZCTA.csv.

8. Jacobsen LA, Mather M, Jarosz B, et al. Understanding and Using American Community Survey Data: What All Data Users Need to Know. U.S. Census Bureau; 2020.

https://www.census.gov/programs-surveys/acs/guidance/handbooks/general.html.

9. Walker K, Herman M. tidycensus: Load US Census Boundary and Attribute Data as "tidyverse" and "sf"-Ready Data Frames. Version 0.11.4. Comprehensive R Archive Network; 2021. https://CRAN.R-project.org/package=tidycensus.

10. Weber M. Economy and Society: An Outline of Interpretive Sociology. University of California Press; 1978.

11. Giddens A. The Class Structure of the Advanced Societies. Hutchinson; 1973.

12. Breen R. Foundations of a neo-Weberian class analysis. In: Wright EO, ed. Approaches to Class Analysis. Cambridge University Press; 2005: 31-50.

13. Alphabetical Indexes of Industries and Occupations. U.S. Census Bureau; 2019. https: //www.census.gov/topics/employment/industry-occupation/guidance/indexes.html.

14. American Community Survey and Puerto Rico Community Survey: 2019 Subject Definitions. U.S. Census Bureau; 2020. https://www.census.gov/programssurveys/acs/technical-documentation/code-lists.2019.html.

15. Denton NA. Racial identity and census categories: can incorrect categories yield correct information? Law Inequal. 1997;15(1):83-97. https://scholarship.law.umn.edu/lawineq/vol15/iss1/4. 
16. Anderson M, Fienberg SE. Race and ethnicity and the controversy over the US census. Curr Sociol. 2000;48(3):87-110. doi:10.1177/0011392100048003007.

17. Fasenfest D, Booza J, Metzger K. Living Together: A New Look at Racial and Ethnic Integration in Metropolitan Neighborhoods, 1990-2000. Brookings Institution; 2004. https://www.brookings.edu/research/living-together-a-new-look-at-racial-and-ethnicintegration-in-metropolitan-neighborhoods/.

18. Simon P, Piché V. Accounting for ethnic and racial diversity: the challenge of enumeration. Ethn Racial Stud. 2012;35(8):1357-1365. doi:10.1080/01419870.2011.634508.

19. Kayyali R. US Census classifications and Arab Americans: contestations and definitions of identity markers. J Ethn Migr Stud. 2013;39(8):1299-1318. doi:10.1080/1369183X.2013.778150.

20. Liebler CA, Porter SR, Fernandez LE, Noon JM, Ennis SR. America's churning races: race and ethnicity response changes between Census 2000 and the 2010 Census. Demography. 2017;54(1):259-284. doi:10.1007/s13524-016-0544-0.

21. Strmic-Pawl HV, Jackson BA, Garner S. Race counts: racial and ethnic data on the U.S. census and the implications for tracking inequality. Sociol Race Ethn. 2018;4(1):1-13. doi:10.1177/2332649217742869.

22. Cabrera JF, Dela Cruz RR. Spatially based rules for reducing multiple-race into single-race data. City Community. 2020;19(3):593-616. doi:10.1111/cico.12418.

23. 2019 TIGER/Line Shapefiles Technical Documentation. U.S. Census Bureau; 2019. https://www.census.gov/programs-surveys/geography/technicaldocumentation/complete-technical-documentation/tiger-geo-line.2019.html.

24. Walker K. tigris: Load Census TIGER/Line Shapefiles. Version 1.0. Comprehensive R Archive Network; 2020. https://CRAN.R-project.org/package=tigris.

25. Population \& Housing Characteristics for Congressional Districts of the 103rd Congress. U.S. Bureau of the Census; 2002. https://www.census.gov/library/publications/1992/dec/cph-4.html.

26. Krieger N, Waterman P, Chen JT, Soobader MJ, Subramanian SV, Carson R. ZIP Code caveat: bias due to spatiotemporal mismatches between ZIP Codes and US Census-defined geographic areas. Am J Public Health. 2002;92(7):1100-1102. doi:10.2105/AJPH.92.7.1100.

27. Grubesic TH, Matisziw TC. On the use of ZIP Codes and ZIP Code Tabulation Areas (ZCTAs) for the spatial analysis of epidemiological data. Int J Health Geogr. 2006;5(58). doi:10.1186/1476-072X-5-58.

28. Beyer KMM, Schultz AF, Rushton G. Using ZIP Codes as geocodes in cancer research. In: Rushton G, Armstrong MP, Gittler J, et al., eds. Geocoding Health Data: The Use of Geographic Codes in Cancer Prevention and Control, Research, and Practice. CRC; 2008: 37-68.

29. Grubesic TH. ZIP Codes and spatial analysis: problems and prospects. Socioecon Plann Sci. 2008;42(2):129-149. doi:10.1016/j.seps.2006.09.001. 
30. Sampson RJ, Morenoff JD, Gannon-Rowley T. Assessing "neighborhood effects:" social processes and new directions in research. Annu Rev Sociol. 2002;28(1):443-478. doi:10.1146/annurev.soc.28.110601.141114.

31. Sharkey P, Faber JW. Where, when, why, and for whom do residential contexts matter?: moving away from the dichotomous understanding of neighborhood effects. Annu Rev Sociol. 2014;40(1):559-579. doi:10.1146/annurev-soc-071913-043350.

32. Jarmin RS. Census tracts for the 2020 Census - final criteria. Fed Regist. 2018;83(219):56277-56284.

https://www.federalregister.gov/documents/2018/11/13/2018-24567/census-tractsfor-the-2020-census-final-criteria.

33. Coulton CJ, Korbin J, Chan T, Su M. Mapping residents' perceptions of neighborhood boundaries: a methodological note. Am J Community Psychol. 2001;29(2):371-383. doi:10.1023/A:1010303419034.

34. Sastry N, Pebley AR, Zonta M. Neighborhood definitions and the spatial dimension of daily life in Los Angeles. RAND Labor and Population Program Working Paper Series. 2002;03-02. https://www.rand.org/pubs/drafts/DRU2400z8.html.

35. Weiss L, Ompad D, Galea S, Vlahov D. Defining neighborhood boundaries for urban health research. Am J Prev Med. 2007;32(6):S154-S159. doi:10.1016/j.amepre.2007.02.034.

36. Campbell E, Henly JR, Elliott DS, Irwin K. Subjective constructions of neighborhood boundaries: lessons from a qualitative study of four neighborhoods. J Urban Aff. 2009;31(4):461-490. doi:10.1111/j.1467-9906.2009.00450.x.

37. Coulton CJ, Jennings MZ, Chan T. How big is my neighborhood?: individual and contextual effects on perceptions of neighborhood scale. Am J Community Psychol. 2013;51(1):140-150. doi:10.1007/s10464-012-9550-6.

38. Jones M, Pebley AR. Redefining neighborhoods using common destinations: social characteristics of activity spaces and home census tracts compared. Demography. 2014;51(3):727-752. doi:10.1007/s13524-014-0283-z.

39. Sharp G, Denney JT, Kimbro RT. Multiple contexts of exposure: activity spaces, residential neighborhoods, and self-rated health. Soc Sci Med. 2015;146:204-213. doi:10.1016/j.socscimed.2015.10.040.

40. Wang Q, Phillips NE, Small ML, Sampson RJ. Urban mobility and neighborhood isolation in America's 50 largest cities. PNAS. 2018;115(30):7735-7740. doi:10.1073/pnas.1802537115.

41. Browning CR, Calder CA, Boettner B, et al. Neighborhoods, activity spaces, and the span of adolescent exposures. Am Sociol Rev. 2021;86(2):201-233. doi:10.1177/0003122421994219.

42. Chaskin RJ. Perspectives on neighborhood and community: a review of the literature. Soc Serv Rev. 1997;71(4):521-547. doi:10.1086/604277. 
43. Bates LK. Does neighborhood really matter?: comparing historically defined neighborhood boundaries with housing submarkets. J Plan Educ Res. 2006;26(1):5-17. doi:10.1177/0739456X05283254.

44. Clapp JM, Wang Y. Defining neighborhood boundaries: are census tracts obsolete? J Urban Econ. 2006;59(2):259-284. doi:10.1016/j.jue.2005.10.003.

45. Lee BA, Reardon SF, Firebaugh G, Farrell CR, Matthews SA, O'Sullivan D. Beyond the census tract: patterns and determinants of racial segregation at multiple geographic scales. Am Sociol Rev. 2008;73(5):766-791. doi:10.1177/000312240807300504.

46. Hart TC, Waller J. Neighborhood boundaries and structural determinants of social disorganization: examining the validity of commonly used measures. West Crim Rev. $2013 ; 14(3): 16-33$.

47. Poorthuis A. How to draw a neighborhood?: the potential of big data, regionalization, and community detection for understanding the heterogeneous nature of urban neighborhoods. Geographical Analysis. 2018;50(2):182-203. doi:10.1111/gean.12143.

48. Krieger N, Chen JT, Waterman PD, Soobader MJ, Subramanian SV, Carson R. Geocoding and monitoring of US socioeconomic inequalities in mortality and cancer incidence: does the choice of area-based measure and geographic level matter? Am J Epidemiol. 2002;156(5):471-482. doi:10.1093/aje/kwf068.

49. Thomas AJ, Eberly LE, Davey Smith G, Neaton JD. ZIP-Code-based versus tract-based income measures as long-term risk-adjusted mortality predictors. Am J Epidemiol. 2006;164(6):586-590. doi:10.1093/aje/kwj234.

50. Schuurman N, Bell N, Dunn JR, Oliver L. Deprivation indices, population health and geography: an evaluation of the spatial effectiveness of indices at multiple scales. $J$ Urban Health. 2007;84(4):591-603. doi:10.1007/s11524-007-9193-3.

51. Rey G, Jougla E, Fouillet A, Hémon D. Ecological association between a deprivation index and mortality in France over the period 1997 - 2001: variations with spatial scale, degree of urbanicity, age, gender and cause of death. BMC Public Health. 2009;9(1):33. doi:10.1186/1471-2458-9-33.

52. Parenteau MP, Sawada MC. The modifiable areal unit problem (MAUP) in the relationship between exposure to $\mathrm{NO}_{2}$ and respiratory health. Int J Health Geogr. 2011;10(1):58. doi:10.1186/1476-072X-10-58.

53. Halonen JI, Vahtera J, Oksanen T, et al. Socioeconomic characteristics of residential areas and risk of death: is variation in spatial units for analysis a source of heterogeneity in observed associations? BMJ Open. 2013;3(4):e002474. doi:10.1136/bmjopen-2012-002474.

54. Lam NSN. Spatial interpolation methods: a review. Am Cartogr. 1983;10(2):129-150. doi:10.1559/152304083783914958.

55. Hawley K, Moellering H. A comparative analysis of areal interpolation methods. Cartogr Geogr Inf Sci. 2005;32(4):411-423. doi:10.1559/152304005775194818. 
56. Pebesma E, Mailund T, Hiebert J. Measurement units in R. R J. 2016;8(2):486-494. doi:10.32614/RJ-2016-061.

57. Pebesma E. Simple features for R: standardized support for spatial vector data. $R J$. 2018;10(1):439-446. doi:10.32614/RJ-2018-009.

58. Rothman KJ, Greenland S, Lash TL. Modern Epidemiology. 3rd ed. Lippincott Williams \& Wilkins; 2008.

59. Liu K. Measurement error and its impact on partial correlation and multiple linear regression analyses. Am J Epidemiol. 1988;127(4):864-874. doi:10.1093/oxfordjournals.aje.a114870.

60. Hutcheon JA, Chiolero A, Hanley JA. Random measurement error and regression dilution bias. BMJ. 2010;340:c2289. doi:10.1136/bmj.c2289.

61. Loken E, Gelman A. Measurement error and the replication crisis. Science. 2017;355(6325):584-585. doi:10.1126/science.aal3618.

62. Hausman J. Mismeasured variables in econometric analysis: problems from the right and problems from the left. J Econ Perspect. 2001;15(4):57-67.

doi:10.1257/jep.15.4.57.

63. Ord K. Estimation methods for models of spatial interaction. J Am Stat Assoc. 1975;70(349):120-126. doi:10.1080/01621459.1975.10480272.

64. Seber GAF, Lee AJ. Linear Regression Analysis. 2nd ed. John Wiley \& Sons; 2003.

65. Anselin L. Spatial Econometrics: Methods and Models. Springer; 1988.

66. LeSage JP, Pace RK. Introduction to Spatial Econometrics. Chapman \& Hall/CRC; 2009 .

67. Bivand R, Piras G. Comparing implementations of estimation methods for spatial econometrics. J Stat Softw. 2015;63(1):1-36. doi:10.18637/jss.v063.i18.

68. Pace RK, LeSage JP. Omitted variable biases of OLS and spatial lag models. In: Páez A, Le Gallo J, Buliung RN, Dall'erba S, eds. Progress in Spatial Analysis: Methods and Applications. Springer; 2010: 17-28.

69. Rüttenauer T. Spatial regression models: a systematic comparison of different model specifications using Monte Carlo experiments. Sociol Methods Res. 2019; doi:10.1177/0049124119882467.

70. Tiefelsdorf M, Griffith DA, Boots B. A variance-stabilizing coding scheme for spatial link matrices. Environ Plan A. 1999;31(1):165-180. doi:10.1068/a310165.

71. Dubin R. Spatial weights. In: Fotheringham AS, Rogerson P, eds. The SAGE Handbook of Spatial Analysis. SAGE; 2009: 125-157.

72. Smith TE. Notebook on Spatial Data Analysis. School of Engineering and Applied Science, University of Pennsylvania; 2014. https://www.seas.upenn.edu/ tesmith/NOTEBOOK/index.html.

73. Bivand RS, Wong DWS. Comparing implementations of global and local indicators of spatial association. TEST. 2018;27(3):716-748. doi:10.1007/s11749-018-0599-x. 
74. Schabenberger O, Gotway CA. Statistical Methods for Spatial Data Analysis. Chapman \& Hall/CRC; 2005.

75. Anselin L, Bera AK, Florax R, Yoon MJ. Simple diagnostic tests for spatial dependence. Reg Sci Urban Econ. 1996;26(1):77-104. doi:10.1016/0166-0462(95)02111-6.

76. Golgher AB, Voss PR. How to interpret the coefficients of spatial models: spillovers, direct and indirect effects. Spat Demogr. 2016;4(3):175-205.

doi:10.1007/s40980-015-0016-y.

77. Gormley TA, Matsa DA. Common errors: how to (and not to) control for unobserved heterogeneity. Rev Financ Stud. 2014;27(2):617-661. doi:10.1093/rfs/hht047.

78. Solon G, Haider SJ, Wooldridge JM. What are we weighting for? J Hum Resour. 2015;50(2):301-316. doi:10.3368/jhr.50.2.301.

79. Kneip T, Bauer G. Did unilateral divorce laws raise divorce rates in Western Europe? J Marriage Fam. 2009;71(3):592-607. doi:10.1111/j.1741-3737.2009.00621.x.

80. Schnapp P. Identifying the effect of immigration on homicide rates in U.S. cities: an instrumental variables approach. Homicide Stud. 2015;19(2):103-122. doi:10.1177/1088767914528907.

81. Sharkey P, Torrats-Espinosa G, Takyar D. Community and the crime decline: the causal effect of local nonprofits on violent crime. Am Sociol Rev. 2017;82(6):1214-1240. doi:10.1177/0003122417736289.

82. Liang KY, Zeger SL. Longitudinal data analysis using generalized linear models. Biometrika. 1986;73(1):13-22. doi:10.1093/biomet/73.1.13.

83. Cameron AC, Miller DL. A practitioner's guide to cluster-robust inference. J Hum Resour. 2015;50(2):317-372. doi:10.3368/jhr.50.2.317.

84. Pustejovsky J. clubSandwich: Cluster-Robust (Sandwich) Variance Estimators with Small-Sample Corrections. Version 0.5.3. Comprehensive R Archive Network; 2021. https://CRAN.R-project.org/package=clubSandwich.

85. Brambor T, Clark WR, Golder M. Understanding interaction models: improving empirical analyses. Polit Anal. 2006;14(1):63-82. doi:10.1093/pan/mpi014.

86. Pepinsky TB. Visual heuristics for marginal effects plots. Research 8 Politics. 2018;5(1). doi:10.1177/2053168018756668.

87. Bivand R. Spatial econometrics functions in R: classes and methods. J Geograph Syst. 2002;4(4):405-421. doi:10.1007/s101090300096.

88. Goulard M, Laurent T, Thomas-Agnan C. About predictions in spatial autoregressive models: optimal and almost optimal strategies. Spat Econ Anal. 2017;12(2-3):304-325. doi:10.1080/17421772.2017.1300679.

89. Davison AC, Hinkley DV. Bootstrap Methods and Their Application. Cambridge University Press; 1997.

90. DiCiccio TJ, Efron B. Bootstrap confidence intervals. Stat Sci. 1996;11(3):189-228. doi: $10.1214 / \mathrm{ss} / 1032280214$. 